University of San Diego

Digital USD

Theses

Theses and Dissertations

Winter 11-25-2019

\title{
The effects of seasonal variations, El Niño-Southern Oscillation, and climate change on the tuna-dolphin association
}

\author{
Caitlynn Birch \\ University of San Diego \\ Michael D. Scott \\ Inter-American Tropical Tuna Commission \\ Zhi-Yong Yin \\ University of San Diego \\ Lisa T. Ballance \\ Oregon State University
}

Follow this and additional works at: https://digital.sandiego.edu/theses

Part of the Aquaculture and Fisheries Commons, Marine Biology Commons, and the Terrestrial and Aquatic Ecology Commons

\section{Digital USD Citation}

Birch, Caitlynn; Scott, Michael D.; Yin, Zhi-Yong; and Ballance, Lisa T., "The effects of seasonal variations, El Niño-Southern Oscillation, and climate change on the tuna-dolphin association" (2019). Theses. 40. https://digital.sandiego.edu/theses/40

This Thesis: Open Access is brought to you for free and open access by the Theses and Dissertations at Digital USD. It has been accepted for inclusion in Theses by an authorized administrator of Digital USD. For more information, please contact digital@sandiego.edu. 
UNIVERSITY OF SAN DIEGO

\author{
San Diego
}

The effects of seasonal variations, EI Niño-Southern Oscillation, and climate change on the tuna-dolphin association

A thesis submitted in partial satisfaction of the requirements for the degree of

Master of Science in Environmental and Ocean Sciences

by

Caitlynn Amber Birch

Thesis Committee

Michael D. Scott, PhD., Chair

Lisa T. Ballance, PhD.

Zhi-Yong Yin, PhD. 
The thesis of Caitlynn Birch is approved by:

\section{Michael D. Scott, Ph.D, Chair}

\section{Zhi-Yong Yin, Ph.D.}

$\uparrow$

Lisa T. Ballance, Ph.D.

University of San Diego

San Diego

2019 
Copyright 2019 Caitlynn Birch 


\section{ACKNOWLEDGEMENTS}

First and most of all, I would like to thank Dr. Michael Scott for his incredible expertise, assistance, guidance and patience throughout the course of this project and thesis. Michael not only are you an amazing research advisor, but a dear friend and collogue. Without you this research would not have been possible. Thank you to my committee members, Dr. Lisa Ballance and Dr. Zhi-Yong Yin for their support, suggestions, and encouragement. Their involvement in this project greatly improved the quality of this research.

I would like to extend my sincere gratitude to the Department of Environmental and Ocean Sciences at USD, who are not only an exceptional team of scientists and educators, but a wonderful group of people who care deeply about each individual who passes through their halls. In particular, I'd like to acknowledge Dr. Drew Tally, for all of his administrative and emotional support throughout the course of this degree.

I am extremely fortunate to have had access to so many incredible scientists who have helped improve and bring this research project above and beyond my own capabilities. Thank you to all of the kind and generous scientists at IATTC, SWFSC, and the observers of the AIDCP, who allowed me to use their facilities and data for the last two years, assisted with technical and statistical solutions, and were always available for questions and guidance. In particular, I'd like to thank Jon Lopez for his help with the Boosted Regression Tree models, Karin Forney for all of her GAM guidance, Ricardo Oliveros Ramos, Eric Archer, Jessica Redfern, Cleridy Lennert-Cody, Haikun Xu, Paul Fiedler, and Nick Vogel. Thank you for the invaluable assistance you all provided during this study. All of the advice and support proved monumental towards the success of this study. A special thank you as well, to those organizations who have funded me throughout this process, including University of San Diego, American Cetacean Society, Dolphin Biology Research Institute, and the IATTC. 
While I am so proud of all that has been accomplished these past few years in terms of this research, I am most grateful for the friendships I have gained through the process. Thank you to my amazing cohort, Rachel Steinberg, Gabriela Yamhure, Lisa Robison, and Marisol Shin. I consider you all lifelong friends.

Lastly, I wish to acknowledge the support and great love of my family, Katie, my mother; Dan, my father; and my siblings, Reid and Brooke. This work would not have been possible without their constant love and support. Thank you, in particular, Katie and Dan for being wonderful people and parents. And to my best friends, Jackson and Juliana, I am forever grateful for your constant, unwavering encouragement, and for enduring countless hours of lamenting and frustrationfueled modeling talk. I love you all. 


\section{TABLE OF CONTENTS}

ACKNOWLEDGEMENTS iv

LIST OF TABLES viii

LIST OF FIGURES IX - ix

ABSTRACT 1

CHAPTER 1: Introduction 2

1.1 Eastern tropical Pacific tuna-dolphin purse-seine fishery 2

1.1.1 History of the fishery 2

1.1.2 The tuna-dolphin controversy 3

1.1.3 Dolphin bycatch and mortality 4

$\begin{array}{ll}1.2 \text { Oceanography of the ETP } & 7\end{array}$

1.2.1 Surface currents and water masses $\quad 7$

1.2.2 Productivity and seasonal variations 10

1.2.3 El Niño-Southern oscillation 11

$\begin{array}{ll}\text { 1.2.4 Climate change } & 12\end{array}$

1.3 Geographic distributions and habitats 13

1.3.1 Tropical dolphin distribution 13

1.3.2 Yellowfin tuna distribution $\quad 15$

1.4 The tuna-dolphin association $\quad 16$

1.5 Objectives and hypotheses 20

$\begin{array}{ll}\text { Figures } & 21\end{array}$

$\begin{array}{ll}\text { References } & 27\end{array}$

CHAPTER 2: The effects of seasonal variations, El Niño Southern

Oscillation, and climate change on the tuna-dolphin association 35

2.1 Introduction $\quad 35$

2.2 Data and methods $\quad 38$

2.2.1 Study area $\quad 38$

2.2.2 Observer data 39

2.2.3 Environmental covariates 40

2.2.4 Model selection and species distribution models $\quad 40$

2.2.5 GIS 44

2.3 Results $\quad 45$

2.3.1 Seasonal variability 45

2.3.2 El Niño-Southern oscillation variability 46

2.3.3 Long-term distribution shifts 46

2.3.4 Model performance 47

2.3.5 Drivers of the tuna-dolphin association 48

2.3.6 Predictions 50

2.4 Discussion $\quad 51$ 
2.4.1 Influence of environmental factors 51

2.4.2 Seasonal distribution patterns 52

2.4.3 ENSO impact on the distribution 53

2.4.4 Climate change and long-term distribution patterns 54

2.4.5 Implications for management and conservation $\quad 55$

Tables and figures $\quad 56$

References 96

CHAPTER 3: Conclusions 101 


\section{LIST OF TABLES}

Table 2.1 Acronyms, units, temporal frequency and coverage, and source, of data used in the species distribution models.

Table 2.2 Performance diagnostics of models; M1 (spotted-tuna, spatial-temporal + environmental variables), M1.env (spotted-tuna, environmental variables only); M2 (spinner-tuna, spatial-temporal + environmental variables), M2.env (spinner-tuna, environmental variables only).

Table 2.3 Relative influence of environmental covariates included in the species distribution boosted regression ree models for the tuna-dolphin association.

Table 2.4 Table of all pairwise environmental interactions and their interaction size for the Boosted Regression Tree spinner-tuna environmental model, M2.env.

Table 2.5 Table of the most important environmental interactions and interaction size in the Boosted Regression Tree spinner-tuna environmental model M2.env.

Table 2.6 Table of all pairwise environmental interactions and their interaction size for the Boosted Regression Tree spotted-tuna environmental model, M1.env.

Table 2.7 Table of the most important environmental interactions and interaction size in the Boosted Regression Tree spotted-tuna environmental model M1.env. 


\section{LIST OF FIGURES}

Figure 1.1 Dolphins being successfully released from the net during the backdown procedure. Note the configuration of the net into a narrow channel to allow dolphins to escape during the backdown (Photograph from IATTC).

Figure 1.2 Dolphin mortality in the ETP, 1959-2017, noting the implementation of particular management policies.

Figure 1.3 Spinner and spotted dolphin stock distributions (AIDCP data, 19922017).

Figure 1.4 Diagram of surface water masses and currents in the eastern tropical Pacific Ocean: Subtropical Surface Water (STSW); Tropical Surface Water (TSW); Equatorial Surface Water (ESW). Cooler colors indicate colder sea surface temperature; warmer colors indicating warmer sea surface temperature (SODA, 2015).

Figure 1.5 The Intertropical Convergence Zone atmospheric belt; Photo: NOAA's GOES Project Science Office.

Figure 1.6 Schematic illustrating the influence of thermocline depth and dolphin swimming depth on the tuna-dolphin association; a) spinner dolphin (Stenella longirostris); b) spotted dolphin (Stenella attenuata); c) yellowfin tuna (Thunnis albarares) (Illustration by Caitlynn Birch 2018).

Figure 2.1 Diagram of surface water masses and currents in the eastern tropical Pacific Ocean: Subtropical Surface Water (STSW); Tropical Surface Water (TSW); Equatorial Surface Water (ESW). Cooler colors indicate colder sea surface temperature; warmer colors indicating warmer sea surface temperature (SODA, 2015).

Figure 2.2 Diagram illustrating the influence of thermocline depth and dolphin swimming depth on the tuna-dolphin association; a) spinner dolphin (Stenella longirostris); b) spotted dolphin (Stenella attenuata); c) yellowfin tuna (Thunnus albacares) (Illustration by Caitlynn Birch 2018).

Figure 2.3 Seasonal averaged distributions of the spinner-tuna association (1992 - 2017). Quadrant a) representing Dec - Feb, b) May - Mar, c) Jun - Aug, d) Sept - Nov.

Figure 2.4 Seasonal averaged distributions of the spotted-tuna association (1992 - 2015). Quadrant a) representing Dec - Feb, b) May - Mar, c) Jun - Aug, d) Sept - Nov. 
Figure 2.5 Distribution of the spinner-tuna association during a) strong El Niño $(\mathrm{ONI}>=1)$ and (b) strong La Niña $(\mathrm{ONI}<=-1)$ events.

Figure 2.6 Area in $\mathrm{km}^{2}$ covered by the spinner-tuna distribution during an average strong El Niño (ONI $>=1)$ and strong La Niña $(\mathrm{ONI}<=-1)$ month 19922015.

Figure 2.7 Distribution of the spotted-tuna association during an average strong $(\mathrm{ONI}>=1$; ONI $<=-1)$ El Niño (a) and La Niña (b) month.

Figure 2.8 Area in $\mathrm{km}^{2}$ covered by the spotted-tuna distribution during an average strong El Niño (ONI $>=1)$ and strong La Niña $(\mathrm{ONI}<=-1)$ month, 19922015.

Figure 2.9 Multi-year averages of the spinner-tuna distribution: a) 1992-2000, b) 2001-2009, c) 2010-2017.

Figure 2.10 Area of distribution $\left(\mathrm{km}^{2}\right)$ covered by the spinner-tuna association averaged by year 1992-2017.

Figure 2.11 Spinner-tuna occurrences 1992 - 2015 overlaid on average annual mixed layer depth.

Figure 2.12 Multi-year averages of the spotted-tuna distribution a) 1992-2000, b) 2001-2009, c) 2010-2017.

Figure 2.13 Area of distribution $\left(\mathrm{km}^{2}\right)$ covered by the spotted-tuna averaged by year, 1992-2017.

Figure 2.14 Spotted-tuna occurrences 1992-2015 overlaid on average annual mixed layer depth.

Figure 2.15 Relative influence of environmental variables included in the species distribution Boosted Regression Tree models: a) relative influence of variables on the spinner-tuna association; b) relative influence of variables on the spotted-tuna association.

Figure 2.16 Partial dependence plots of presence-absence Boosted Regression Tree (BRT), showing relative probability of the presence of the spinnertuna association as a response to each environmental variable in M2.env. Variable relative importance scores are listed for each variable in parentheses. $Y$ axes are on the logit scale.

Figure 2.17 Partial dependence plots of presence-absence Boosted Regression Tree (BRT), showing relative probability of the presence of the spottedtuna association as a response to each environmental variable in model 
M1.env. Variable relative importance scores are listed below for each variable in parentheses. $Y$ axes are on the logit scale.

Figure 2.18 Three-dimensional partial dependence plot for the strongest environmental interaction (SSH - SST_100) in the Boosted Regression Tree model for the spinner-tuna association (M2.env).

Figure 2.19 Three-dimensional partial dependence plot for the second strongest environmental interaction (Sal - SST) in the Boosted Regression Tree model for the spinner-tuna association (M2.env).

Figure 2.20 Three-dimensional partial dependence plot for the strongest environmental interaction (MLD-SST) in the Boosted Regression Tree model for the spotted-tuna association (M1.env).

Figure 2.21 Three-dimensional partial dependence plot for the second strongest environmental interaction ( $\mathrm{SSH}-\mathrm{Sal}$ ) in the Boosted Regression Tree model for the spotted-tuna association (M1.env).

Figure 2.22 Habitat suitability projected for the full year 2015 by the spinner-tuna Boosted Regression Tree spatio-temporal model (M2): a) 2015 predicted habitat suitability, b) overlaid with 2015 spinner-tuna occurrence data.

Figure 2.23 Habitat suitability projected for the months Dec - Feb of 2015 by the spinner-tuna Boosted Regression Tree spatio-temporal model (M2); a) Dec - Feb predicted habitat suitability, b) overlaid with spinner-tuna occurrence data.

Figure 2.24 Habitat suitability projected for the months Mar - May of 2015 by the spinner-tuna Boosted Regression Tree spatio-temporal model (M2): a) Mar - May predicted habitat suitability, b) overlaid with spinner-tuna occurrence data.

Figure 2.25 Habitat suitability projected for the months Jun - Aug of 2015 by the spinner-tuna Boosted Regression Tree spatio-temporal model (M2): a) Jun - Aug predicted habitat suitability, b) overlaid with spinner-tuna occurrence data.

Figure 2.26 Habitat suitability projected for the months Sept - Nov of 2015 by the spinner-tuna Boosted Regression Tree spatio-temporal model (M2): a) Sept - Nov predicted habitat suitability, b) overlaid with spinner-tuna occurrence data.

Figure 2.27 Habitat suitability projected for the full year 2015 by the spotted-tuna Boosted Regression Tree spatio-temporal model (M2): a) 2015 predicted habitat suitability, b) overlaid with 2015 spinner-tuna occurrence data. 
Figure 2.28 Habitat suitability projected for the months Dec - Feb of 2015 by the spotted-tuna Boosted Regression Tree spatio-temporal model (M1): a) Dec - Feb predicted habitat suitability, b) overlaid with spotted-tuna occurrence data.

Figure 2.29 Habitat suitability projected for the months Mar - May of 2015 by the spotted-tuna Boosted Regression Tree spatio-temporal model (M1): a) Mar - May predicted habitat suitability, b) overlaid with spotted-tuna occurrence data.

Figure 2.30 Habitat suitability projected for the months Jun - Aug of 2015 by the spotted-tuna Boosted Regression Tree spatio-temporal model (M1): a) Jun - Aug predicted habitat suitability, b) overlaid with spotted-tuna occurrence data.

Figure 2.31 Habitat suitability projected for the months Sept - Nov of 2015 by the spotted-tuna Boosted Regression Tree spatio-temporal model (M1): a) Sept - Nov predicted habitat suitability b) overlaid with spotted-tuna occurrence data. 


\begin{abstract}
Tuna and dolphins swim together in the waters of the eastern tropical Pacific, and this association has long benefitted tuna fishermen and intrigued scientists. Although the tuna-dolphin association is often referred to as a "mystery," much is known about the association. Yellowfin tuna are primarily caught with spotted dolphins and, to a lesser extent, spinner dolphins; historically the spotted dolphin has borne the brunt of the bycatch mortality. The tuna-dolphin association is thought to be a product of the distinct oceanography of the ETP: a shallow mixed layer, a thick oxygen minimum zone, and warm surface waters. As the mixed layer deepens, the association begins to break down: first with spinner dolphins, then with spotted dolphins.

Important ecological and management questions remain. What are the effects of season, El Niño Southern Oscillation (ENSO) cycles, and long-term climate change on the association? What will be the future effects on the association with the continued influence of climate change? And how will these changes affect the fishery and dolphin mortality?

We used the IATTC observer data from 1992-2017 for pure herds of spotted dolphins and spinner dolphins ( $n=201,988$ sightings), oceanographic data from global data assimilative models $\left(0.25^{\circ} \times 0.25^{\circ}\right.$ resolution $)$, GIS and explanatory and predictive models (R-based Boosted Regression Trees) to understand the tuna-dolphin distribution and dynamics in the ETP. The mixed layer depth and chlorophyll were the most significant factors, and sea surface temperature, temperature at depth, and sea surface height were also important factors. The spatial distribution of the association expanded and contracted with season and ENSO events, overlaid on a long-term expansion caused by climate change. The conditions that promote the tuna-dolphin association are intensifying and the management implications are already apparent: sets on pure spinner dolphin herds have increased, and spinner dolphins have replaced spotted dolphins as the leading component of incidental dolphin mortality.
\end{abstract}




\section{CHAPTER 1: Introduction}

\subsection{Eastern tropical Pacific tuna-dolphin purse-seine fishery}

\subsubsection{History of the fishery}

The commercial tuna fishery in the eastern tropical Pacific Ocean (ETP) is predominantly a purse-seine fishery, but its roots began as a coastal baitboat fishery in the early 1900s. Much of the yellowfin tuna was caught by pole-andline fishing, using live bait or "chum" to attract schools of tuna to the fishing vessel, that were then caught with baited lures on bamboo poles (Yoshida et al. 1977). It is not known exactly when west coast fishermen first discovered the bond between tropical tunas and dolphins. The first record of California fishermen fishing tuna associated with dolphin herds comes from Zane Grey, a famous author of western novels, in the late 1920's as tuna vessels expanded their search south to the fishing areas albacares), skipjack (Katsuwonus pelamis), and occasionally albacore (T. alalonga) for canning, and reached its peak between WWII and the 1950s (Felando and Medina 2011). The most renowned fleet of live-bait boats hailed from San Diego, CA, and exploited the rich stocks found coastally. By the 1950's fishermen had long observed the relationship between tuna and dolphins, and had their own theories on which species, the tuna or the dolphin, followed the other (Godsil 1938, Silva 1941). After consistent observations of dolphins leaving baitboats and the tuna following suit, even when the water was being actively chummed, the fishermen came to believe it was the tuna that followed the dolphins (Felando and Medina 2011). It became a common practice to use dolphins and foraging seabirds to locate schools of tuna swimming beneath them (Green et al. 1971, Au and Pitman 1986).

The development of the Puretic power block and nylon nets began a shift in the commercial tuna industry (McNeely 1961, Green et al. 1971), so that by the early 1960s, purse-seine fishing had displaced baitboats as the major producer of commercial tuna in the eastern Pacific (Gosliner 1999). Dolphins were no longer used just to find the tuna but were actively chased and encircled with nets in order 
to catch the tuna (Perrin 1968, Green et al. 1971). Purse-seine vessels in the early days initially located dolphins and therefore, mature yellowfin tuna, using highpower binoculars. Later, new technologies would be used for searching; helicopters began being used in the 1970s and X-band or "bird" radar in the late 1980s (Lennert-Cody et al. 2001). Once a school was located, the seiner and its speedboats herded the dolphins and associated tuna into a cluster, and then the net was set around both.

\subsubsection{The tuna-dolphin controversy}

The controversy began in the 1970s when it became apparent that the eastern Pacific fishery was killing high numbers of dolphins during the fishing process (Perrin 1968). At this point, the tuna-dolphin association was virtually unstudied other than observations by fishermen. William Perrin, a cetacean biologist and former National Marine Fisheries Service (NMFS) scientist, documented the mortality of dolphins in tuna purse-seine nets. In his paper "Early Days of the Tuna/Dolphin Problem" (Perrin 2009), he details his first encounter in spring of 1966 with the tuna purse-seine industry when he was offered a technician job aboard a fishing vessel by the Bureau of Commercial Fisheries, the precursor of NMFS. He described his shock that dolphins were involved in the fishing process at all:

"The most amazing part was the use of dolphins - schools of tuna were found by looking for schools of dolphins. Then, the fishermen herded the dolphins with speedboats to move the associated tuna into a good configuration for setting the net...The whole operation revolved around dolphins: how to find them, catch them, and deal with them" (Perrin 2009).

Perrin estimated that up to a thousand dolphins, mostly spotted dolphins, were captured at a time; up to 400 were killed in some sets, and perhaps hundreds of thousands of dolphins died each year in the fishery. In the 1990's early dolphin 
mortality estimates were revised based on stock structure, and there was estimated to be nearly 5 million deaths during the period between 1959 and 1972 (Wade 1995). Northeastern spotted dolphins were killed more than any other dolphin stock; a total estimated to be 3 million. Total estimates for other stocks were 400,000 for western/southern spotted dolphins, 1.3 million eastern spinner dolphins, 50,000 whitebelly spinner dolphins, and 15,000 dolphins of other species (Wade 1994, 1995).

\subsubsection{Dolphin mortality reduction}

Perrin was at the center of the decades of research by the NMFS to reduce the mortality of dolphins in the tuna fishery and to study their biology. Fishermen had taken the first steps to reducing dolphin mortality by developing the "backdown" method of herding dolphins out of the back of the net in the late 1960s (Figure 1.1). The net was then modified to have finer-mesh netting along the "backdown channel" to reduce dolphin entanglement during the release.

In addition to net innovations, the complex process of introducing management policies to a fishery that operated in mixed-nationality and international waters began. The Marine Mammal Protection Act (MMPA) was implemented in October of 1972, protecting all marine mammals in United States waters under its legislature. Although the original MMPA largely exempted the fishery from limits imposed on other fisheries, it was clear that much more data was needed about the dolphins, the tuna, and the fishery (Gosliner 1999).

Soon after the implementation of the MMPA, National Marine Fisheries Service placed observers on the US fleet. In 1979, the Inter-American Tropical Tuna Commission (IATTC) followed suit and placed observers on the international fleets, and, by 1986, observers had been placed on all national fleets. By this time the US fleet operating in the eastern tropical Pacific was shrinking, going from 112 large seiners in the mid-1970s to only 44 by 1984, and by 1992 what 
remained of the US fleet had largely moved to the western Pacific (Gosliner 1999).

In 1992, ten nations fishing in the ETP grounds adopted the La Jolla Agreement (IATTC 1992). For the first time, both annual and international dolphin mortality limits were implemented. The La Jolla Agreement also initiated a voluntary observer program with $100 \%$ observer coverage and the setting of Dolphin Mortality Limits (DMLs) per vessel and Stock Mortality Limits (SMLs) per dolphin stock. This agreement proved to be highly successful in rapidly reducing mortality. The Declaration of Panama was adopted by 12 nations in 1995 to make the La Jolla Agreement a legally binding document with the objective of progressively reducing dolphin mortality with the eventual goal of zero (IATTC 1995). The observer program was no longer voluntary, but the document also spells out the expectations that, for fish caught in compliance with the Declaration, the U.S. would lift embargos and allow market access, and change U.S. "dolphin-safe" labeling standards. To provide more structure to previous agreements, the Agreement on the International Dolphin Conservation Program (AICDP) was established in 1999 (IATTC 1999) and 14 nations have since ratified the AIDCP. Currently, participating fleets operate under a mandatory DML of 5,000 animals, with each vessel receiving a limit of about 50 mortalities annually. The IATTC and national observer programs monitor virtually $100 \%$ of purse-seiners fishing in the ETP; these observers record dolphin sightings, tuna catches, and the mortalities of dolphin and other bycatch species (Bayliff 2001, AIDCP 2018).

Annual reported dolphin mortality has been under 1,000 per year since 2011, well below the maximum limit (Figure 1.2). Additionally, current stock mortalities are all well below the SMLs (AICDP 2018). Accurate dolphin stock definitions and abundance estimates are needed both for estimating the impact of the fishery on dolphin species and for ensuring conservation of genetic variation (Dizon et al. 1994). There are two main dolphin species targeted by the fishery due to their 
association with yellowfin tuna in the ETP. Historically, spotted dolphins are the most targeted, and are most often found with yellowfin tuna (Perrin 2009). In the ETP three spotted dolphin stocks are recognized: the coastal, northeastern offshore, and western/southern offshore spotted dolphins (Dizon et al. 1994) (Figure 1.3). Based on abundance surveys conducted from 1979 to 2001, the northeastern offshore spotted stock is estimated to be at $20 \%$ of its historical population (Reilly et al. 2005, but see Gerrodette et al.2008 and Barlow 2015). The second-most targeted dolphin species, the spinner dolphin, also has three stocks recognized in the ETP: the eastern, whitebelly, and Central American spinner dolphins (Dizon et al. 1994) (Figure 1.3). The eastern spinner dolphins are estimated to be at $35 \%$ of their historical abundance (Reilly et al. 2005, but see Gerrodette et al. 2008 and Barlow 2015). Despite the decrease in observed mortality, the dolphin populations of the ETP were thought initially not recovering as expected (Gerrodette \& Forcada, 2005), but after two more surveys in 2003 and 2008, it was suggested that dolphin stocks may indeed be recovering, just very slowly (Gerrodette et al. 2008).

Studies have also been done to evaluate the stress and other effects that the fishery has on current populations. As the dolphins of the ETP have been exposed to the fishery over time, they have learned to evade capture (Edwards 2007), and once captured, to wait for the "back-down" procedure which releases them. Research investigating the issues of stress physiology, behavior, and population dynamics of dolphins and the purse-seining operation has been complex but inconclusive (St. Aubin et al. 2013).

Through the use of fishermen's innovations, national legislation, and international agreements and cooperation, dolphin mortality appears to be biologically insignificant. Nevertheless, the use of dolphins in the tuna fishery continues to be controversial. 


\subsection{Oceanography of the ETP}

The eastern tropical Pacific Ocean's biological environment stems from a combination of powerful oceanographic features (Figure 1.4). The region is characterized by the convergence and intermingling of five surface currents and strong trade winds, resulting in wind-driven upwelling, shallow thermoclines, and the most hypoxic oxygen minimum layer in the world. Important ecological features also characterize the region, such as the Costa Rica Dome, the equatorial cold tongue, and the eastern Pacific warm pool. The intense sun and warm water along the equator, combined with the convergence of the trade winds, creates the intertropical convergence zone (ITCZ) - a belt of low pressure that circles the earth along the equator - and seasonal shifts in this atmospheric belt result in different seasonal rainfall (Figure 1.5). In addition to seasonal fluctuations, El Niño-Southern Oscillation cycles have an interannual affect; on a timescale of two to seven years the eastern equatorial Pacific climate varies between anomalously cold (La Niña) and warm (El Niño) conditions. These temperature fluctuations are accompanied by changes to the structure of the sub-surface ocean, a strengthening and weakening of the equatorial easterly trade winds, and a shallowing and deepening of thermoclines (Collins et al. 2010). These compounded oceanographic effects create a complex biological environment.

\subsubsection{Surface currents and water masses}

The five primary surface currents that form the ETP current system are the west-flowing North Equatorial $\left(10^{\circ} \mathrm{N}-15^{\circ} \mathrm{N}\right)$ and the South Equatorial Currents $\left(15^{\circ} \mathrm{S}-7^{\circ} \mathrm{N}\right)$, the east-flowing North Equatorial Countercurrent $\left(3^{\circ} \mathrm{N}-10^{\circ} \mathrm{N}\right)$, and the south-flowing California and north-flowing Peru currents that run along the west coasts of North America and South America (Wyrtki 1966) (Figure 1.4). There is one principle subsurface current, the Equatorial Undercurrent, flowing eastward along the equator. Current circulation in the ETP is maintained by energy transfer to the ocean surface by the trade winds, which circle the globe 
between approximately $30^{\circ} \mathrm{S}$ and $30^{\circ} \mathrm{N}$, converging at the Intertropical Convergence Zone (ITCZ) (Figure 1.5).

The Coriolis force, caused by the Earth's rotation, also affects wind and ocean currents, causing westward-flowing currents to deviate right in the northern hemisphere, and left in the southern hemisphere. Eastward-flowing currents veer left in the northern hemisphere and right in the south. As a result, the North Equatorial Current (NEC) and South Equatorial Current (SEC) are redirected to the poles, creating the western boundary Kuroshio and the Eastern Australian Currents. The Kuroshio Current converges into the North Pacific Current which turns south upon striking the North American continent, and becomes the California Current. The California Current then merges in the North Equatorial Countercurrent (NECC), finishing the current system circling the North Pacific Gyre. This system is mirrored in the southern Pacific; the Eastern Australian current flows south merging into the Antarctic Circumpolar Current; it then strikes the South American continent and becomes the Peru Current, eventually joining the SEC (Hinton 2015).

Three main water masses dominate the ETP region: the Sub-tropical Surface, Tropical Surface, and Equatorial Surface Waters (Wyrtki 1966). In regions where evaporation exceeds precipitation, Sub-tropical Surface Water is formed that has a high salinity ( $>35 \mathrm{ppt}$ ) in water ranging in temperature between $28^{\circ} \mathrm{C}$ to $15^{\circ} \mathrm{C}$. Tropical Surface Waters also have high temperatures $\left(>25^{\circ} \mathrm{C}\right)$, but lower salinity (<34 ppt) (Wyrtki 1966). Sub-tropical and Tropical Surface Waters intermingle and create the Equatorial Surface Water mass, which has intermediate properties of temperature and salinity $\left(<25^{\circ} \mathrm{C} ;>34 \mathrm{ppt}\right)$ (Wyrtki 1966).

A strong and shallow thermocline is present in the entire eastern tropical Pacific, particularly in the eastern Pacific warm pool. Mean thermocline depth generally deepens from east to west, caused by easterly trade winds and wind-driven upwelling and mixing (Fiedler and Lavín 2017). There are two main thermocline ridges in the ETP region; the equatorial thermocline ridge along the equator that 
coincides with the equatorial cold tongue and the countercurrent thermocline ridge along $10^{\circ} \mathrm{N}$. These ridges are areas of shallow thermocline that extend westward in the ETP. The countercurrent thermocline ridge peaks at $89^{\circ} \mathrm{W}$, in an area known as the Costa Rica Dome, which is a significant biodiversity hotspot. Both zonal thermocline ridges correspond to sea surface troughs, and the thermocline is strongest between $5^{\circ} \mathrm{S}$ and $15^{\circ} \mathrm{N}$, with the exception of directly over the equator.

Due to thermocline strength in the ETP region, there is less exchange of dissolved oxygen and nutrients between the surface waters and sub-thermocline waters beneath (Pennington et al. 2006). This contributes to a hypoxic and thick oxygen minimum layer laying below the thermocline, a layer with the lowest oxygen content in the world's oceans (Fiedler and Talley 2006). Areas with the lowest oxygen levels occur beneath the Peru Current off northern Peru, and under the eastern Pacific warm pool along the coast of southwest Mexico (Fiedler and Lavín 2017). The level of hypoxia of the ETP oxygen minimum zone is caused by several factors: high primary productivity, a strong thermocline that prevents subsurface water ventilation, and slow deep circulation that cause "aged" subthermocline waters (Fiedler and Lavín 2017). This combination of shallow thermocline and strong $\mathrm{OMZ}$ restricts the vertical habitat of the yellowfin tuna to the mixed layer (Prince and Goodyear 2006) and causes them to occupy similar depths to those of tropical dolphins, an important precursor to the tuna-dolphin association. The physiological restrictions of yellowfin tuna prevent them from diving below this low oxygen zone for long periods, and instead are generally found near the thermocline and above the OMZ. 


\subsubsection{Productivity and seasonal variations}

In most oceans, primary productivity is limited by the availability of nutrients and/or light, but in the ETP productivity is limited by iron availability and zooplankton grazing (Pennington et al. 2006). Therefore, the ETP is mostly productive in both coastal and pelagic waters, where currents or wind-driven upwelling supplies nutrients (Ballance et al. 2006). Coastally, iron input is introduced through the mixing of bottom sediments along the continental shelf and via river runoff during the rainy season (Fiedler and Lavín 2017). Other regions of high productivity occur beneath the Central American wind jets (Tehuantepec, Papagayo, and Panama) and the Peru Current upwelling system during the austral summer. During the boreal summer, productivity is highest along the Equatorial Cold Tongue driven by southeast trade winds, and around the Costa Rica Dome.

Seasonal changes in oceanography and productivity are influenced by the seasonal meridional migration of the ITCZ. The ITCZ is in its southern most position $\left(5^{\circ} \mathrm{N}\right)$ during the boreal winter bleeding into spring, intensifying the northeasterly trade winds and jet streams of Tehuantepec, Papagayo, and Panama (Amador et al. 2006). Due to the strong winds, water advects southward which allows for deeper nutrient rich waters to upwell to the surface, particularly along the Peruvian coastline. This seasonal upwelling along Peru has a seasonal peak in productivity during the austral summer and fall (Pennington et al. 2006). During this same season, the three Central American wind jets produce eddies off of Guatemala, which interrupt the warm low-productivity waters of the eastern Pacific warm pool (Willet et al. 2006). This process advects the relatively high productive waters westward and into the gulfs (Lavín et al. 2006). The eastern Pacific warm pool, an area of high sea surface temperatures and nutrient poor waters due to high stratification and a decrease in vertical mixing, is caused by the convergence of trade winds along the ITCZ, which leaves a "shadow" zone on the western coast of Mexico and Central America where winds are weak (Fiedler and Talley 2006, Lavín et al. 2006, Pennington et al. 2006). In the winter and spring, 
when the wind jets are strong, these waters become cooler and more productive (Pennington et al. 2006).

In the boreal summer and fall months, the ITCZ reaches its northernmost point $\left(10^{\circ} \mathrm{N}\right)$, which results in weaker upwelling winds, wind jets, and the formation of eddies that dominate the winter and spring in the ETP (Pennington et al. 2006). Once highly productive coastal waters decrease in productivity. The equatorial cold tongue however, an open ocean upwelling region that falls between the equator and $10^{\circ} \mathrm{N}$, reaches peak productivity during the boreal summer and fall. Phytoplankton and zooplankton biomass reach highest levels in this region during this time, when equatorial upwelling is strongest (Fernández-Álamo and FärberLorda 2006). The Costa Rica Dome does not exhibit large seasonal ranges in SST or productivity (Pennington et al. 2006), but does exhibit seasonal variations in extent, reaching its largest and westernmost extent at the end of the northern fall, when the ITCZ is at its southmost position, and is smallest and coastal bound in March.

\subsubsection{El Niño-Southern Oscillation}

Annual sun cycles result in seasonal changes in winds, rainfall, and physical oceanographic characteristics, but seasonal variability in the ETP is not as pronounced as it is in higher latitudes. Conversely, inter-annual variability caused by ENSO is considered very important in the ETP (Pennington et al 2006). ENSO is the cyclic change between El Niño, La Niña, and Niño neutral states as atmospheric pressure changes across the Pacific. El Niño events are prompted by a weakening of coastal trade winds in the western Pacific in response to increasing atmospheric pressure in the west, while pressure decreases in the eastern Pacific. The result is a weakening of the westward flowing NEC and SEC, and a strengthening of the NECC advecting warm waters into the ETP along the South American coast. El Niño events are associated with an increase in sea surface height, causing a deepening of the thermocline and nutricline, and the suppression of primary production (Pennington et al. 2006). Upwelling in the 
Costa Rica Dome, Peru coastal waters, and the equatorial cold tongue continue during El Niño events, however the upwelled waters are supplied by the warm, nutrient-poor upper layer which causes diminished primary productivity in normally productive areas of the ETP. Diminished primary productivity and the deepened thermocline have negative effects on the survival, reproduction, and distribution, of many higher trophic level organisms (Ballance et al. 2006). In contrast, La Niña states are associated with a strengthening of the westward flow of the Southern Equatorial current, which leads to increased equatorial upwelling, shoaling of the thermocline and nutricline, and an extension of the equatorial cold tongue (Pennington et al. 2006, Carlisle et al. 2017).

\subsubsection{Climate change}

Long-term climate change caused by natural and anthropogenic global warming is changing the physical oceanography in the ETP (Fiedler and Lavín 2017). Sea surface temperatures are warming as atmospheric $\mathrm{CO}_{2}$ levels increase, sea levels are rising due to ocean warming and glacier melt (IPCC 2007), thermoclines are shoaling and steepening in temperature gradient, and oxygen minimum zones are vertically expanding. Projections predict that temperatures will continue to increase, thermoclines will continue to shoal, stratification of near-surface waters will increase, and primary production in the tropical oceans will decrease as global warming continues (Collins et al. 2010, Fiedler and Lavín 2017). Any of these changes in mean climate may also lead to changes in ENSO amplitude. Changes in ENSO amplitude have been attributed to changes in depth and strength of the equatorial thermocline by theoretical, modeling, and observational studies (Wang et al 2017). However, a stronger and deeper thermocline drives weaker ENSO amplitude in coupled ocean-atmosphere modeling, while observations indicate that the strong ENSO events of the 1980s and 1990s are a result of a deepening or sharpening of the thermocline (Wang et al. 2017). Regardless, mean changes in climate of the ETP region are expected, though the resulting ENSO predictions are uncertain. 


\subsection{Geographic distributions and habitats}

\subsubsection{Tropical dolphin distribution}

The pantropical spotted dolphin (Stenella attenuata) is one of the most abundant cetaceans in the world's oceans (Folkens and Reeves 2002). They have a

moderately slender body, a dark back and lighter belly, and a complex and variable system of spotting, the degree of which varies greatly with age (Perrin 1970). Calves are born unspotted, and acquire dark spots on their ventral surfaces, and later, light spots on their dorsal surfaces as they age.

The pantropical spotted dolphin occurs in tropical and warm temperate waters worldwide. There are two subspecies in the ETP. One occurs in the offshore waters of the eastern tropical Pacific (S. a. attenuata), and the other occurs in coastal waters from Baja to the northwestern coast of South America (S. a. graffmani). From tagging studies, data suggests that the home ranges of the eastern Pacific offshore spotted dolphins are approximately 200 to 300 nautical miles, and their overall distribution shifts seasonally towards the coast in the boreal fall and winter, and further offshore in the boreal spring (Perrin et al. 1979).

In offshore areas, the pantropical spotted dolphin is often encountered in schools of hundreds or thousands, comprised of smaller social units (Scott and Chivers 2009). Group membership is fluid, and groups of spotted dolphins often associate with schools of spinner dolphins. These groups grow in size during the day and fragment at night.

Natural predators of these dolphins include large pelagic sharks, killer whales $(O$. orca) and false killer whales ( $P$. crassidens), and potentially even pygmy killer whales (F.attenuata) and pilot whales (Globicephala spp.) (Leatherwood et al. 1973, Perryman and Foster 1980; Cockcroft et al. 1989, Pitman et al. 2003). They themselves are predators of small pelagic fish and cephalopods (Perrin et al. 1973, 
Galván-Magaña 1999, Román-Reyes 2005, Scott et al. 2012). Tracking studies indicate these dolphins are primarily night-time feeders, foraging for vertically migrating prey that approaches the surface between dusk and dawn, and predominantly on mesopelagic prey species (Scott et al. 2012). In the eastern tropical Pacific, the pantropical spotted dolphin is commonly found in association with yellowfin tuna, spinner dolphins, and flocks of oceanic birds (Au and Perryman 1985, Au and Pitman 1986, Au and Pitman 1988, Clua and Grosvalet 2001, Ballance et al. 2006, Scott et al. 2012).

There are estimated to be more than 1.5 million pantropical spotted dolphins in the eastern tropical Pacific (Gerrodette et al. 2008). This species is considered of "least concern" under the IUCN Redlist, however the tuna fishery in the ETP is estimated to have reduced the northeastern offshore population to about 25 percent of its historical population size, is considered "depleted" under the MMPA (Reilly et al. 2005).

The spinner dolphin (Stenella longirostris) is named after its distinctive behavior of leaping from the surface and spinning aerially on its longitudinal axis. Four subspecies have been described, with regional variability in color and morphology. The general characteristics across all populations however are a fairly flat melon and a long, narrow beak. The spinner dolphins found in the eastern Pacific are grey with a white belly-patch and are mid-sized for their species. Adult male eastern spinners have prominent bulges on the ventral surface of the caudal peduncle, and forward-canted dorsal fins, giving them a "backwards" appearance.

The spinner dolphin occurs throughout the tropics and subtropics in several discrete geographical populations. The eastern spinner's (S. l. orientalis) range is generally east of $145^{\circ} \mathrm{W}$, and between $24^{\circ} \mathrm{N}$ off Baja California and $10^{\circ} \mathrm{S}$, off of the Peruvian coast. Hybrids between the Hawaiian spinner (S. l. longirostris) and the eastern spinner subspecies are found throughout most of the offshore eastern 
tropical Pacific (Perrin et al. 1991). These are known as the "whitebelly" spinners. The Central American spinner (S. l. centroamericana) occupies the coastal shelf waters between Southern Mexico and Costa Rica. Like most pelagic dolphins, spinner dolphins form large aggregations. In the open ocean, group size can be up to several thousand and composed of several groups. In coastal waters, they generally live in groups of a few dozen to a few hundred, that also grow in size throughout the day and fragment at night (Scott and Chivers 2009).

Spinner dolphins have similar predators to the pantropical spotted dolphin (Perryman and Foster 1980). Prey of the spinner dolphin is generally mesopelagic fishes and squids. Feeding studies suggest, like the spotted dolphin, that spinner dolphins mainly forage at night when the deep scattering layer is migrating vertically (Perrin et al. 1973, Scott et al. 2012).

There are estimated to be more than 1.7 million pantropical spinner dolphins in the eastern tropical Pacific (Gerrodette et al. 2008). The spinner dolphin is abundant and prevalent, however its population size in the eastern Pacific is likely less than half of its original population size (Reilly et al. 2005). The spinner dolphin is listed as "least concern" by the IUCN Redlist, but the eastern and whitebelly stocks are both considered "depleted" under the MMPA.

\subsubsection{Yellowfin tuna distribution}

Yellowfin tuna (Thunnus albacares) are found circumglobally in tropical and some temperate oceans with the exception of the Mediterranean. Several populations of yellowfin tuna have been described, however morphological and genetic data continue to support a single, worldwide species (Gibbs and Collette 1967, Scoles and Graves 1993).

Yellowfin tuna are epipelagic, occupying surface ocean waters ranging in temperature from $18^{\circ} \mathrm{C}$ to $31^{\circ} \mathrm{C}$, and spend most of their time in the mixed layer above the thermocline. Like many organisms in the ETP, vertical habitat and time spent diving is restricted by their physiological tolerance to oxygen and 
temperature, and the characteristic thick, hypoxic OMZ of the region (Schaefer et al. 2007, 2009). During darkness, yellowfin spend more time closer to the surface (Scott et al. 2012).

Yellowfin tuna often school in surface waters by size, either in monospecific or multi-species groups. In the eastern Pacific, they are often seen aggregating around floating objects, or schooling with dolphins, a key characteristic upon which much of the tuna fishery depends. They are visual predators that feed opportunistically on a wide range of organisms - fishes, squids, and crustaceans.

Fish found in their stomachs have been both pelagic and mesopelagic prey species, and during certain seasons, coastal fishes.

\subsection{The tuna-dolphin association}

Large mixed-species aggregations of dolphins, tuna, and seabirds are characteristic of the ETP. For many decades the biological basis for the association between dolphins and yellowfin tuna was not well understood despite the extensive history of fishing tuna in association with dolphins. Now we know the association is a result of several factors, but most prominently the oceanography of the ETP.

Early studies of ETP oceanography documented several distinguishing features of the region, including warm surface waters, a shallow thermocline, and a thick oxygen minimum zone resting just below the thermocline (Fiedler and Talley 2006). These features largely limit the vertical distribution of the yellowfin tuna to the surface mixed layer (Prince and Goodyear 2006, Schaefer et al. 2009) and promote the tuna-dolphin association (Scott et al. 2012). Tuna are most reliably found with spotted dolphins but are also caught with other dolphin species such as spinner dolphins and common dolphins (Delphinus delphis).

The association with dolphins occurs when the yellowfin tuna become large enough to keep up with the fast-swimming dolphins (Edwards 1992). It is thought 
that tuna, a schooling fish, have a genetic predisposition to associate with objects (Cayré et al. 1991, Hall et al. 1999); first as small tuna with floating objects, and then as larger tuna $(>1 \mathrm{~m})$ with dolphins. This schooling predisposition with objects and other species may serve as a manner to facilitate their own school formation; a passing dolphin herd may provide a cue that facilitate yellowfin tuna to aggregate into larger mixed-species schools. The association between tuna and dolphins is not an obligatory association (Scott et al. 2012), and forms and fades on a diel basis (Scott and Cattanach 1998).

Hypotheses have been presented to explain the complicated nature and possible benefits of the tuna-dolphin bond. The hypotheses that proposes increases in foraging efficiency (Au and Pitman 1986) was not supported by studies examining the foraging patterns and stomach contents of both tuna and dolphins (Scott et al. 2012). Food habits and tracking studies indicated spotted and spinner dolphins are primarily night-time feeders, foraging for vertically migrating prey that approaches the surface between dusk and dawn. During the day, spotted dolphins travel at depths of 15 to $20 \mathrm{~m}$ in the mixed layer while spinner dolphins travel mostly at the surface. Typically, the tuna feed throughout daylight hours and swim deeper, just above the thermocline during the day. After dusk, when dolphins begin deeper foraging dives, the tuna swim closer to the surface. This suggests that tuna and dolphin have different diel-feeding patterns that can overlap briefly during the dusk and dawn periods. Studies examining the stomach contents of tuna and dolphins in the ETP support this finding (Perrin et al. 1973, Olson and Galván 2002, Román-Reyes 2005), with digestion and fullness data indicating that dolphins feed mainly at night and in the early morning, whereas tuna feed throughout the daylight hours (Scott et al. 2012). Yellowfin and spotted dolphins swimming in association together were all found with two common prey species, the ommastrephid squid (Dosidicus gigas), and the frigate tuna (Auxis spp.), indicating they share more of an overlap of prey than the spinner dolphin and yellowfin tuna (Perrin et al. 1973). The most important prey species for the tuna included portunid crabs, ommastrephid squids, frigate tunas, and flyingfishes 
(Perrin et al. 1973). Long-term diet analysis of the yellowfin tuna in the ETP showed significant shifts in diet composition over a ten-year period (Olson et al. 2014), indicating possible diet shifts due to climate change. The tuna-dolphin association is primarily a diurnal one (Scott and Cattanach 1998), and if the association was based on feeding advantages or feeding overlap, it would be expected both dolphins and tuna would feed at the same time (Scott et al. 2012). However, the overlap of feeding between spotted dolphins and yellowfin tuna at dawn may serve as a catalyst for the day-time association that follows.

Tuna and dolphins in the ETP both form large groups, primarily because traveling in groups provides more protection from predators (Scott and Cattanach 1998). It is thought that this advantage extends to multi-species aggregations, in that larger groups dilute the risk of predation (Diamond 1998). Spotted dolphins and yellowfin tuna are similar in size and have the same potential predators - mostly large pelagic sharks and small toothed whales. An advantage of the association for one or both species may be the reduction of predation risk. Tuna predation risk may be especially high in the ETP where the vertical habitat is restricted by the strong and shallow OMZ (Au 1991, Hunsicker et al. 2012, Schaefer et al. 2009). Additionally, observations of predation on spotted dolphins has been recorded after the herd structure has been disturbed by fishing operations (Leatherwood et al. 1973, Perryman and Foster 1980), suggesting dolphin herd structure is essential for safety against predators. Shark attacks on dolphins are typically ambushes from behind and below (Cockcroft et al. 1989, Mead and Potter 1990, Scott and Cattanach 1998). In mixed-species aggregations of tuna and dolphins, risk of predation may decrease as a result of increased herd size and each species may also benefit from tracking each other's alarm responses (Scott et al. 2012). Dolphins are capable of echolocation and detect predators at greater distances, benefiting the tuna, while reactions by deeper-swimming tuna could alert dolphins to predators beneath them. 
With this predation hypothesis, more questions arise. Why is the association between tuna and dolphins mainly with spotted dolphins and spinner dolphins and not with other dolphin species, as theoretically any large dolphin herd would provide this dilution effect? The weaker association between yellowfin tuna and common dolphins is explained by their occupation of different habitats; yellowfin occupy tropical waters while common dolphins inhabit cooler upwelling waters (Au and Perryman 1985, Reilly 1990, Fiedler and Reilly 1994, Ballance et al. 2006). Spinner dolphins, however, occupy tropical waters and do associate with yellowfin tuna, but generally as part of mixed-species spotted-spinner herds. The apparent weaker association between yellowfin tuna and spinner dolphins may be because tuna encounter pure spotted herds and mixed spotted-spinner herds at a higher frequency than pure spinner dolphin herds (Scott et al. 2012). The predominance of the spotted-yellowfin association is also explained by the differences in swimming depths of spotted and spinner dolphins (Figure 1.6). Tuna swim near or just above the thermocline (Schaefer et al. 2007, 2009). Aerial photogrammetry studies suggest spinner dolphins swim closer to the surface than spotteds, as they are usually easier to photograph (Scott et al. 2012, Cramer et al. 2008). Spotted dolphins swim deeper during the day traveling 15 to $20 \mathrm{~m}$ below the surface (Scott et al. 2012). Therefore, it was easier for the yellowfin tuna, traveling just above the thermocline, to maintain an association with the deeperswimming spotted dolphins. Where the thermocline in the ETP was shallowest, approximately $20 \mathrm{~m}$ deep, the tuna associated with herds of pure spinner dolphins. The depth of the thermocline, and the characteristic thick hypoxic OMZ beneath, were an essential promoter of the tuna-dolphin association, and also a predictor of which dolphin species was involved. 


\subsection{Objectives and Hypotheses}

The objective of this study is to better understand how environmental factors influence the tuna-dolphin association in the ETP. Understanding spatiotemporal patterns, habitat preferences, and environmental influencers is necessary to predict spatial distributions of the tuna-dolphin association as oceans continue to warm and change due to global climate change. Knowledge gleaned during this study will also be used to advise future management strategies of the tuna-dolphin fishery. This was done by generating seasonal and ENSO averages over a 24-year period, and the construction of community-level species distribution boosted regression tree models. The following questions were addressed:

1. Which environmental factors in the ETP influence the distribution of the tuna-dolphin association?

$\mathrm{H}_{0}$ : There is no significant relationship between oceanographic factors and the tuna-dolphin association.

2. How do seasonal and ENSO environmental variability influence the distribution of the tuna-dolphin association in the ETP?

$\mathrm{H}_{0}$ : There is no distribution variability caused by seasonal and ENSO variability.

3. How have long-term oceanographic trends due to global climate change impacted the distribution of the tuna-dolphin association?

$\mathrm{H}_{0}$ : There is no correlation between long-term oceanographic changes in the ETP due to global warming and tuna-dolphin distribution changes. 


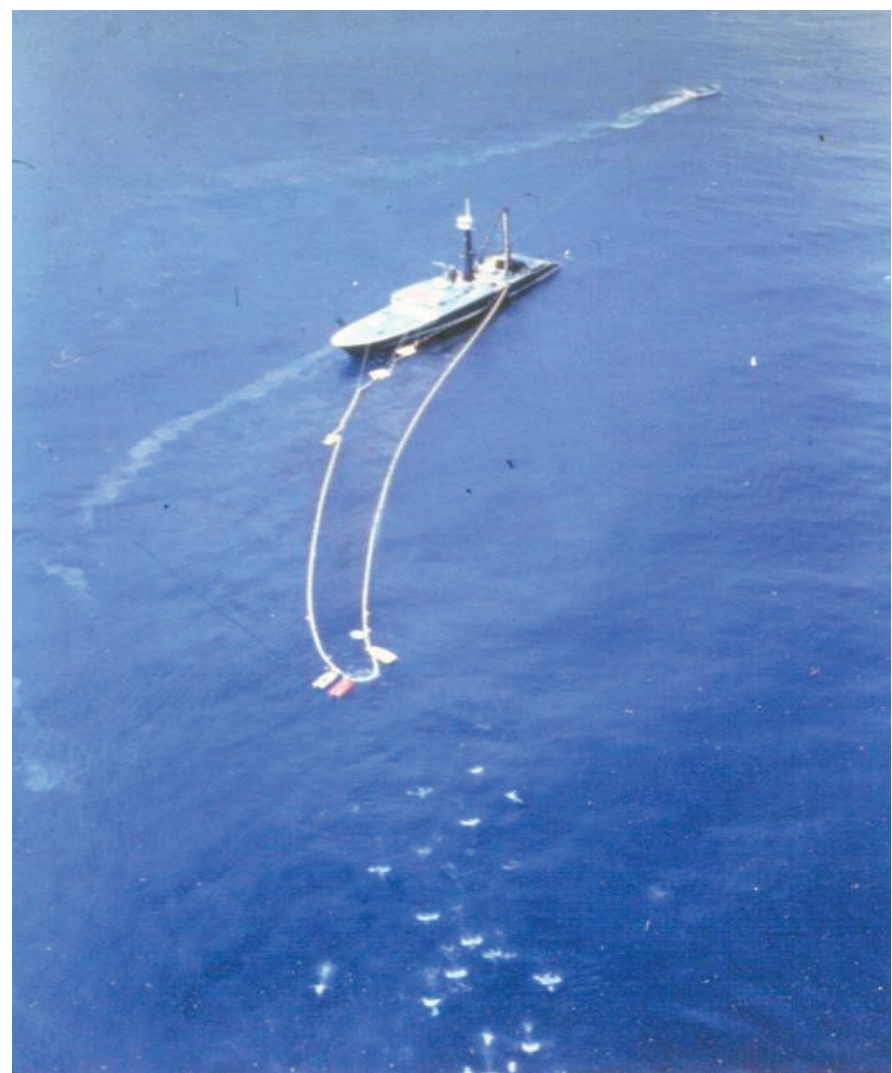

Figure 1.1 Dolphins being successfully released from the net during the backdown procedure. Note the configuration of the net into a narrow channel to allow dolphins to escape during the backdown (Photograph from IATTC). 


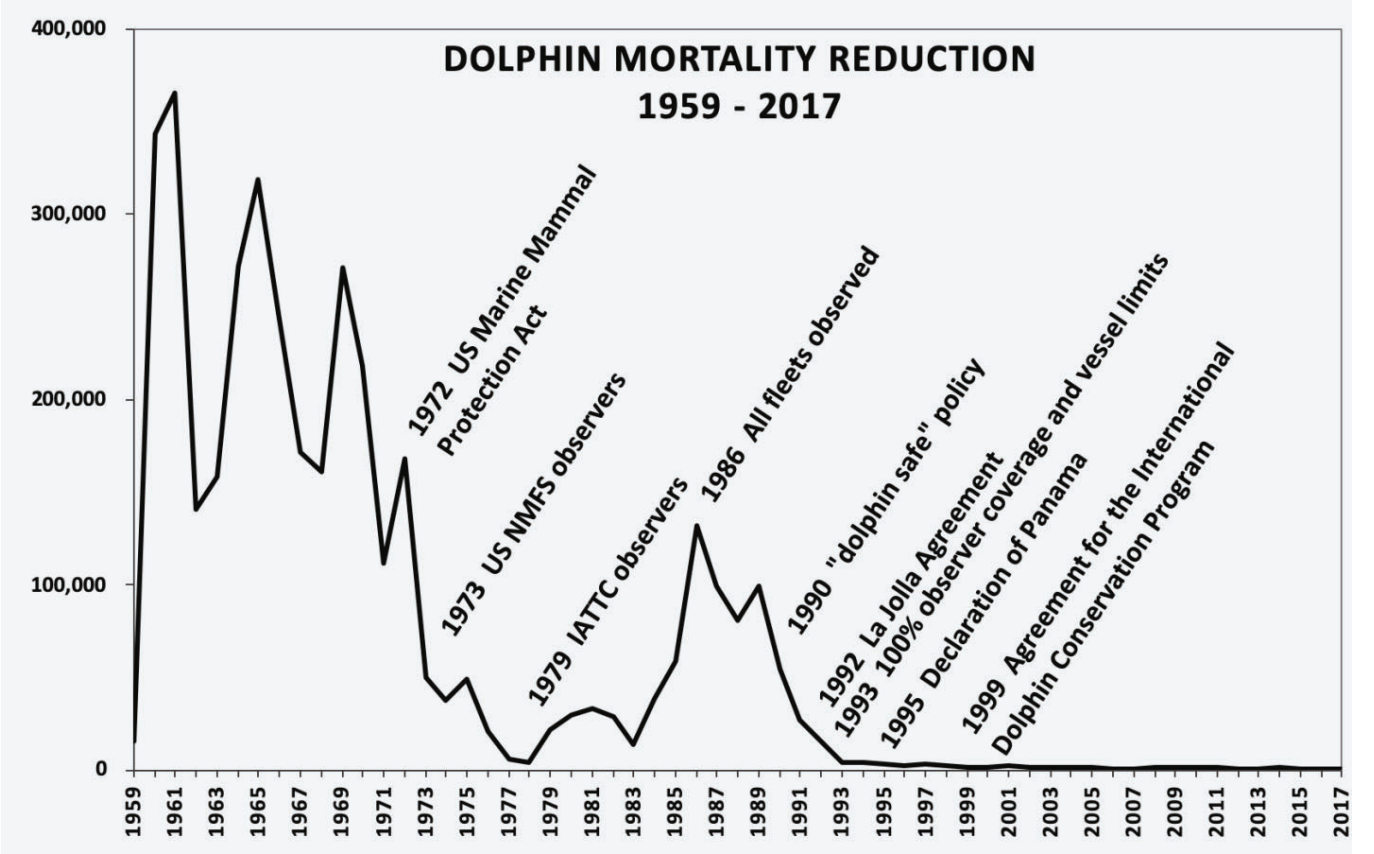

Figure 1.2 Dolphin mortality in the ETP, 1959-2017, noting the implementation of particular management policies. 

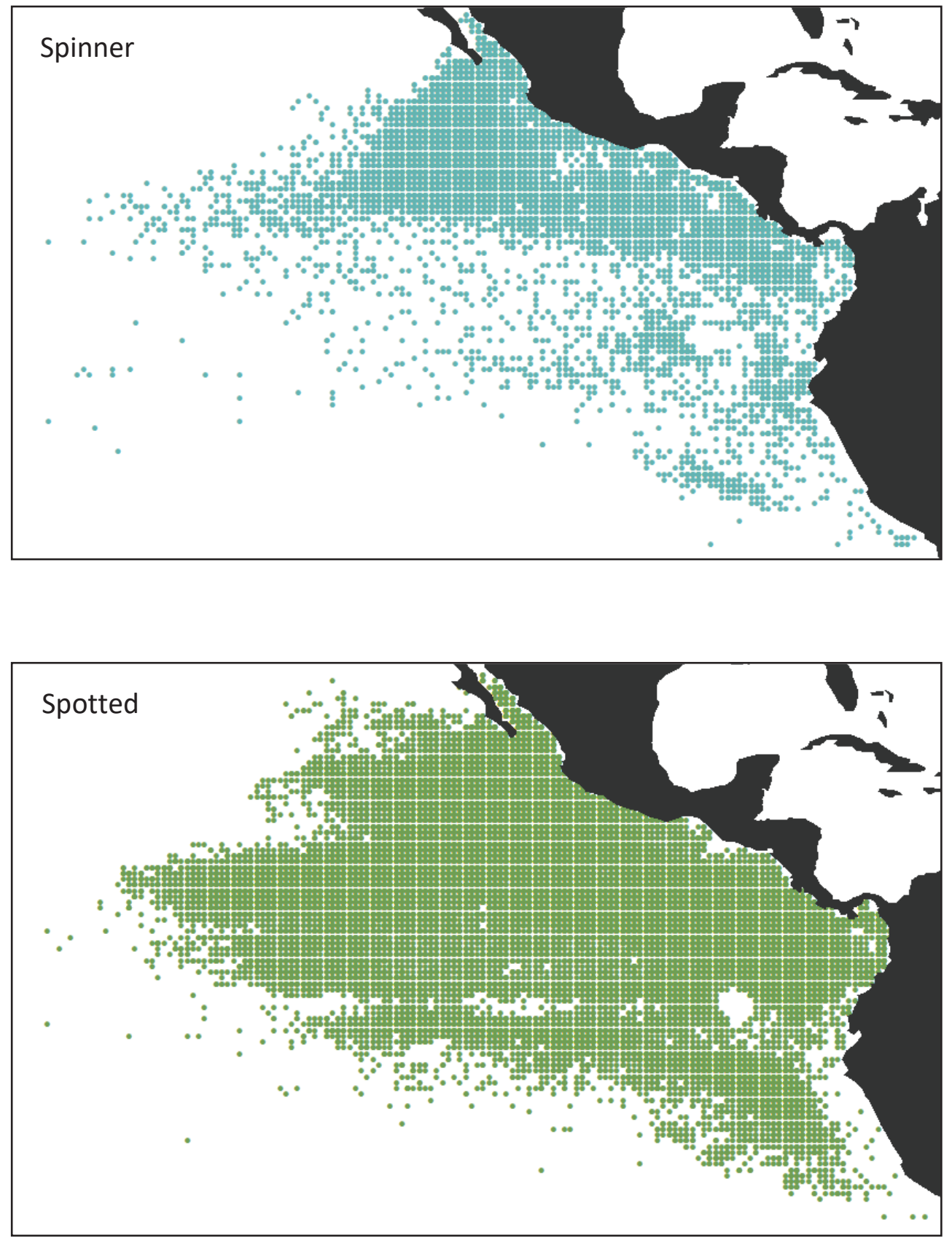

Figure 1.3 Spinner and spotted dolphin stock distributions (AIDCP data, 19922017). 


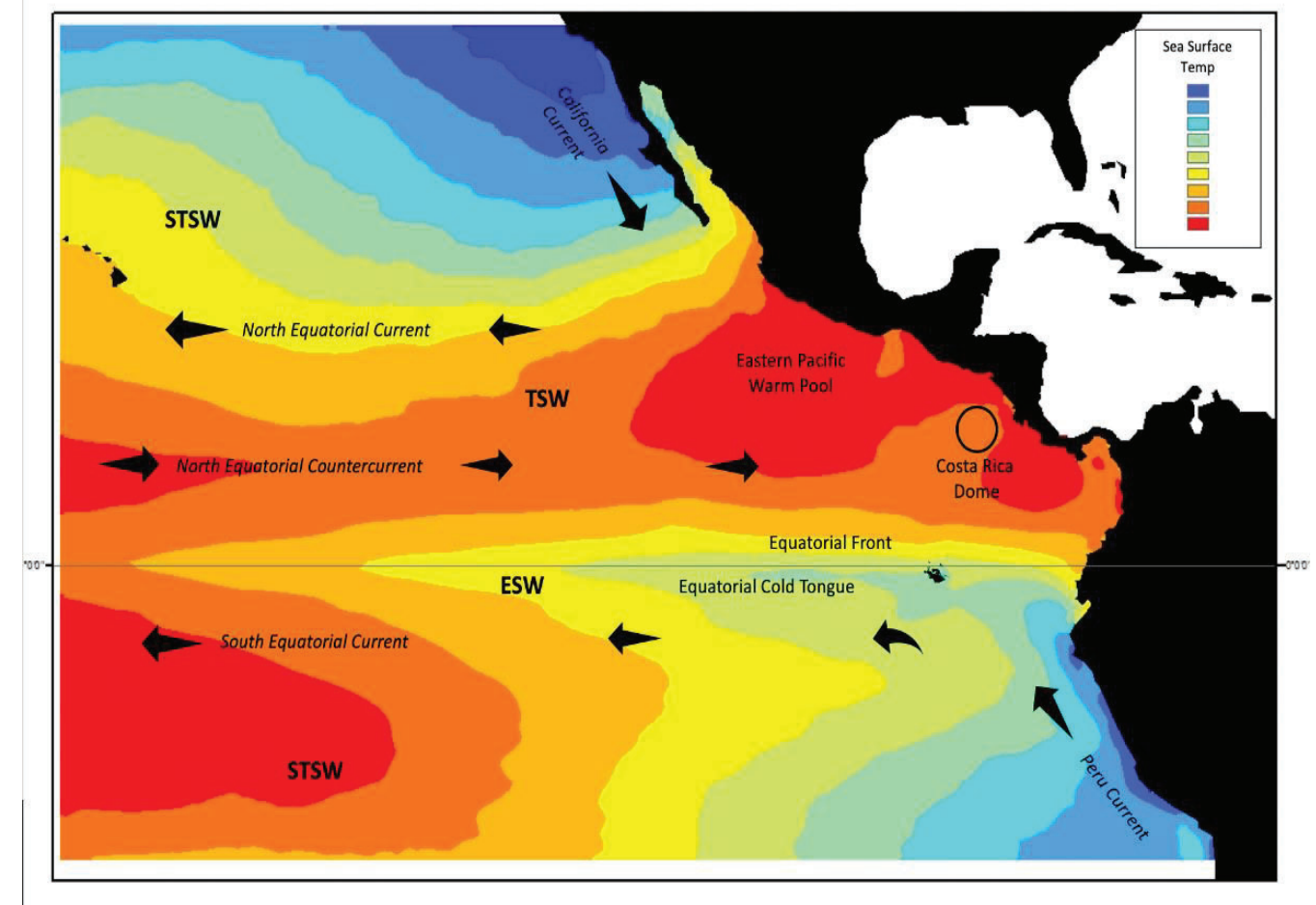

Figure 1.4 Diagram of surface water masses and currents in the eastern tropical Pacific Ocean: Subtropical Surface Water (STSW); Tropical Surface Water (TSW); Equatorial Surface Water (ESW). Cooler colors indicate colder sea surface temperature; warmer colors indicating warmer sea surface temperature (SODA, 2015). 


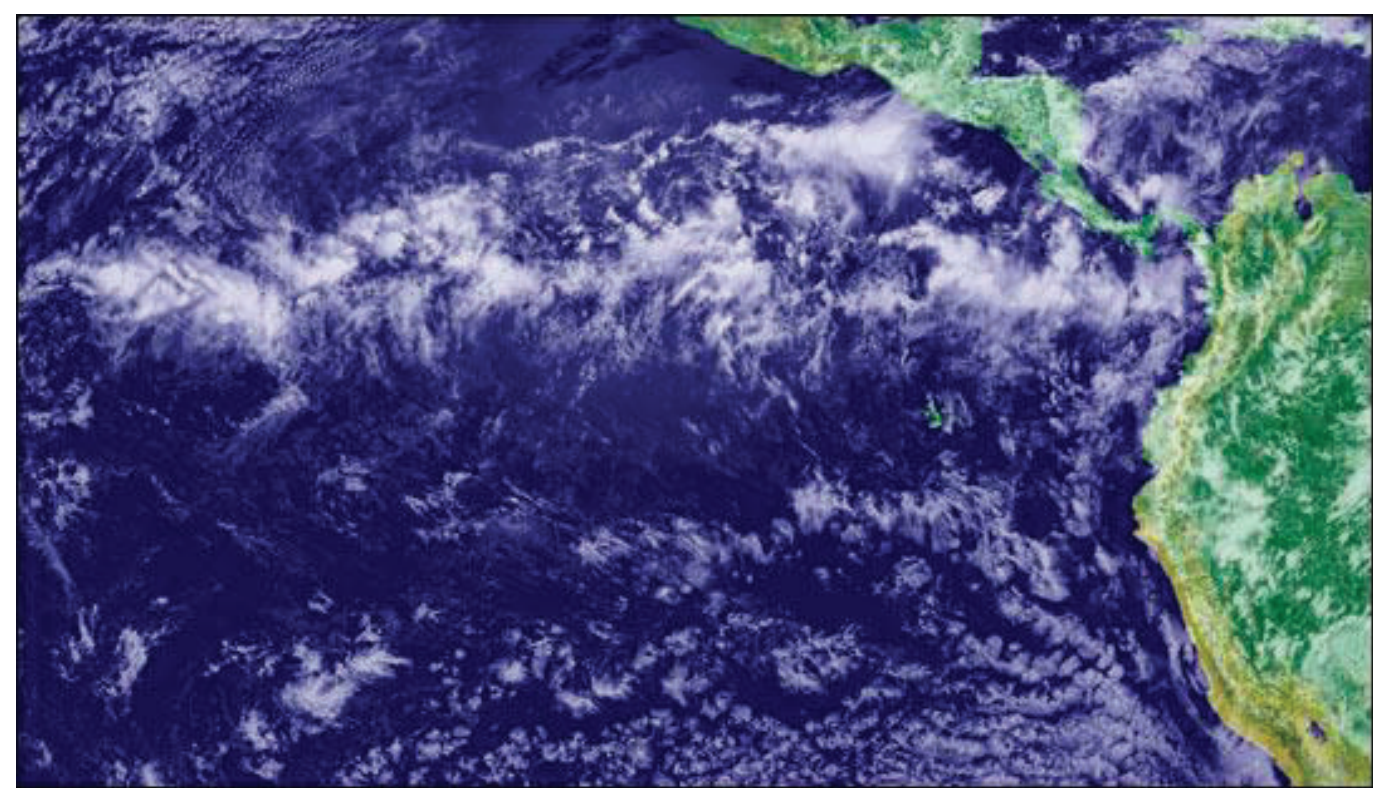

Figure 1.5 The Intertropical Convergence Zone atmospheric belt; Photo: NOAA's GOES Project Science Office. 


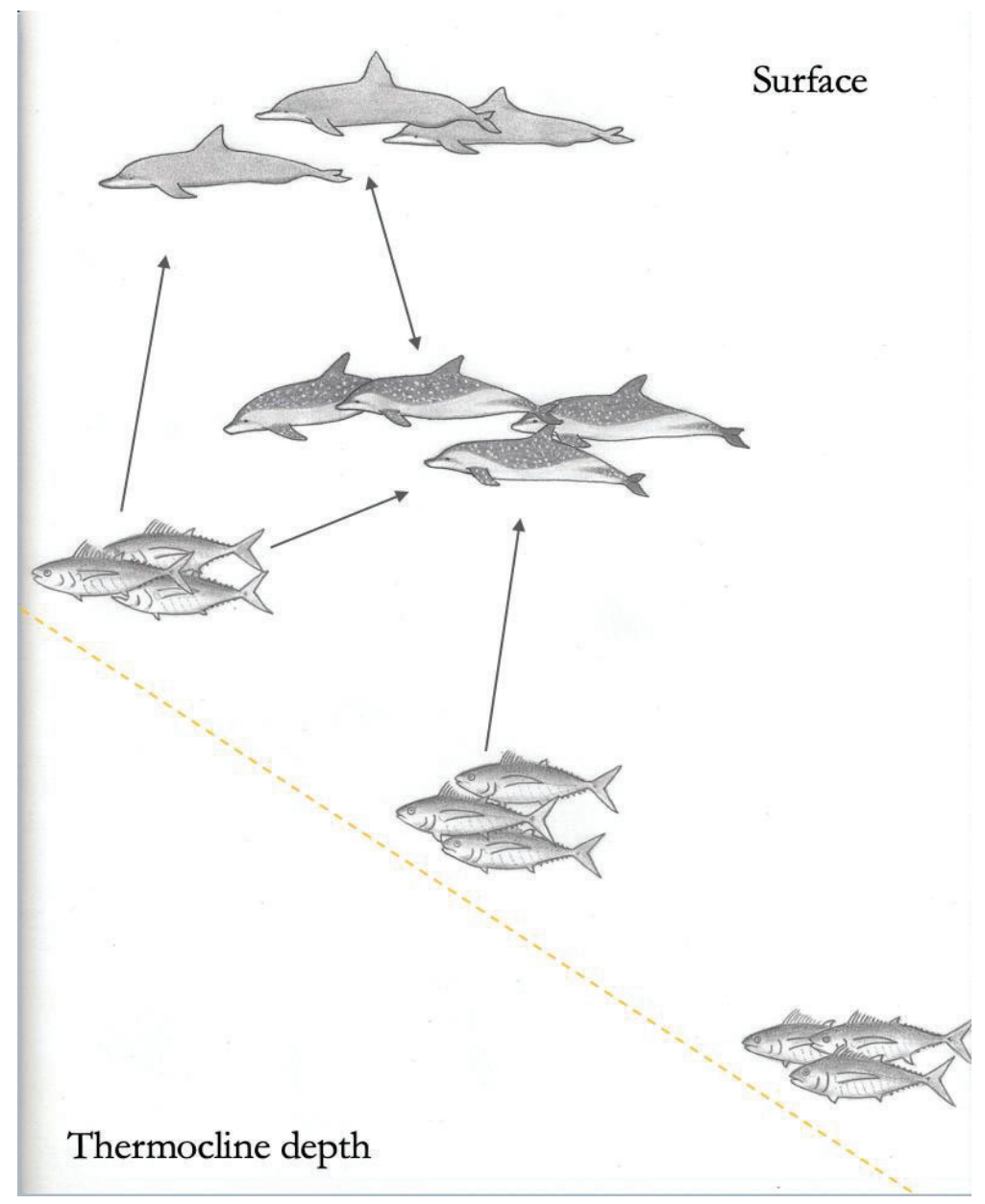

Figure 1.6 Schematic illustrating the influence of thermocline depth and dolphin swimming depth on the tuna-dolphin association; a) spinner dolphin (Stenella longirostris); b) spotted dolphin (Stenella attenuata); c) yellowfin tuna (Thunnis albarares) (Illustration by Caitlynn Birch 2018). 


\section{REFERENCES}

AIDCP. 2018. Report on the International Dolphin Conservation Program. MOP38-01.21 pp.

Amador, J. A., E. J. Alfaro, O. G. Lizano, and V. O. Magaña. 2006. Atmospheric forcing of the eastern tropical Pacific: A review. Progress in Oceanography 69:101-142.

Au, D. K. 1991. Polyspecific nature of tuna schools: Shark, dolphin, and seabird associates. Fishery Bulletin 89:343-354.

Au, D. K., and W. Perryman. 1982. Movement and speed of dolphin schools responding to an approaching ship. Fishery Bulletin 80:371-379.

Au, D. W. K., and W. L. Perryman. 1985. Dolphin habitats in the eastern tropical Pacific. Fishery Bulletin 83:623-643.

Au, D. W. K., and R. L. Pitman. 1986. Seabird interactions with dolphins and tuna in the eastern tropical Pacific. Condor 88:304-317.

Au, D. W., and R. L. Pitman. 1988. Seabird relationships with tropical tunas and dolphins. Pages 174-121 in B. J, editor. Seabirds and other marine vertebrates: competition, predation, and other interactions. Columbia University Press, New York, NY.

Ballance, L., R. L. Pitman, and P. Fiedler. 2006. Oceanographic influences on seabirds and cetaceans of the eastern tropical Pacific: A review. Progress in Oceanography 69(2-4):360-390.

Bayliff, W. H. 2001. Organization, functions, and achievements of the InterAmerican Tropical Tuna Commission. Inter-American Tropical Tuna Commission Special Report 13.

Carlisle, A., R. Kochevar, M. Arostegui, J. Ganong, M. Castleton, J. Schratwieser, and B. Block. 2017. Influence of temperature and oxygen on the distribution of blue marlin (Makaira nigricans) in the Central Pacific. Fisheries Oceanography 26:34-48.

Cayré, P. 1991. Behaviour of yellowfin tuna (Thunnus albacares) and skipjack tuna (Katsuwonus pelamis) around Fish Aggregating Devices (FADs) in the Comoros Islands as determined by ultrasonic tagging. Aquatic Living Resources 4:1-12. 
Clua, E., and F. Grosvalet. 2001. Mixed-species feeding aggregations of dolphins, large tunas, and seabirds in the Azores. Aquatic Living Resources 14:1118.

Cockcroft, V. G., G. Cliff and G. J. B. Ross 1989. Shark predation on Indian Ocean bottlenose dolphins Tursiops truncatus off Natal, South Africa. South African Journal of Zoology 24:305-310.

Collette, B., and G. John. 2019. Tunas and billfishes of the world. Pages 232-235. Johns Hopkins University Press, Baltimore, Maryland.

Collins, M., S.-I. An, W. Cai, A. Ganachaud, E. Guilyardi, F.-F. Jin, M. Jochum, M. Lengaigne, S. Power, A. Timmermann, G. Vecchi, and A. Wittenberg. 2010. The impact of global warming on the tropical Pacific Ocean and El Niño. Nature Geoscience 3:391-397.

Cramer, K. L., W. L. Perryman, and T. Gerrodette. 2008. Declines in reproductive output in two dolphin populations depleted by the yellowfin tuna purseseine fishery. Marine Ecology Progress Series 369:273-285.

Diamond, J. 1988. Strange traveling companions. Natural History 97:22-27.

Dizon, A. E., W. F. Perrin, and P. A. Akin. 1994. Stocks of dolphins (Stenella spp. and Delphinus delphis) in the eastern tropical Pacific: A phylogeographic classification. NOAA Technical Report NMFS 119. 20pp.

Edwards, E. F. 1992. Energetics of associated tunas and dolphins in the eastern tropical Pacific: A basis for the bond. Fishery Bulletin 90:678-690.

Edwards, E. F. 2007. Fishery effects on dolphins targeted by tuna purse-seiners in the eastern tropical Pacific Ocean. International Journal of Comparative Psychology 20:217-227.

Filando, A., and H. Medina. 2011. The tuna/porpoise controversy. Western Sky Press, San Diego, CA. 305pp.

Fernández-Álamo, M. A., and J. Färber-Lorda. 2006. Zooplankton and the oceanography of the eastern tropical Pacific. Progress in Oceanography 69:143-180. 
Fiedler, P. C., and B. S. Reilly. 1994. Interannual variability of dolphin habitats in the eastern tropical Pacific II: effects on abundances estimated from tuna vessel sightings, 1975-1990. Fishery Bulletin 92:451-463.

Fiedler, P. C., and M. F. Lavín. 2017. Oceanographic conditions of the eastern tropical Pacific. Pages 59-83 in P. W. Glynn, D. Manzello, and I. C. Enochs, editors. Coral reefs of the eastern tropical Pacific: Persistence and loss in a dynamic environment. Springer.

Fiedler, P. C., and L. D. Talley. 2006. Hydrography of the eastern tropical Pacific: A review. Progress in Oceanography 69:143-180.

Folkens, P. A., and R. R. Reeves. 2002. Guide to marine mammals of the world. Pages 366-377 in National Audubon Society field guide series. Knopf Doubleday Publishing Group, New York.

Galván-Magaña, F. 1999. Interespecific trophic relationships of the epipelagic predators community of the eastern Pacific Ocean. Ph.D. Thesis CICESE. Centro de Investigaciones, Mexico, $212 \mathrm{pp}$.

Gerrodette, T. G. Watters, W. Perryman, L. Ballance. 2008. Estimates of 2006 dolphin abundance in the eastern tropical Pacific, with revised estimates from 1986-2003. NOAA Technical Memorandum NOAA-TM-NMFSSWFSC-422. $39 \mathrm{pp}$.

Gerrodette, T., and J. Forcada. 2005. Non-recovery of two spotted and spinner dolphin populations in the eastern tropical Pacific Ocean, Marine Ecology Progress Series. 291:1-21.

Gibbs, R. H., and B. Collette. 1967. Comparative anatomy and systematics of the tunas, genus Thunnus. Fishery Bulletin 66:65-130.

Godsil, H. 1938. The high seas tuna fishery of California. Fishery Bulletin 51:141.

Gosliner, M. L. 1999. The tuna-dolphin controversy. Pages 120-155 in J. R. Twiss and R. R. Reeves, editors. Conservation and management of marine mammals. Smithsonian Institutional Press, Washington, D.C.

Green, R. E., W. F. Perrin, and B. P. Petrich. 1971. The American purse seine fishery. Pages 3-15 in H. Kristjonsson, editor. Modern fishing gear of the world: 3. Fish finding, purse seining, aimed trawling. Fishing News, Ltd., London. 
Hall, M., M. García, C. Lennert-Cody, P. Arenas, and F. Miller. 1999. The association of tunas with floating objects and dolphins in the eastern Pacific Ocean: a review of the current purse-seine fishery. Inter-American Tropical Tuna Commission Special Report No. 11, La Jolla, CA

Hinton, M. 2015. Oceanographic conditions in the EPO and their effects on tuna fisheries. Inter-American Tropical Tuna Commission Stock Assessment Report 16:68-112.

Hunsicker, M. E., M. N. Maunder, L. M. Duffy, J. F. Kitchell, R. J. Olson, and T. E. Essington. 2012. The potential for top-down control on tropical tunas based on size structure of predator-prey interactions. Marine Ecology Progress Series 445:263-277.

IATTC. 1991. The La Jolla Agreement. http://www.iattc.org/PDFFiles/AIDCP/_English/La-Jolla-Agreement-0198.pdf

IATTC. 1995. The Declaration of Panama. http://www.iattc.org/PDFFiles/AIDCP/ English/Declaration of Panama.pdf

IATTC. 1999. The Agreement on the International Dolphin Conservation Program. http://www.iattc.org/PDFFiles/AIDCP/ English/AIDCP-amended-Oct2017.pdf

IUCN 2019. The IUCN Red List of Threatened Species. Version 2019-2. http://www.iucnredlist.org. Downloaded on 18 July 2019.

Leatherwood, J. S., W. F. Perrin, R. L. Garvie, and J. C. La Grange. 1973. Observations of sharks attacking porpoises (Stenella spp. and Delphinus ef D. delphis). Naval Undersea Center Technical Note NUC TN 908:1-7.

Lennert-Cody, C. E., S. T. Buckland, and F. F. C. Marques. 2001. Trends in dolphin abundance estimated from fisheries data: a cautionary note. Journal of Cetacean Research and Management 3:305-319.

Maldini, D. 2003. Evidence of predation by a tiger shark (Galeocerdo cuvier) on a spotted dolphin (Stenella attenuata) off O'ahu, Hawai'i. Aquatic Mammals 29:84-87. 
McNeely, R. L. 1961. The purse seine revolution in tuna fishing. Pacific Fisherman 1961:27-58.

Mead, J. G., and C. W. Potter. 1990. Natural history of bottlenose dolphins along the central Atlantic Coast of the United States. Pages 165-196 in S. Leatherwood and R. R. Reeves, editors. The bottlenose dolphin. Academic Press, San Diego.

Olson, R., and F. Galván-Magaña. 2002. Food habits and consumption rates of common dolphinfish (Coryphaena hippurus) in the eastern Pacific Ocean. Fishery Bulletin 100:279-298.

Olson, R. J., L. M. Duffy, P. M. Kuhnert, F. Galván-Magaña, N. BocanegraCastillo, and V. Alatorre-Ramírez. 2014. Decadal diet shift in yellowfin tuna Thunnus albacares suggests broad-scale food web changes in the eastern tropical Pacific Ocean. Marine Ecology Progress Series 497:157178.

Pennington, J. T., K. L. Mahoney, V. S. Kuwahara, D. D. Kolber, R. Calienes, and F. P. Chavez. 2006. Primary production in the eastern tropical Pacific: A review. Progress in Oceanography 69:285-317.

Perrin, W. F. 1968. The porpoise and the tuna. Sea Frontiers 14:166-174.

Perrin, W. F. 1970. Color pattern of the eastern Pacific spotted porpoise Stenella graffmani Lönnberg (Cetacea, Delphinidae). Zoologica 54:135-142.

Perrin, W. F., R. R. Warner, C. H. Fiscus, and D. B. Holts. 1973. Stomach contents of porpoise, Stenella spp., and yellowfin tuna, Thunnus albacares, in mixed-species aggregations. Fishery Bulletin 71:1077-1092.

Perrin,W. F., W. E. Evans, and D. B. Holts. 1979. Movements of pelagic dolphins (Stenella spp.) in the eastern tropical Pacific as indicated by results of tagging, with summary of tagging operations, 1969-1976. Southwest Fisheries Center Administrative Report LJ-77-6. 38pp.

Perrin, W. F. 2009. Early days of the tuna/dolphin problem. Aquatic Mammals 35:293-305.

Perryman, W. L., and T. C. Foster. 1980. Preliminary report on predation by small whales, mainly the false killer whale, Pseudorca crassidens, on dolphins (Stenella spp. and Delphinus delphis) in the eastern tropical Pacific. Southwest Fisheries Center Administrative Report LJ-80-05:9. 
Pitman, R. L., S. O’Sullivan, and B. Mase. 2003. Killer whales (Orcinus orca) attack a school of pantropical spotted dolphins (Stenella attenuata) in the Gulf of Mexico. Aquatic Mammals 29:321-324.

Prince, E. D., and C. P. Goodyear. 2006. Hypoxia-based habitat compression of tropical pelagic fishes. Fisheries Oceanography 15:451-464.

Reilly, S. B. 1990. Seasonal changes in habitat differences among dolphins in the eastern tropical Pacific. Marine Ecology Progress Series 66:1-11.

Reilly, S.B. and P. Fiedler. 1994. Interannual variability of dolphin habitats in the eastern tropical Pacific. I: Research vessel surveys, 1986-1990. Fishery Bulletin 92:434-450.

Reilly, S. B., M.A. Donahue, T. Gerrodette, K. Forney, P. Wade, L. Ballance, J. Forcada, P. Fiedler, A. Dizon, W. Perryman, F. A. Archer, and E. F. Edwards. 2005. Report of the scientific research program under the international dolphin conservation program act. Southwest Fisheries Science Center, La Jolla, CA.

Román-Reyes, J. 2005. Análisis del contenido estomacal y la razón de isótopos estables de carbono (13C) y nitrógeno $(15 \mathrm{~N})$ del atún aleta amarilla (Thunnus albacares), delfín manchado (Stenella attenuata) y delfín tornilla (Stenella longirostris) del Océano Pacífico Oriental. Instituto Politécnico, Nacional, Mexico.

St. Aubin, D. J., K. A. Forney, S. J. Chivers, M. D. Scott, K. Danil, T. A. Romano, R. S. Wells, and F. M. D. Gulland. 2013. Hematological, serum, and plasma chemical constituents in pantropical spotted dolphins (Stenella attenuata) following chase, encirclement, and tagging. Marine Mammal Science 29:14-35.

Schaefer, K., D. Fuller, and B. Block. 2009. Vertical movements and habitat utilization of skipjack (Katsuwonus pelamis), Yellowfin (Thunnus albacares), and Bigeye (Thunnus obesus) tunas in the equatorial eastern Pacific Ocean, ascertained through archival tag data. Pages 12-44 in J. L. Nielsen, H. Arrizabalaga, N. Fragoso, A. Hobday, M. Lutcavage, and J. Sibert, editors. Tagging and Tracking of Marine Animals with Electronic Devices. Springer, New York, NY.

Schaefer, K., D. Fuller, and B. Block. 2007. Movements, behavior, and habitat utilization of yellowfin tuna (Thunnus albacares) in the northeastern 
Pacific Ocean, ascertained though archival tag data. Marine Biology 152:503-525.

Scoles, D., and J. Graves. 1993. Genetic analysis of the population structure of yellowfin tuna Thunnus albacares in the Pacific Ocean. Fishery Bulletin 91:690-698.

Scott, M. D., and K. L. Cattanach. 1998. Diel patterns in aggregations of pelagic dolphins and tunas in the eastern Pacific. Marine Mammal Science 14:401422.

Scott, M. D., and S. J. Chivers. 2009. Movements and diving behavior of pelagic spotted dolphins. Marine Mammal Science 25:137-160.

Scott, M. D., S. J. Chivers, R. J. Olson, P. C. Fiedler, and K. Holland. 2012. Pelagic predator associations: Tuna and dolphins in the eastern tropical Pacific Ocean. Marine Ecology Progress Series 458:283-302.

Silva, G. 1941. Porpoise fishing. Pacific Fisherman 39:36.

Wade, P. R. 1994. Abundance and population dynamics of two eastern Pacific dolphins, Stenella attenuata and Stenella longirostris orientalis. $\mathrm{PhD}$ dissertation, University of California, San Diego. 255pp.

Wade P.R. 1995. Revised estimates of incidental kill of dolphins (Delphinidae) by the purse-seine tuna fishery in the eastern tropical Pacific, 1959-1972. Fishery Bulletin 93:345-354.

Wade, P. R., G. M. Watters, T. Gerrodette, and S. B. Reilly. 2007. Depletion of spotted and spinner dolphins in the eastern tropical Pacific: Modeling hypotheses for their lack of recovery. Marine Ecology Progress Series 343:1-14.

Wang, C., C. Deser, J.-Y. Yu, P. DiNezio, and A. Clement. 2017. El Niño and Southern Oscillation (ENSO): A review. Pages 85-106 in P. W. Glynn, D. P. Manzello, and I. C. Enochs, editors. Coral Reefs of the Eastern Tropical Pacific: Persistence and Loss in a Dynamic Environment. Springer Netherlands, Dordrecht.

Wang, C., and P. C. Fiedler. 2006. ENSO variability and the eastern tropical Pacific: A review. Progress in Oceanography 69:239-266. 
Willett, C. S., R. R. Leben, and M. F. Lavín. 2006. Eddies and tropical instability waves in the eastern tropical Pacific: A review. Progress in Oceanography 69:218-238.

Wyrtki, K. 1966. Oceanography of the eastern equatorial Pacific Ocean. Oceanography and Marine Biology Annual Review 4:33-68.

Yoshida, H. O., R. N. Uchida, and T. Otsu. 1977. The Pacific tuna pole-and-line and live bait fisheries. Pages 36-51 in R. S. Shomura, editor. Collection of tuna baitfish papers. U.S.Department of Commerce, NOAA Technical Report NMFS Circular 408. 


\section{CHAPTER 2:}

\section{The effects of seasonal variations, El-Niño Southern Oscillation, and climate change on the tuna-dolphin association}

\subsection{Introduction}

The eastern tropical Pacific Ocean (ETP) is home to rich coastal habitats, diverse wildlife, and some of the most productive fisheries in the world (Figure 2.1). Large mixed-species aggregations of seabirds, tropical dolphins, and yellowfin tuna (Thunnus albacares) are a distinct characteristic of the ETP and have been exploited by the tuna fishing industry for the better part of eight decades (Au and Pitman 1986, Perrin 2009). Fishermen have used the association between dolphins and tuna to locate and catch yellowfin tuna that follow beneath because the airbreathing dolphins are easily seen at a distance by searching for splashing or foraging seabirds flying overhead (Au and Pitman 1986). In modern practices, once a school is located, the seiner and its speedboats herd the dolphins and the associated tuna into a compact group and set the net around the mixed-species herd. Built upon early observations of fishermen, research into the biology and ecology of the tuna and dolphin species has been ongoing. There are four main factors that are now known to foster this association: the oceanography of the ETP region, predisposition to form schools, risk of predation, and dawn feeding aggregations.

Skipjack and small yellowfin swim under or near floating objects (log sets) or free-swimming schools (Cayré 1991), but once yellowfin tuna grow large enough to keep pace, they are found with dolphins (Edwards 1992, Fréon and Misund 1999, Fréon and Dagorn 2000, Scott et al. 2012). Yellowfin are most frequently caught with spotted dolphins (Stenella attenuata) and/or spinner dolphins $(S$. longirostris), occasionally with common dolphins (Delphinus delphis), and rarely with other dolphin species. The distinctive oceanography of the ETP -a strong and shallow thermocline, a thick oxygen minimum zone, and warm surface waters 
- is thought to be the promoter of the association between tuna and dolphins (Perrin et al. 1973, 1976, Au and Perryman 1985, Scott et al. 2012). These aggregations are most common where the tuna habitat is compressed to the surface waters of the mixed layer by the hypoxic waters of the oxygen minimum zone (OMZ) beneath the thermocline (Prince and Goodyear 2006, Schaefer et al. 2009). The tuna-dolphin bond has been recorded in other oceans with similar oceanographic conditions, but is most prevalent and common in the ETP, where the OMZ is widespread and particularly hypoxic (Fiedler and Talley 2006, Scott et al. 2012). Yellowfin tuna typically swim near or just above the thermocline, and forage beneath the mixed layer throughout the day by bounce-diving below the OMZ in short bursts due to low levels of dissolved oxygen (Green 1967, Buckly and Miller 1994, Prince and Goodyear 2006, Schaefer et al. 2009). This habitat compression puts the tuna in closer day-time proximity to the surface swimming dolphins (Perrin et al. 1973, Au and Perryman 1985). Spotted dolphins have historically been found in association with yellowfin tuna more than other dolphin species, which is explained by differences in dolphin swimming depths. Spotted dolphins swim deeper in the water column than spinner dolphins, who are primarily found at the surface (Cramer et al. 2008, Scott et al. 2012). It is then easier for the tuna, swimming just above the thermocline, to maintain an association with the deeper-swimming spotted dolphins than the surfaceswimming spinner dolphins (Figure 2.2). As the thermocline deepens, the tuna's association with either dolphin species is no longer supported, as the tuna are swimming at a depth that is too great to maintain a bond.

It appears the association between dolphins and tuna is largely a diurnal one that begins during the dawn feeding hours, when the dolphins and yellowfin are both foraging. This association is then maintained throughout the day, fragmenting near dusk (Scott and Cattanach 1998). Previous studies have suggested the 'meeting point' hypothesis (Fréon and Misund 1999, Fréon and Dagorn 2000), which proposes that tuna have a genetic tendency to associate with floating objects, dolphins, whales, or whale sharks. Due to the habitat compression created 
by the OMZ (Prince and Goodyear 2006), encounter rates with sharks and other common predators to tuna and dolphins may increase, making these large mixedspecies aggregations more advantageous (Brock 1960, Scott and Cattanach 1998). All of these species - tunas, dolphins, and sharks - may be drawn to the same prey patches, particularly during early morning feeding bouts when the vertically migrating prey organisms in the deep scattering layer are near the surface before beginning their dawn descent. The dolphin-tuna association may then be maintained throughout the day because of the threat sharks pose as predators to both species (Scott et al. 2012). Tunas and dolphins brought together perhaps by dawn feeding aggregations, then maintain an association throughout the day due to the shallow OMZ, predation pressure, and the tunas' disposition to school. This bond then fragments as thermoclines deepen, or at dusk, when dolphins begin their night-time foraging dives and yellowfin tuna move toward the surface (Scott et al. 2012).

The distributions of many species and communities are rapidly shifting in the face of habitat and climate change (Sydeman et al. 2015, Cheung et al. 2009).

Predicting where and under which conditions changes in species compositions are likely to occur is a major challenge in ecology today. Attempts to predict the impact of global change on communities of species are usually made by developing models based on statistical relationships between species and their environment (Guisan and Zimmermann 2000, Guisan and Thuiller 2005, Ferrier and Guisan 2006, Elith and Leathwick 2009, Rodgers et al. 2019). Ecologists frequently use models to identify and describe patterns, or to predict to new or changing environments.

It has been predicted that global climate change will significantly alter the oceanography of the ETP: the tropical easterly trade winds will weaken, the surface waters will warm, and the subsurface thermocline will shoal and strengthen (Collins et al. 2010). Given that the association between tuna and dolphins is tied so tightly with the environment, one would expect that changes in 
oceanography due to seasonal variation, El Niño Southern Oscillation (ENSO) cycles, and global climate change will affect the spatial distribution of the association and the fishery. A further shoaling of the ETP thermocline and mixed layer due to long-term oceanographic changes are likely to cause an expansion of the oceanographic area that fosters the tuna-dolphin association, and an increase in the frequency of occurrence of the association between tunas and dolphins. These changes may affect the management of the tuna fishery and the bycatch of dolphins.

This study used boosted regression trees (BRT), an ensemble method for fitting statistical models, to distinguish important environmental variables that foster the tuna-dolphin association, and a historical dataset to elucidate changing patterns in the distribution of the association. Fitted BRT models identified significant environmental variables for the tuna-dolphin association in the ETP, and were used to explain seasonal, ENSO, and long-term distribution trends of where and when dolphins and tuna are associating. The results are relevant for modelling climate change effects on marine predators and for providing novel insights into community responses to global climate change. This study is also applicable for the continued monitoring of potential affects these particular species may endure as a result of future ocean conditions and an adaptive fishery.

\subsection{Data and methods}

\subsubsection{Study Area}

The study area encompasses approximately 20 million $\mathrm{km}^{2}$ of the eastern Pacific Ocean from $25^{\circ} \mathrm{N}-20^{\circ} \mathrm{S}$ latitudes and $70^{\circ} \mathrm{W}-150^{\circ} \mathrm{W}$ longitudes. The ETP's distinct biological environment stems from a combination of powerful oceanographic features. The region is characterized by the convergence and intermingling of five ocean current systems and strong trade winds, resulting in wind-driven upwelling, shallow thermoclines, and has the most hypoxic oxygen minimum layer in the world (Fiedler and Lavín 2017). The intense sun and warm water of the equator, along with the convergence of the trade winds, creates the intertropical 
convergence zone (ITCZ), and seasonal shifts in this atmospheric belt result in drastically different seasonal rainfall. In addition to seasonal fluctuations, El Niño-Southern Oscillation cycles have an interannual affect; on a timescale of two to seven years, the eastern equatorial Pacific climate varies between anomalously cold (La Niña) and warm (El Niño) conditions. These temperature fluctuations are accompanied by changes to the structure of the sub-surface ocean, a strengthening and weakening of the equatorial easterly trade winds, and a shallowing and deepening of thermoclines (Collins et al. 2010). Like all oceans, climate change is affecting the ETP's physical and biological oceanography. Thermoclines are expected to shallow, productivity to decrease, and sea temperatures to rise (Collins et al. 2010).

\subsubsection{Observer Data}

IATTC and national observer programs have monitored virtually all large tuna purse-seiners fishing in the eastern Pacific Ocean since 1992. We used IATTC and national observer data collected aboard all Class-6 tuna purse-seine vessels fishing exclusively on dolphin sets from 1992 to 2017. Only trips that exclusively set on dolphin-associated tuna were used in this study. Data collected by observers and applied in this analysis included dolphin sighting and dolphin set data, dolphin mortalities, dolphin species, tuna catches, sighting and set times and dates, dolphin school size, and latitude and longitude coordinates.

For the modeling portion of the study, the dataset was restricted to $1995-2015$ by environmental data availability. The dataset was stratified by dolphin species: pure spotted herds, pure spinner herds, and mixed-species herds of these two species. The two subspecies, the Central American spinner, and coastal spotted, were excluded because they don't often carry tuna, live along the continental shelf and not in the offshore pelagic waters, and have different ecologies than offshore spotteds and spinner dolphins. Dolphin sightings that did not result in a set were used as a proxy for the absence of the tuna-dolphin association, and dolphin sets 
indicated the presence of the association. Cells of $0.25^{\circ} \times 0.25^{\circ}$ in which at least one set occurred during a 24-hour period were assigned as a presence, and cells in which at least one sighting occurred resulting in no set within a 24-hour period were assigned as an absence (Redfern et al. 2017).

\subsubsection{Environmental covariates}

A total of 13 variables were tested for inclusion in the species distribution models (SDMs) (Table 2.1). The four spatio-temporal variables included location of sets and sightings, year, and month.

Most of the environmental data was sourced from daily/weekly/monthly fields of global data assimilative models that include the ETP region at $0.25^{\circ}(\sim 25 \mathrm{~km})$ resolution. These factors included: sea surface temperature (SST), sea temperature at 100m (SST_100m), mixed layer depth (MLD), sea surface height (SSH), chlorophyll $a(\mathrm{Chl})$, current direction (Dir), current speed (Vel), and salinity (SAL). The statistical software R (v. 3.5.1; R Core Team, 2019) was used to match the time and location values of the observer data with values for these variables. This process creates a matrix of corresponding values, which were then used in statistical analyses of habitat and distribution.

\subsubsection{Model selection and species distribution models}

Generalized additive models (GAMs) (Hastie and Tibshirani 1990) were developed in R using the $m g c v$ package (v. 1.8-17; Wood, 2011). These models are extensions of generalized linear models (GLMs) in which the linear predictor depends on smooth functions of predictor variables (Wood 2017). Presenceabsence models were built for both dolphin species' tuna association using the binomial method (logit link). To be certain models were not overfit, variables were removed that had $p$-values $>0.05$, and models were then refit (Redfern et al. 2017, Roberts et al. 2016, Becker et al. 2017). 
In addition to GAMs, Boosted Regression Trees (BRT) were fit to the same set of environmental covariates and IATTC observer data. All BRT algorithms were fit in R, using the dismo package (v. 1.1-4; Hijmans et al. 2017). Boosted Regression Trees are a flexible classification algorithm based on machine learning principles (De'ath 2007, Elith et al. 2008), which avoids some of the caveats of some commonly used techniques (e.g., generalized linear or generalized additive models). While GLMs and GAMs attempt to fit a single best model to a set of data, BRTs combine predictions of many simple models (i.e., many simple classification trees) to maximize robustness, predictive performance, and decrease associated errors (Scales et al. 2017). The advantages of BRTs include being tolerant to missing values, outliers, collinearity, and non-independence, which can be common in ecological data sets (Leathwick et al. 2006). As such, the BRTs performed better than their corresponding GAMs for our tuna-dolphin presenceabsence data set, and BRTs were used to build all models in this study.

The BRT-fitting protocols used in this study were based upon those detailed in Elith et al. 2008 and the dismo package. The presence-absence models were built using the bernoulli (binomial) distribution, with a tree complexity (tc) of 4 for spinner-tuna models, a tree complexity of 5 for spotted-tuna models, and a bag fraction of 0.7 for both dolphin-tuna models. Tree complexity determines the number of nodes in each tree and determines whether interactions between covariates are fitted. With larger data sets, models usually perform better with higher $t c$ values, likely because more data provides more comprehensive information about the full extent of sites in which the species is found, and the complexity in that information can be better modelled using more complex trees (Elith et al. 2008). Because the spotted-tuna models were built on a larger number of observations, it was determined that a higher $t c$ value performed better during the fitting process. Bag fraction denotes the fraction the data that is randomly used for model building at each tree, which usually ranges between 0.6-0.75 (Elith et al. 2008). The learning rate ( $l r$, also known as the shrinkage rate) for the final models was decided by conducting sensitivity analyses for each model, with the 
objective of at least 1,000 trees in final model configurations and lowest residual deviance. The final learning rate used in the models was a $l r$ of 0.05 for the spinner-tuna models, and 0.15 for the spotted-tuna models.

Two sets of models were independently generated for each dolphin species and their association with yellowfin: Model 1 (environmental + spatial-temporal) and Model 2 (environmental only). Model 1 was a predictive model created for the purpose of spatially predicting where the association may occur and Model 2 was an explanatory model created to understand which environmental covariates have the most influence on the tuna-dolphin association.

The percentage of deviance explained, the relative influence of variables, and the interactions between variables were estimated for all the models using several functions: a deviance explained function ( $\mathrm{dev}=(($ null - res $) /$ null $) * 100)$, and the functions summary and gbm.interactions. Final tuna-dolphin models were run 10 times to investigate consistency and to estimate standard deviations. These functions and procedures are described in further detail by Elith et al. (2008), Soykan et al. (2014), Elith and Leathwick (2017), Scales et al. (2017), and Hazen et al. (2018).

A k-fold cross-validation method was used to evaluate the reliability and the predictive performance of final models. This method involves using independent data sets for model building and model validation, where data is partitioned into $\mathrm{k}$ equal-sized fragments through random resampling. Model performance was evaluated by successively removing each subset, re-building the model on the remaining data, and predicting on the omitted data (Elith and Leathwick 2009). In this study, a $\mathrm{k}=4$ partitioning method was used, meaning that $75 \%$ of the observations were used for model building, and the other $25 \%$ for model validation in a procedure that was repeated 10 times. This technique avoids the overlap between training data and test data, yielding a more accurate estimate of model performance (Villarino et al. 2015). 
The predictive quality of the models was assessed using several diagnostic measures. The mean Area Under the receiver-operating Curve (AUC) (Hanley and McNeil 1982) and the mean True Skill Statistic (TSS) (Allouche et al. 2006) were calculated for each repetition. The AUC provides a measure of overall model accuracy that is threshold independent, and ranges in value from 0 to 1 . A model whose predictions are $100 \%$ wrong has an AUC of 0.0 ; one whose predictions are 100\% correct has an AUC of 1.0. (Fielding and Bell 1997). AUC has been broadly used in SDMs and assesses the model's ability to correctly predict where a species is present or absent (Elith et al. 2006). An AUC value of $>0.75$ is considered acceptable for informing conservation efforts (Pearce and Ferrier 2000). TSS is an alternative assessment of model accuracy that is threshold dependent and therefore not affected by the number of observations in the data set (Allouche et al. 2006). TSS is on a scale from -1 to +1 similar to the kappa statistic, with 0 representing no predictive skill and 1 as perfect predictive skill. TSS is calculated as: sensitivity plus specificity minus 1 (i.e., TSS = sensitivity + specificity -1 ) from values generated in the confusion matrix. Threshold independent and dependent statistic measures, such as AUC and TSS, should be used jointly when assessing the predictive quality of a SDM (Pearson et al. 2006).

In addition to cross validation, spatial-temporal + environmental models predicted for a year (2015) left out of the final models. A series of time-matched environmental data rasters equivalent to those used in the final models were used to generate monthly predictions for both the spinner-tuna and spotted-tuna association habitat suitability. Predictions were generated based on final models and their best number of trees using the function predict in the package raster (Hijmans et al. 2015). Monthly predictions were then combined to indicate seasonal means of the tuna-dolphin association habitat suitability, and a yearly suitability map. Actual occurrence data for 2015 was overlaid during corresponding time periods to visualize the model's predictive performance. 


\subsubsection{GIS}

Kernel density distribution maps were made using ArcGIS software (ArcMap 10.1, ESRI 2011) of average seasonal and ENSO and 4-year averages of dolphintuna distributions throughout the study period of 1992-2015. ENSO states were evaluated by the NOAA ONI index, with values $>=1.0$ considered El Niño states, and values $<=-1.0$ considered La Niña states. Distribution maps of monthly dolphin sets that occurred under each of these ENSO states were made and averaged. Dolphin sets that occurred during the seasonal quarters (Dec - Feb; Mar - May; Jun - Aug; Sept - Oct) were averaged over the 24-year period and made into seasonal distribution maps. Multi-year averages of the distribution starting in 1992 were also made to visualize the long-term changes spatially over time. The area of these distributions was calculated using a count of the number of cells $(25 \mathrm{~km} \times 25 \mathrm{~km}$ resolution) for each kernel density distribution, to track the spatial changes seasonally, over ENSO events, by multi-year averages.

Additionally, maps were made to visualize the yearly, seasonal, and ENSO average mixed layer depths in relation to spinner and spotted dolphin sets data. The Simple Ocean Data Assimilation, or SODA, database was used for mixed layer depth data. Raster layers were averaged accordingly and bilinearly interpolated in GIS. IATTC observer data for dolphin sets and sightings was then overlaid on the averaged mixed layer depths during corresponding time periods. 


\subsection{Results}

\subsubsection{Seasonal variability}

The distribution of the associations of both dolphins with yellowfin tuna shifted seasonally.

Spinner-tuna association -In the northern hemisphere, the distribution in the northern winter (Dec-Feb; Figure 2.3a) is largely east of $120^{\circ} \mathrm{W}$ longitude. In the northern spring (Mar-May; Figure 2.3b) and summer (Jun-Aug; Figure 2.3c), the distribution expands to the west and northwest before contracting in the northern fall (Sep-Nov; Figure 2.3d).

In the southern hemisphere, the seasonal pattern is even more dramatic. The distribution in the southern winter (Jun-Aug; Figure 2.3c) is restricted to patches along the Equator east of $100^{\circ} \mathrm{W}$ longitude. It expands south in other seasons and by the southern summer the distribution extends as far south as Peru (15S, Figure 2.3a).

Spotted-tuna association - In the northern hemisphere, the distribution in the northern winter (Dec-Feb; Figure $2.4 \mathrm{a}$ ) is largely east of $130^{\circ} \mathrm{W}$. In the northern spring (Mar-May; Figure 2.4b) and summer (Jun-Aug; Figure 2.4c), the distribution expands to the west to $150^{\circ} \mathrm{W}$ and northwest out $25^{\circ} \mathrm{N}$, before contracting in the northern fall (Sep-Nov; Figure 2.4d).

In the southern hemisphere, the seasonal pattern is largely the expansion and contraction of the distribution southeast of the equator along the coast of Peru. In the southern hemisphere winter (Jun-Aug; Figure 2.4c) and spring (Sep-Nov; Figure 2.4d), the association tracks the equator, and doesn't occur below $10^{\circ} \mathrm{S}$. In the southern summer (Dec-Feb; Figure 2.4a) and fall (Mar-May; Figure 2.4b) the distribution expands southeast along the coast of Peru, as far as $20^{\circ} \mathrm{N}$. 


\subsubsection{El Niño-Southern oscillation variability}

The distribution of the association of both dolphin species shifted as a result of El Niño and La Niña events.

Spinner-tuna association -During El Niño events, the distribution extends further westward $\left(130^{\circ} \mathrm{W}\right)$ and further south $\left(15^{\circ} \mathrm{S}\right)$, than during La Niña events, when the distribution is largely restricted east of $120^{\circ} \mathrm{W}$ and north of $5^{\circ} \mathrm{S}$ (Figure 2.5). The coastal area of Mexico, between $105^{\circ} \mathrm{W}$ and $95^{\circ} \mathrm{W}$, is notably absent of the association during El Niño phases, as well as coastal Guatemala and El Salvador. Despite this overall spatial expansion of the perimeter of the distribution during El Niño states, the average total area covered by the distribution is much greater during La Niña events, with a higher average density as well (Figures $2.5 \& 2.6$ ). Spotted-tuna association -The westward extent of the distribution remained essentially the same for both phases, restricted east of $145^{\circ} \mathrm{W}$ (Figure 2.7). The largest distribution changes between El Niño and La Niña events occurred north and south; El Niño events caused the distribution to expand northwest and southeast, while La Niña events caused a contraction in these areas. The average area during El Niño events was significantly greater for the spotted-tuna distribution than during La Niña events (Figures 2.7 \& 2.8).

\subsubsection{Long-term distribution shifts}

The association of tuna with both dolphin species showed long-term expansions westward following the expansion of shallow thermocline areas in the ETP (Figures 2.9-2.14).

Spinner-tuna association - Long-term distribution shifts were observed over the study period of $1992-2015$ for the spinner-tuna association (Figure $2.9 \& 2.10$ ). Over time, the association between spinner dolphins and yellowfin tuna expanded westward further off the coast of the Americas from roughly $125^{\circ} \mathrm{W}$ in $1992-$ 1994 , out to $140^{\circ} \mathrm{W}$ during $2012-2015$. . The prevalence of the association also expanded southward, particularly between the latitudes $10^{\circ} \mathrm{N}$ and $10^{\circ} \mathrm{S}$; and 
northwest throughout the Baja region. The main area of the distribution - the belt from $130^{\circ} \mathrm{W}$ to $85^{\circ} \mathrm{W}$, between the latitudes $20^{\circ} \mathrm{N}$ and $10^{\circ} \mathrm{N}-$ increased dramatically in density over the 24-year period (Figure 2.9).

Spotted-tuna association - Similar long-term distribution shifts were seen for the spotted-tuna association. The distribution expanded westward, from $135^{\circ} \mathrm{W}$ to $145^{\circ} \mathrm{W}$ throughout the study period, and also expanded northwest and increased in prevalence southward (Figure $2.12 \& 2.13$ ). A northwest lobe of the association along the west coast of Baja, while the southeast lobe observed at the start of the study period melted northwest to become a belt parallel to the equator. The distribution expanded overtime in both area covered by the association and density in occurrences.

\subsubsection{Model performance}

Models were evaluated using the mean AUC (Hanley and McNeil 1982) and the mean TSS (Alluche et al. 2006). The AUC provides a threshold independent measure of overall model accuracy, and AUC values of $>0.75$ are considered predictively good and acceptable for use (Pearce and Ferrier 2000). TSS is an alternate assessment of model accuracy that is threshold dependent (i.e., not affected by the number of observations in the validation set), that is useful for predictive presence-absence models (Alluche et al. 2006). In contrast to the commonly used metric, the kappa statistic, TSS can be inferred as evidence for real ecological significance rather than statistical side effects (Alluche et al. 2006). TSS operates on a scale of -1 to +1 , with zero representing no predictive skill. Like the kappa statistic, scores of 0.2-0.4 are considered "fair," 0.41-0.6 are considered "moderate," 0.61-0.8 are considered "good," and scores $>0.81$ are "very good" (Cohen 1960, McHugh 2012). Deviance explained, the last diagnostic metric used, is equivalent to the $\mathrm{R}^{2}$ value in linear models and measures the proportion of data the model accounts for (Guisan \& Zimmermann 2000). 
Models that included environmental and spatio-temporal variables performed better overall under the diagnostic metrics used than models with only environmental variables (Table 2.2). The spatial-temporal + environmental spotted-tuna model explained $30.7 \%$ of the deviance in the data, had a TSS value of 0.49, and an AUC value of 0.82. The environmental spotted-tuna model explained $28.5 \%$ of the deviance in the data, had a TSS value of 0.45 , and an AUC value of 0.80 . Spinner-tuna models performed better overall, for both environmental, and spatial-temporal + environmental. The spatial-temporal + environmental spinner-tuna model explained $48.4 \%$ of the deviance in the data, had a TSS score of 0.67 , and an AUC value of 0.91. The environmental model was able to explain $44.8 \%$ of the deviance, had a TSS of 0.62 , and an AUC of 0.89 .

\subsubsection{Drivers of the tuna-dolphin association}

Of the 9 environmental covariates used in the boosted regression tree models, all were considered significant, with varying levels of relative influence (Figures $2.15 \& 2.16$, Table 2.3). Environmental explanatory models built for both dolphin species' association with yellowfin tuna showed similar results in terms of relative influence of the environmental covariates. Relative influence of environmental covariates in the spinner-tuna environmental model showed chlorophyll (15.87\%) and mixed layer depth (12.56\%) as the most significant, while the ONI scale (4.55\%) was the least (Figure 2.15, Table 2.3). Similar trends were seen in the spotted-tuna environmental model: chlorophyll (16.43\%) and mixed layer depth (13.41\%), ranked as the two highest contributors, down to ONI (4.07\%) as the lowest contributor (Figure 2.15, Table 2.3).

For the spinner-tuna association, the model (M2.env) identified a range of environmental values in which habitat was considered most suitable. Probability of the spinner-tuna association occurring increased with moderate values of CHL (0-2mg/L), and with mixed-layer depth values of 10-45m (Figure 2.16). The spinner-tuna association was also found to be positively correlated with SST_100 
values between $12-20^{\circ} \mathrm{C}$, moderate SST values between $22-26^{\circ} \mathrm{C}$, salinity levels between 32-35 PSU, and high SSH values (0 - > 0.6m) (Figure 2.16). The effect of the remaining environmental predictors on the spinner-tuna association included in model M2.env are detailed in the partial dependence plots of Figure 2.16. In comparison with partial dependence plots produced for the spotted-tuna model (M1.env), the spinner-tuna model (M2.env) showed a more specific range of suitable environmental values.

For the spotted-tuna association, a much wider range of environmental values were found to promote the association and produce suitable habitat. Probability of the spotted-tuna association occurring increased with moderate to high CHL values $(0-4 \mathrm{mg} / \mathrm{L})$, and with mixed-layer depth values between $10-60 \mathrm{~m}$ (Figure 2.17). The spotted-tuna association was also found to be positively correlated with moderate to high SST values between $20-32^{\circ} \mathrm{C}$, salinity levels between $28-35$ PSU, and higher SSH values (0 - 0.6m) (Figure 2.17). The effect of the remaining environmental predictors on the spotted-tuna association included in model M1.env are detailed in the partial dependence plots of Figure 2.17.

The equivalent GAM models, though not used in this study, produced similar qualitative results in terms of the relative influence of the environmental factors, for both the spinner and spotted models.

Interactions between environmental covariates were tested, and ranked for the 4 strongest pairwise interactions for each environmental model (Tables $2.4-2.7$ ). Interactions between predictors will only be allowed to occur in a BRT model if the data supports it and if the tree has multiple nodes. To quantify interactions, a function (gbm.interactions) is used to create a grid of variables representing combinations of values at fixed intervals along each of the possible pairs of predictor's ranges. For this grid of values, predictions are formed on the linear predictor scale, and a linear model is used to relate these predictions to the two marginal predictions, fitting the latter as a factor. Relative strength of the 
interaction fitted by the BRT is called interaction size and is measured as the residual variance in this linear model.

The identified most important interactions were visualized in joint partial dependence plots (Figures 2.18 - 2.21). In the spinner-tuna environmental model, $\mathrm{M} 2 . e n v$, the strongest environmental interaction occurred between $\mathrm{SSH}$ and SST_100 (Figure 2.18) and indicated environments with median to SSH values, and low to median SST_100 temperature as suitable for the spinner-tuna association. The second strongest environmental interaction identified by the spinner-tuna environmental model was between SAL and SST, and indicated probability of the spinner-tuna occurrence increased in areas of high salinities and high temperatures (Figure 2.19). Interactions between environmental covariates for the spinner-tuna environmental model were overall less pronounced than for the equivalent spotted dolphin model.

In the spotted-tuna environmental model, M1.env, the strongest environmental interaction occurred between MLD and SST (Figure 2.20) and indicated environments with higher SST values, and low to median MLD values, as highly suitable for the spotted-tuna association. The second strongest environmental interaction identified by the spotted-tuna environmental model was between SSH and SAL, and indicated in areas of median SSHs and high salinities, probability of the spotted-tuna association increased (Figure 2.21).

\subsubsection{Predictions}

Models M1 and M2 (spatio-temporal + environmental) were used to predict habitat suitability for the tuna-dolphin association in the ETP region for 2015 seasonally and for the full year using the predict function in the $\mathrm{R}$ package raster (v:3.0-7, Hijmans et al. 2015). Seasonal maps of habitat suitability showed seasonal changes in potential distribution of the tuna-dolphin association, and yearly habitat suitability maps were consistent with known tuna-dolphin association distribution (Figures $2.22-2.29$ ). 


\subsection{Discussion}

IATTC observer data from the eastern Pacific tuna purse-seine fisheries, ocean reanalysis environmental data, and boosted regression tree models identified the conditions that foster the tuna-dolphin association. Our results showed seasonal patterns in the tuna-dolphin association, shifts in distribution due to ENSO events, both overlaid on a long-term expansion of the tuna-dolphin association. Models created during this study elucidated the most influential environmental factors that affect the association between tunas and dolphins, and how climate is affecting, and likely will continue to affect, the tuna-dolphin association and the fishery.

\subsubsection{Influence of environmental factors}

Previous papers examining the tuna-dolphin association had suggested that environmental conditions fostering the tuna-dolphin bond in the ETP were warm equatorial sea surface temperatures, shallow mixed layer depths, and a strong and shallow OMZ (Green 1967, Perrin et al. 1968, Au \& Perryman 1985, Edwards 1992, Norris et al. 1978). This study tested this hypothesis using ecological models, high-resolution environmental data, and an extensive fishery database on dolphin sets and sightings. These analyses found that productivity and shallow mixed layer depths were the most significant predictors of the tunadolphin bond; other influential factors included warm sea surface temperatures, low-moderate temperatures at depth, median salinity levels, and high sea surface height.

The tuna-dolphin association is highly influenced by chlorophyll levels, suggesting habitat suitability increases in productive areas. In most of the openocean ETP, low iron results in limited productivity (Pennington et al. 2006), while coastally, mixing of bottom sediments and continental run-off supplies iron and allows for high phytoplankton production along the continental coast (Fiedler and Lavín 2017). 
The spinner-tuna association is largely contained within the $10-45 \mathrm{~m}$ mixed layer depth range - in near-coastal waters and the north equatorial thermocline ridge (Figures 2.11 and 2.16). Within this area, the association is concentrated in areas of moderate productivity and where the sea surface temperature ranges between $22-26^{\circ} \mathrm{C}$ (Figure 2.16). It is particularly prevalent where the southern end of the California Current transitions into the North Equatorial current. The association, particularly between spinner dolphins and tuna, occurs within a narrow sea surface temperature range. It is less prevalent where sea surface temperatures are too warm (the inner-most portion of the Eastern Pacific warm pool) or too cool (the Equatorial cold tongue).

The spotted-tuna association is found in a much wider range of environmental conditions which explains their more extensive distribution and historically important role in the tuna fishery. Species with more distinct environmental requirements are expected to be modeled better (Guisan and Zimmerman 2000), which may explain the spinner-tuna model's higher TSS and AUC measures, compared to the spotted-tuna models. The spotted-tuna association typically occurs in areas of warm sea surface temperature, moderate productivity, and mixed layer depths of 10-60m (Figures 2.14 and 2.17). Other influential environmental factors were found to be current direction and velocity, sea temperature at depth, salinity, and sea surface height. While the association between spotteds and tuna extends westward as far as $160^{\circ} \mathrm{W}$, it is more concentrated coastally in regions of upwelling and moderate productivity, particularly around the Costa Rica Dome, the southern end of the California current, and the northern end of the Peru Current.

\subsubsection{Seasonal Distribution Patterns}

Spinner-tuna association - The association between spinner dolphins and yellowfin undergoes seasonal distribution shifts (Figure 2.3). In the northern 
summer, the distribution expands to the north and west, coinciding with the expansion of the north equatorial thermocline ridge and productivity changes. In the southern summer, the distribution expands to the south. Within the shallow thermocline area, the spinner-tuna association responded to seasonal shifts in upwelling, productivity, current and temperature changes. Distribution shifts mirrored variability in size and position of highly suitable areas such as the Costa Rica Dome, the Tehuantepec bowl, and the California and Peru upwelling zones (Figure 2.3).

Spotted-tuna association - The association between spotted dolphins and yellowfin also undergoes seasonal distribution shifts (Figure 2.4). In the northern summer, the distribution expands to the north and west, coinciding with the expansion of both ETP thermocline ridges and productivity changes. In the southern summer, the distribution expands to the south. Spotteds and tuna associate south in the southern summer when waters are productive in the Peru coastal upwelling, and shift northward during the spring as productivity increases in the California current and with the appearance of the Costa Rica Dome. Our data also suggests current stock structures for the offshore spotted stock should be reconsidered. The seasonal distribution shifts suggest E-W movements across the stock boundary line at $120^{\circ} \mathrm{W}$; this is also in accord with the tagging data from Perrin et al. (1976). There are N-S seasonal shifts as well, calling into doubt the southern boundary as well. The abundance trends (Gerrodette 2008) suggested that the NE and W/S offshore stocks may be one stock and this study supports that idea.

\subsubsection{ENSO Impact on the Distribution}

Temporal variability in the ETP is dominated by ENSO cycles. Most of the effects of El Niño involve a deepening of the thermocline and nutricline resulting in diminished primary productivity, while La Niña conditions produce the opposite: a shoaling of the thermocline and a positive effect on primary productivity (Fiedler and Lavín 2017). 
Spinner-tuna association - The area covered by the association increased during La Niña events and decreased during El Niño events (Figures 2.5 and 2.6), however the distribution extended similar distances offshore. During El Niño events, the association was absent from the inner-most portion of the Eastern Pacific Warm pool and the Gulf of Papagayo, potentially due to high sea surface temperatures in the warm pool and strong winds associated with the Papagayo Jet. The absence of the association in these areas seems to be the largest contributor to the reduced distribution area during El Niño events.

Spotted-tuna association - The area covered by the distribution decreased during La Niña events and increased during El Niño events (Figures 2.7 and 2.8). The association extended similar distances offshore during each phase, however during El Niño phases a prominent northern and southern lobe occurred, extending the area of the distribution north and south. Similar to the spinner-tuna association, during El Niño's the association in the Gulf of Papagayo was scarce.

\subsubsection{Climate Change and Long-term Distribution Patterns}

For both dolphin species' association with yellowfin tuna, a long-term expansion in the area of the distribution has occurred over the 24-year period. Climate change, caused by natural changes and anthropogenic global warming, is altering the physical structure of the ETP (Fiedler and Lavín 2017). Surface temperatures have already increased by $0.4-1.0^{\circ} \mathrm{C}$ since 1990 (Deser et al. 2010), and warming is expected to continue (DiNezio et al. 2009). Winds along the equator (Vecchi and Soden 2006) and future projections show that the equatorial thermocline is expected to shoal and have steeper temperature gradients (Collins et al. 2010). Fiedler et al. (2013) have shown that surface temperatures have already warmed, the thermocline has already shoaled, and stratification of near-surface waters has already decreased, all of which have and will continue to promote the tunadolphin association. The spinner-tuna association has predominantly expanded 
along the north equatorial thermocline ridge at $10^{\circ} \mathrm{N}$, but has also increased coastally in regions of current and wind driven upwelling (Figure 2.09). The spotted-tuna association has expanded following both the north equatorial and equatorial thermocline ridges, and has expanded northward along Baja (Figure 2.12). These long-term changes in the tuna-dolphin association seem to be in direct relation to changing ocean conditions and shoaling thermoclines in the ETP (Figures 2.11 and 2.14). As the climate continues to warm, primary productivity is expected to decrease in tropical oceans such as the ETP (Fiedler and Lavin 2016), likely shifting the coastal regional hotspots of the tuna-dolphin association. Oxygen minimum zones at intermediate depths have expanded vertically during the past 50 years, causing a further restriction of vertical habitat in the ETP. As the thermocline continues to shoal, sea surface temperatures continue to warm, the $\mathrm{OMZ}$ continues to expand, and the area that fosters the association continues to expand, the tuna-dolphin association will likely continue to move further offshore.

\subsubsection{Implications for Management and Conservation}

The area that fosters the tuna-dolphin association in the ETP region has expanded. The long-term oceanographic changes occurring in the ETP have predictive value for the management of the tuna fishery and dolphin bycatch. A shift in the proportions of dolphin mortality has already been seen; the proportion of spinner dolphin mortality has increased over time, becoming the species most. These oceanographic changes have resulted notably in more-frequent sets on pure spinner dolphin herds. Climate change will likely further promote the tunadolphin association, and, in turn, influence where the tuna fishery operates, and which dolphin species are affected. The spatio-environmental models have the potential to predict new areas of suitable habitat for the tuna-dolphin association as the climate and oceanography of the region continue to shift. 


\begin{tabular}{|c|c|c|c|c|c|c|c|c|c|c|c|c|c|c|c|c|}
\hline 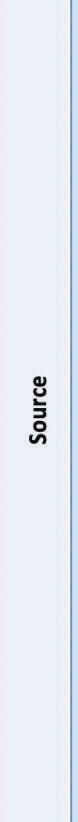 & & 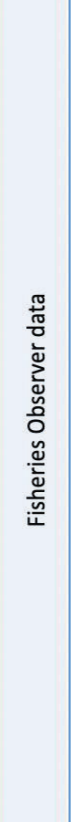 & 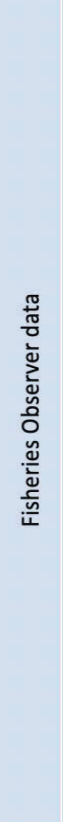 & 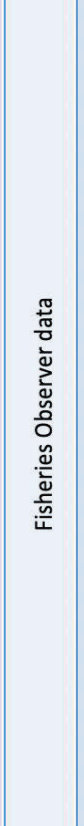 & 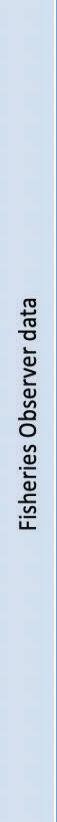 & & 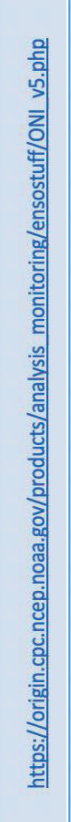 & 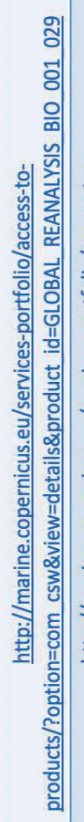 & 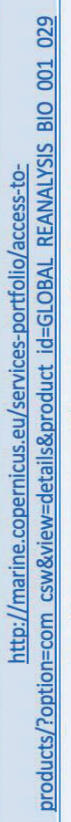 & 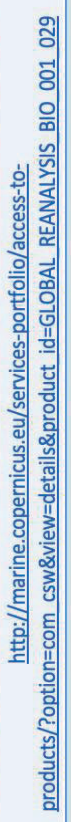 & 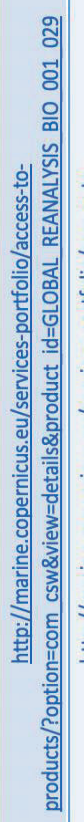 & 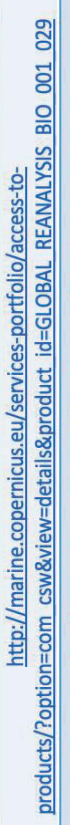 & 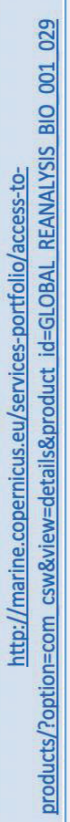 & & 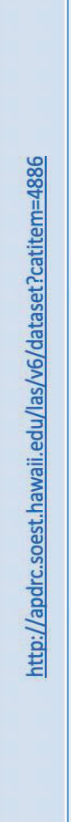 & 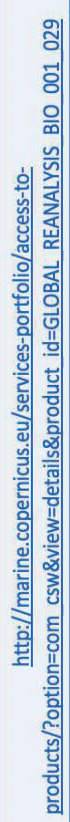 \\
\hline 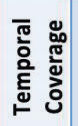 & & 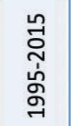 & 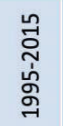 & $\begin{array}{l}\text { 号 } \\
\text { ते } \\
\text { مे } \\
\text { مे }\end{array}$ & 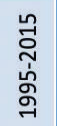 & & 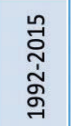 & 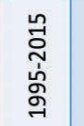 & 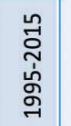 & 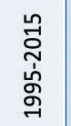 & 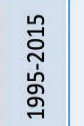 & 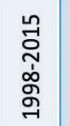 & 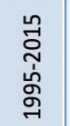 & & 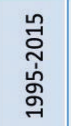 & 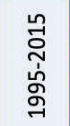 \\
\hline 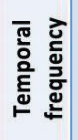 & & 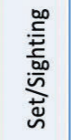 & 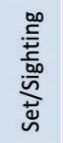 & 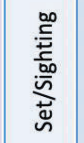 & 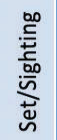 & & $\begin{array}{l}\text { 产 } \\
\text { 王 } \\
\text { 衣 }\end{array}$ & 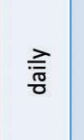 & 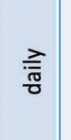 & 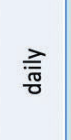 & 產 & 离 & 층 & & 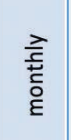 & 产 \\
\hline 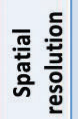 & & 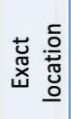 & 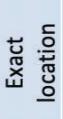 & & & & . & in & $\begin{array}{l}\stackrel{\circ}{n} \\
\text { On }\end{array}$ & in & $\stackrel{\text { in }}{\text { On }}$ & in & in & & 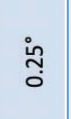 & $\begin{array}{l}\stackrel{i}{n} \\
0\end{array}$ \\
\hline 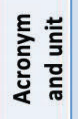 & $\overline{\mathrm{g}}$ & 焉 & $\frac{\bar{\sigma}}{\bar{\sigma}}$ & 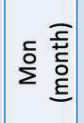 & $\begin{array}{l}\bar{\Sigma} \\
\bar{z} \\
\stackrel{\Xi}{\Xi} \\
\searrow\end{array}$ & & $\sum_{0}^{\frac{1}{ \pm}} \sigma$ & $\begin{array}{l}\frac{\overline{0}}{5} \\
\text { 号 }\end{array}$ & $\begin{array}{l}\overline{\widetilde{W}} \\
\frac{\bar{\omega}}{\bar{N}}\end{array}$ & $\begin{array}{l}\bar{E} \\
\bar{\Xi} \\
\text { 出 }\end{array}$ & 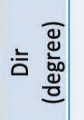 & 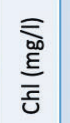 & $\frac{\overline{\bar{n}}}{\frac{\underline{\varepsilon}}{\tilde{N}}}$ & & $\begin{array}{l}\overline{\mathrm{E}} \\
\overline{\mathrm{\Sigma}}\end{array}$ & $\begin{array}{l}{ }_{-1}^{8} \\
\text { 芯 }\end{array}$ \\
\hline 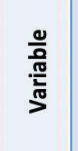 & 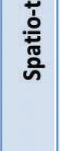 & 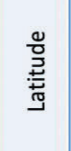 & 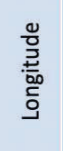 & $\begin{array}{l}\text { 亳 } \\
\stackrel{0}{\Sigma}\end{array}$ & 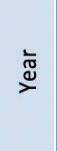 & 莺 & 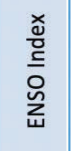 & 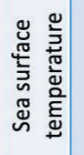 & 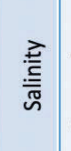 & 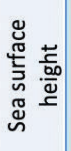 & 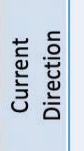 & 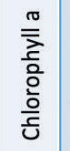 & 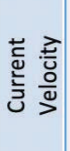 & 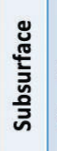 & 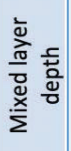 & 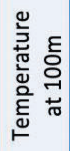 \\
\hline
\end{tabular}

Table 2.1 Acronyms, units, temporal frequency and coverage, and source, of data used in the species distribution models. 


\begin{tabular}{|c|c|c|c|c|}
\hline 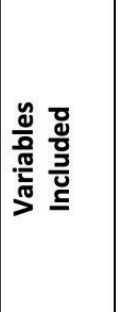 & 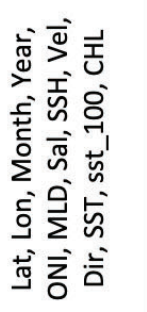 & 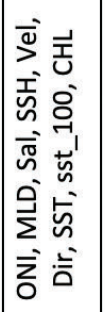 & 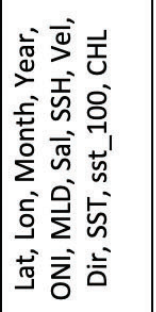 & 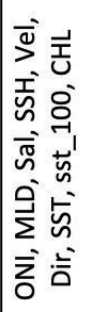 \\
\hline 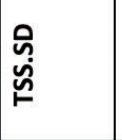 & $\begin{array}{l}\hat{\tilde{m}} \\
\tilde{N} \\
0 \\
0\end{array}$ & 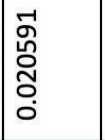 & $\mid \begin{array}{l}0 \\
0 \\
0 \\
0 \\
0 \\
0\end{array}$ & 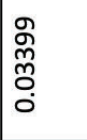 \\
\hline$\tilde{\mu}$ & $\begin{array}{l}\text { O. } \\
\text { ơ } \\
\text { ợ } \\
0\end{array}$ & $\begin{array}{l}\text { 告 } \\
\text { Oे } \\
\text { gे } \\
0\end{array}$ & | & 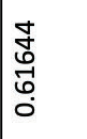 \\
\hline 乌্ & 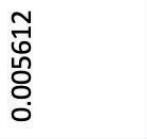 & 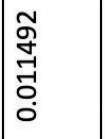 & 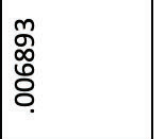 & $\begin{array}{l}\qquad \\
0 \\
0 \\
0 \\
0 \\
0 \\
0\end{array}$ \\
\hline$\overleftrightarrow{\mathrm{u}}$ & 总 & $\begin{array}{l}\hat{\tilde{O}} \\
\text { o. } \\
0 \\
0\end{array}$ & $\begin{array}{l}\hat{m} \\
\text { o. } \\
\text { o. } \\
0\end{array}$ & $\mid \begin{array}{l}n \\
0 \\
0 \\
\infty \\
0 \\
0\end{array}$ \\
\hline $\begin{array}{l}\text { ज़े } \\
\dot{u} \\
\stackrel{u}{u}\end{array}$ & 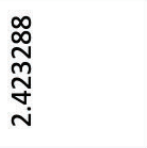 & 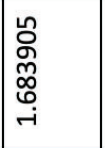 & $\mid \begin{array}{l}0 \\
0 \\
0 \\
m \\
m\end{array}$ & 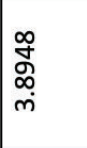 \\
\hline 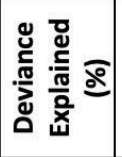 & 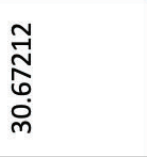 & 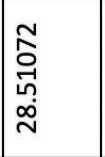 & $\mid \begin{array}{l}8 \\
0 \\
0 \\
\infty \\
\infty \\
d\end{array}$ & $\underset{\substack{\mathbb{N} \\
\dot{J}}}{j}$ \\
\hline 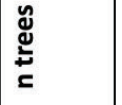 & 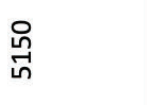 & 总 & 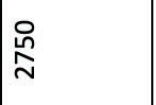 & 过 \\
\hline$\triangleq 3$ & $\stackrel{n}{?}$ & 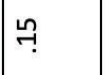 & 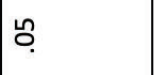 & 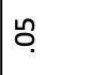 \\
\hline 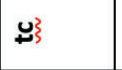 & in & in & $\sigma$ & o \\
\hline $\begin{array}{l}\overline{\mathrm{d}} \\
\\
\end{array}$ & 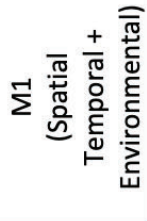 & 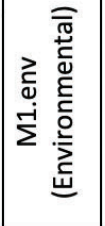 & 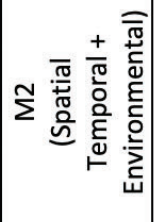 & 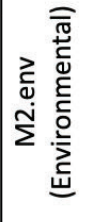 \\
\hline & 高 & 言站 & 㝘吾 & 言骂 \\
\hline
\end{tabular}

Table 2.2 Performance diagnostics of models; M1 (spotted-tuna, spatial-temporal + environmental variables), M1.env (spotted-tuna, environmental variables only); M2 (spinner-tuna, spatial-temporal + environmental variables), M2.env (spinner-tuna, environmental variables only). 


\begin{tabular}{|c|c|c|}
\hline \multicolumn{2}{|c|}{ Spinner-tuna model: M2.env } & Spotted-tuna model: M1.env \\
\hline Variable & Rel.Infl (\%) & Rel.Infl (\%) \\
\hline ChI & & 16.43 \\
\hline MLD & 15.87 & 13.41 \\
\hline SSt_100 & 12.56 & 12.79 \\
\hline Dir & 12.04 & 12.45 \\
\hline Vel & 11.6 & 11.87 \\
\hline Sal & 11.44 & 11.00 \\
\hline SSH & 10.94 & 9.88 \\
\hline SST & 10.56 & 8.09 \\
\hline ONI & 10.44 & 4.55 \\
\hline
\end{tabular}

Table 2.3 Relative influence of environmental covariates included in the species distribution boosted regression tree models for the tuna-dolphin association 


\begin{tabular}{|c|c|c|c|c|c|c|c|c|c|}
\hline \multicolumn{7}{|c|}{ Model: M2.env Interactions } \\
\hline & SST & MLD & ONI & SST_100 & CHL & SAL & SSH & DIR & VEL \\
\hline SST & 0 & 62.66 & 74.39 & 16.17 & 15.61 & 108.62 & 15.24 & 39.61 & 49.27 \\
\hline MLD & 0 & 0 & 32.4 & 58.6 & 75.55 & 75.49 & 37.17 & 14.58 & 10.79 \\
\hline ONI & 0 & 0 & 0 & 59.99 & 4.09 & 8.68 & 19 & 9.19 & 5.54 \\
\hline SST_100 & 0 & 0 & 0 & 0 & 24.88 & 56.08 & 271.52 & 29.14 & 20.74 \\
\hline CHL & 0 & 0 & 0 & 0 & 0 & 72.12 & 7.44 & 29.41 & 11.6 \\
\hline SAL & 0 & 0 & 0 & 0 & 0 & 0 & 85.08 & 54.77 & 72.87 \\
\hline SSH & 0 & 0 & 0 & 0 & 0 & 0 & 0 & 25.12 & 39.67 \\
\hline DIR & 0 & 0 & 0 & 0 & 0 & 0 & 0 & 0 & 13.35 \\
\hline VEL & 0 & 0 & 0 & 0 & 0 & 0 & 0 & 0 & 0 \\
\hline
\end{tabular}

Table 2.4 Table of all pairwise environmental interactions and their interaction size for the Boosted Regression tree spinner-tuna environmental model, M2.env.

\begin{tabular}{|c|c|c|}
\hline \multicolumn{3}{|c|}{ Model: M2.env Interactions | Ranked } \\
\hline SSH & SST_100 & 271.52 \\
\hline SAL & SST & 108.62 \\
\hline SSH & SAL & 85.08 \\
\hline CHL & MLD & 75.55 \\
\hline
\end{tabular}

Table 2.5 Table of the most important environmental interactions and interaction size in the Boosted Regression tree spinner-tuna environmental model M2.env. 


\begin{tabular}{|c|c|c|c|c|c|c|c|c|c|}
\hline \multicolumn{1}{|c|}{ Model: M1.env Interactions } \\
\hline & SST & CHL & MLD & SAL & SSH & SST_100 & DIR & VEL & ONI \\
\hline SST & 0 & 5.41 & 219.26 & 57.28 & 134.42 & 38.9 & 40.22 & 128.43 & 58.17 \\
\hline CHL & 0 & 0 & 25.77 & 16.92 & 58.72 & 28.7 & 14.55 & 43.3 & 6.63 \\
\hline MLD & 0 & 0 & 0 & 56.74 & 49.75 & 77.45 & 33.37 & 136.99 & 34.38 \\
\hline SAL & 0 & 0 & 0 & 0 & 168.65 & 117.58 & 74.94 & 39.57 & 28.27 \\
\hline SSH & 0 & 0 & 0 & 0 & 0 & 130.02 & 35.79 & 65.85 & 105.55 \\
\hline SST_100 & 0 & 0 & 0 & 0 & 0 & 0 & 49.71 & 93.93 & 33.07 \\
\hline DIR & 0 & 0 & 0 & 0 & 0 & 0 & 0 & 70.43 & 15.49 \\
\hline VEL & 0 & 0 & 0 & 0 & 0 & 0 & 0 & 0 & 17 \\
\hline ONI & 0 & 0 & 0 & 0 & 0 & 0 & 0 & 0 & 0 \\
\hline
\end{tabular}

Table 2.6 Table of all pairwise environmental interactions and their interaction size for the Boosted Regression Tree spotted-tuna environmental model, M1.env.

\begin{tabular}{|c|c|c|}
\hline \multicolumn{3}{|c|}{ Model: M1.env Interactions | Ranked } \\
\hline MLD & SST & 219.26 \\
\hline SSH & SAL & 168.65 \\
\hline VEL & MLD & 136.99 \\
\hline SSH & SST & 134.42 \\
\hline
\end{tabular}

Table 2.7 Table of the most important environmental interactions and interaction size in the Boosted Regression Tree spotted-tuna environmental model M1.env. 


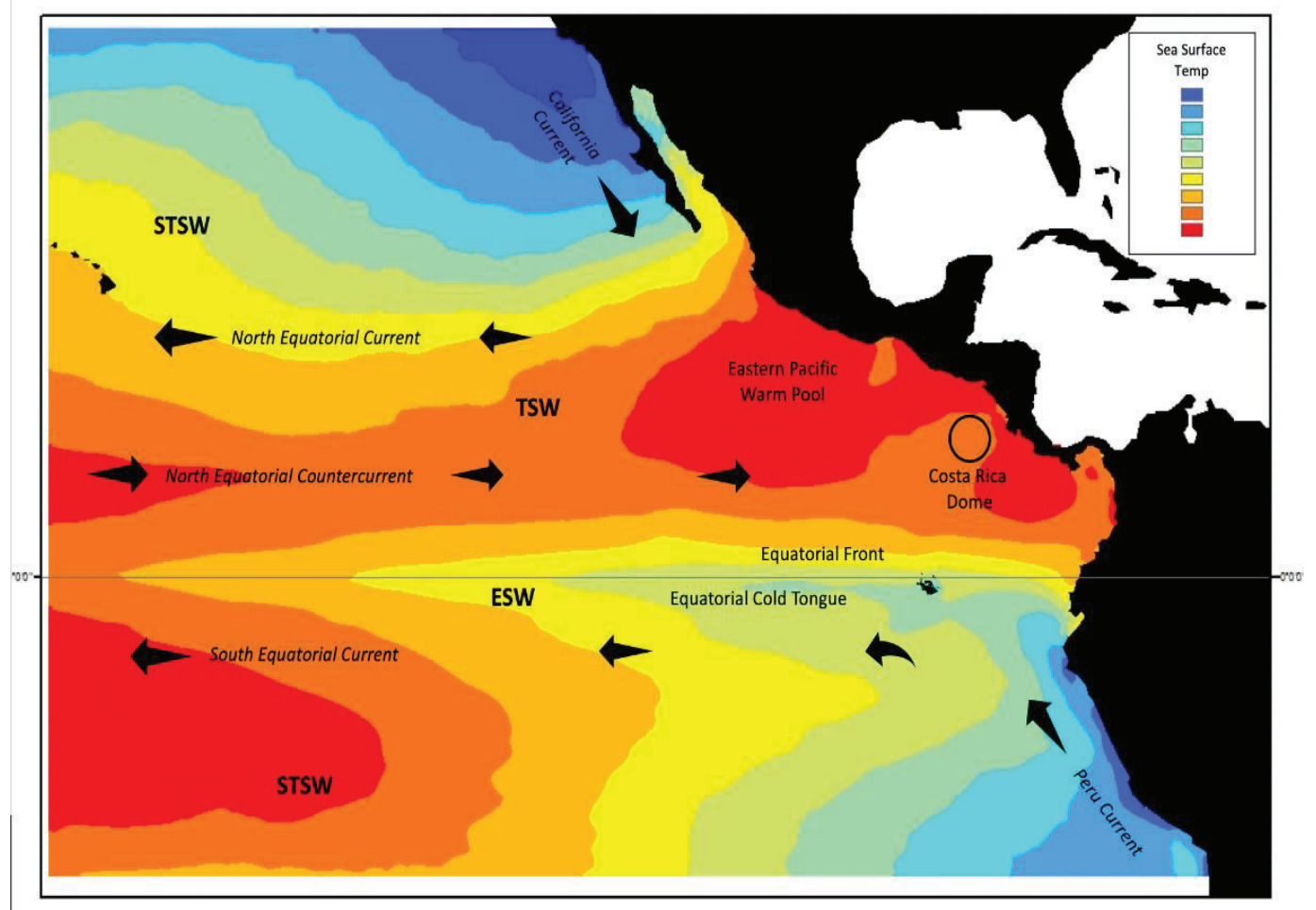

Figure 2.1 Diagram of surface water masses and currents in the eastern tropical Pacific Ocean: Subtropical Surface Water (STSW); Tropical Surface Water (TSW); Equatorial Surface Water (ESW). Cooler colors indicate colder sea surface temperature; warmer colors indicating warmer sea surface temperature (SODA, 2015). 


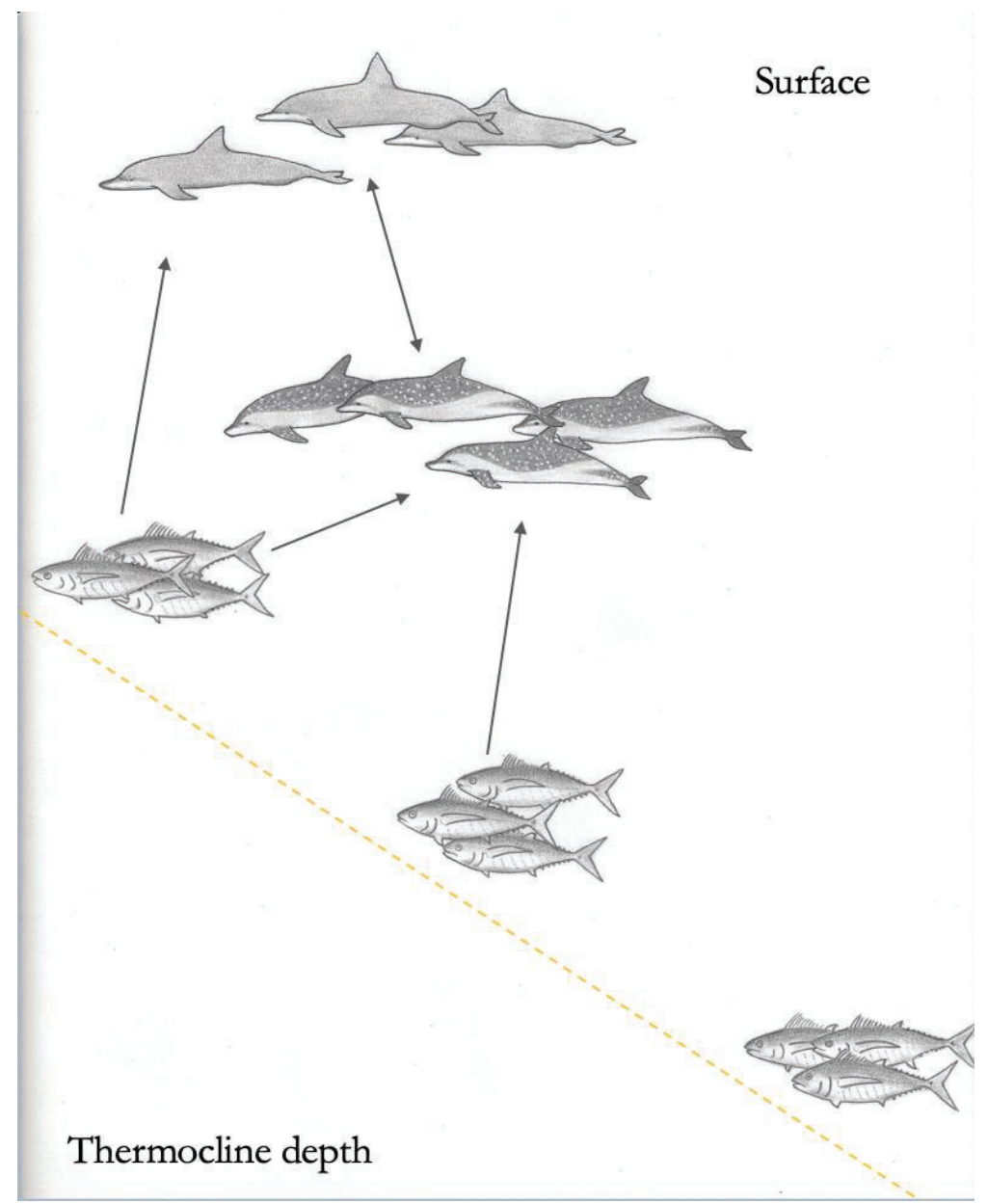

Figure 2.2 Diagram illustrating the influence of thermocline depth and dolphin swimming depth on the tuna-dolphin association; a) spinner dolphin (Stenella longirostris); b) spotted dolphin (Stenella attenuata); c) yellowfin tuna (Thunnus albacares) (Illustration by Caitlynn Birch 2018). 

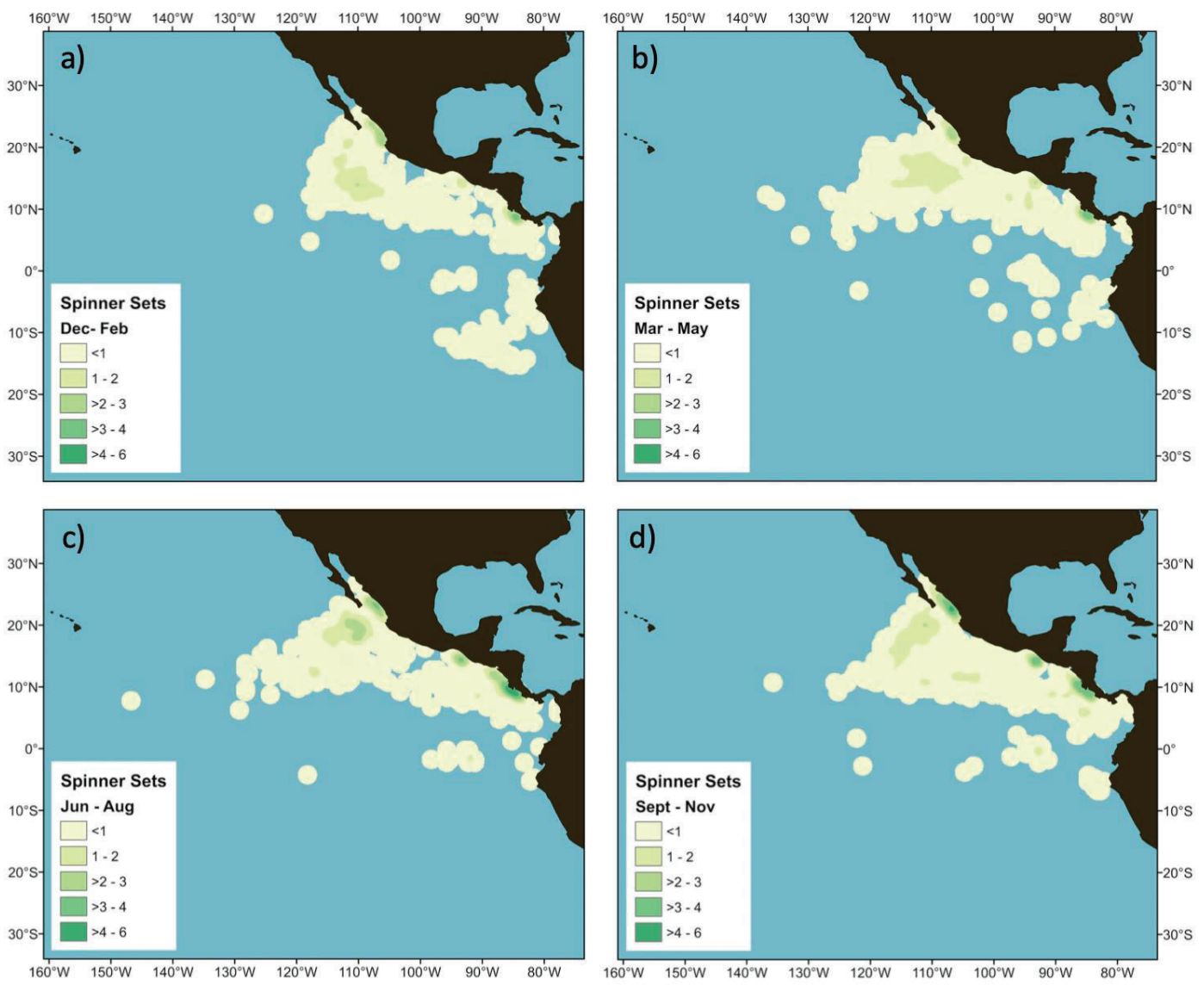

Figure 2.3 Seasonal averaged distributions of the spinner-tuna association (1992 - 2017). Quadrant a) representing Dec - Feb, b) May - Mar, c) Jun - Aug, d) Sept - Nov. 

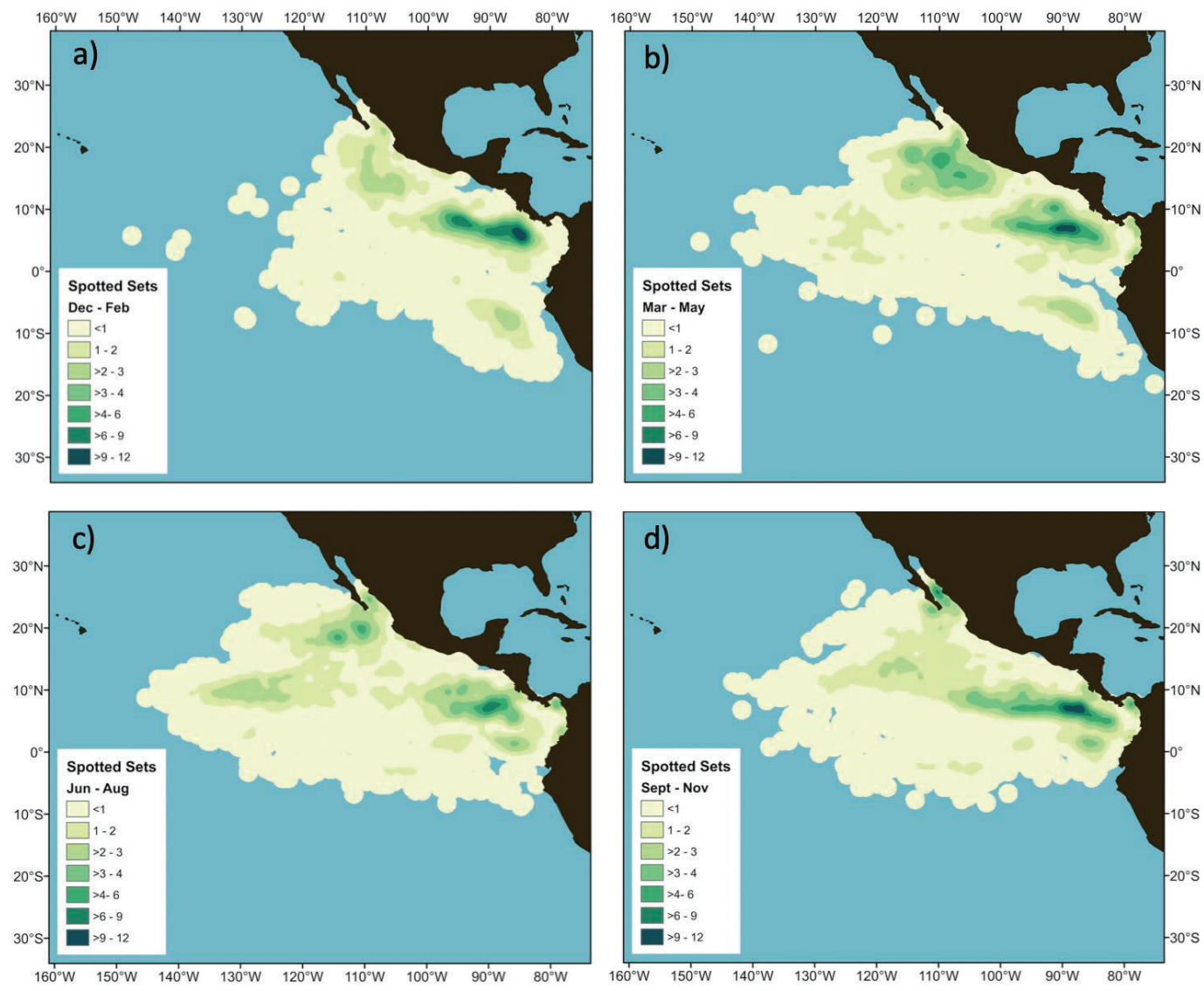

Figure 2.4 Seasonal averaged distributions of the spotted-tuna association (1992 - 2015). Quadrant a) representing Dec - Feb, b) May - Mar, c) Jun - Aug, d) Sept - Nov. 

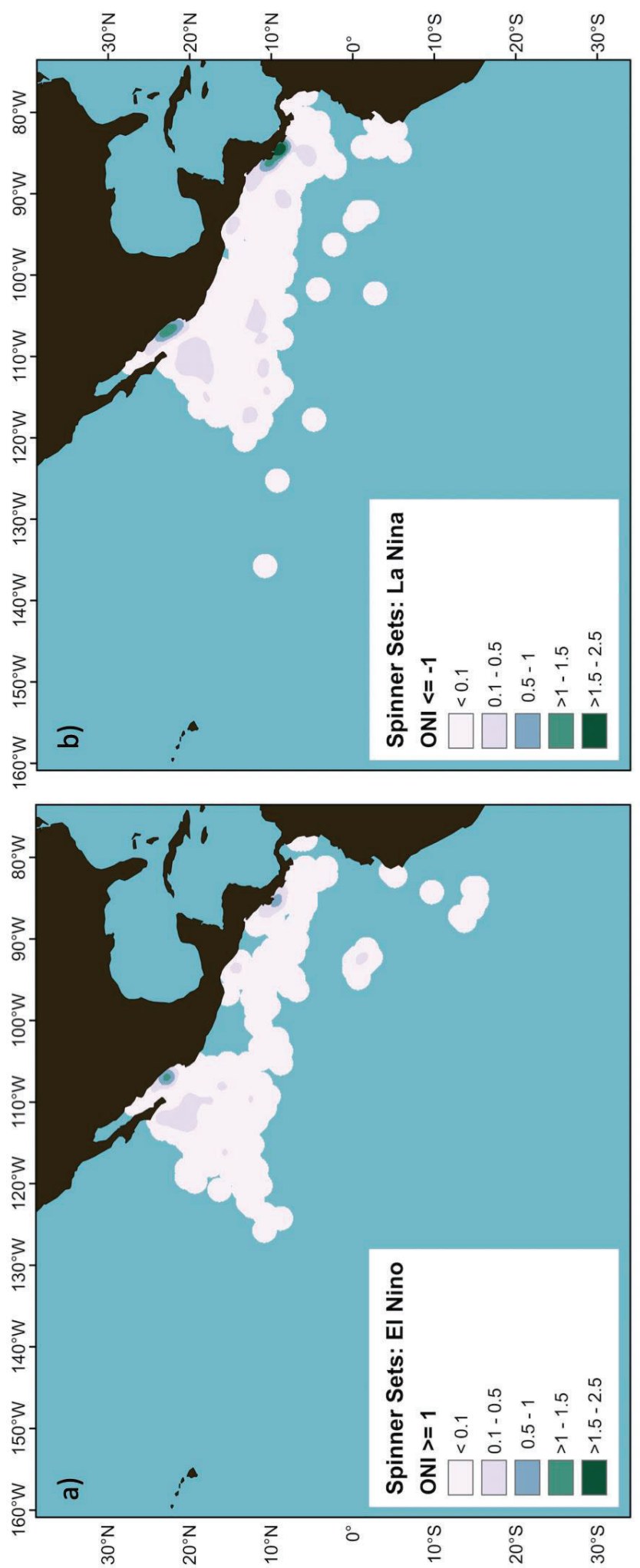

Figure 2.5 Distribution of the spinner-tuna association during a) strong El Niño $(\mathrm{ONI}>=1)$ and (b) strong La Niña $(\mathrm{ONI}<=-1)$ events. 


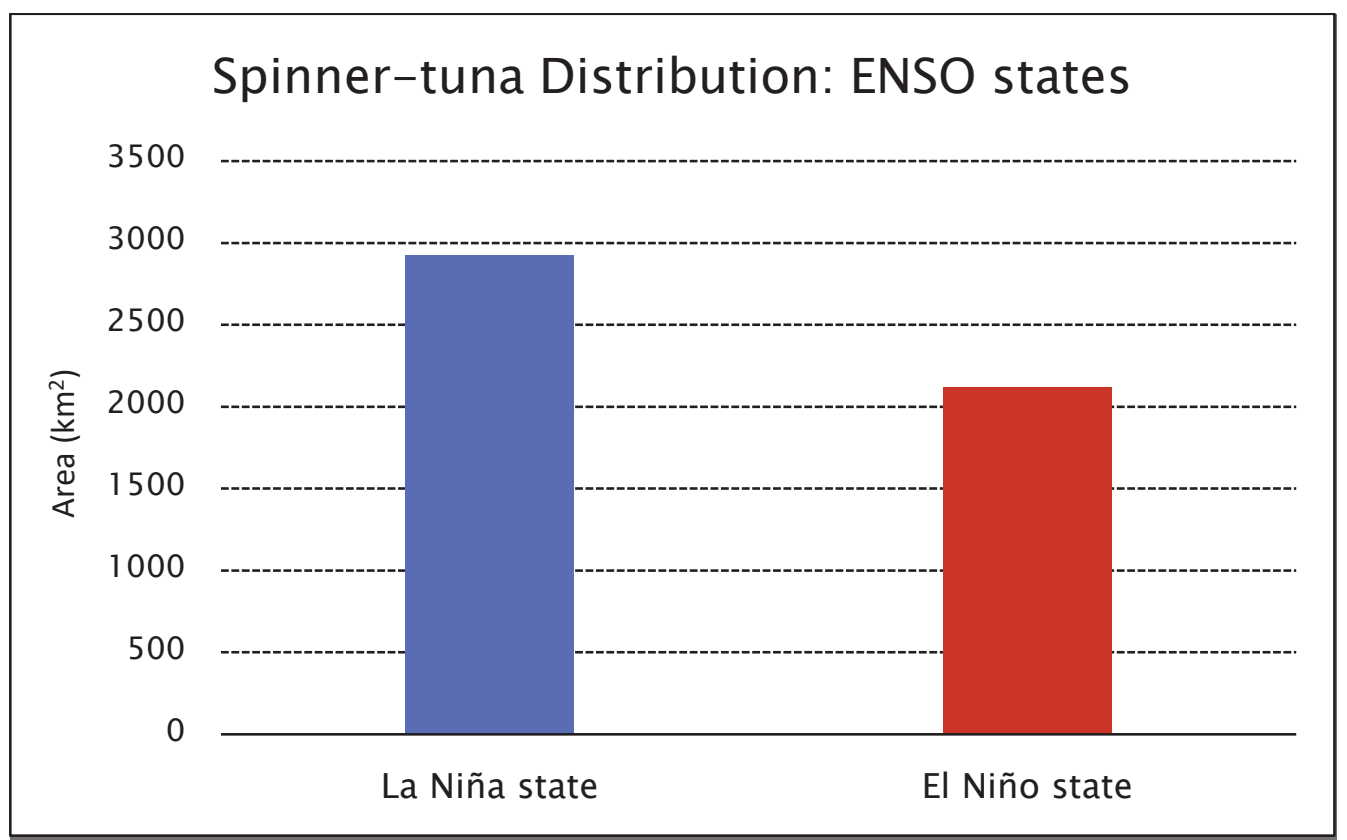

Figure 2.6 Area $\left(\mathrm{km}^{2}\right)$ covered by the spinner-tuna distribution during an average strong El Niño (ONI $>=1)$ and strong La Niña (ONI $<=-1)$ month 19922015. 

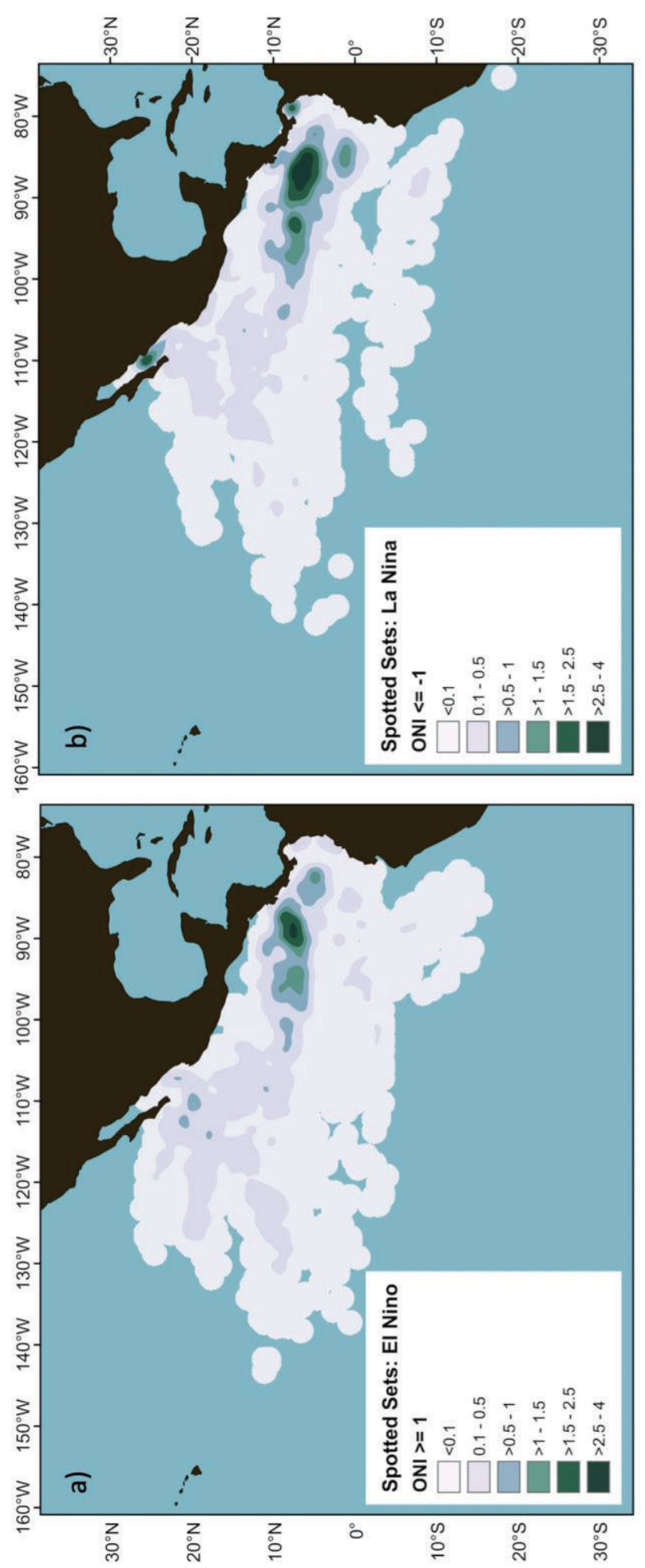

Figure 2.7 Distribution of the spotted-tuna association during an average strong $(\mathrm{ONI}>=1$; ONI $<=-1)$ El Niño (a) and La Niña (b) month. 


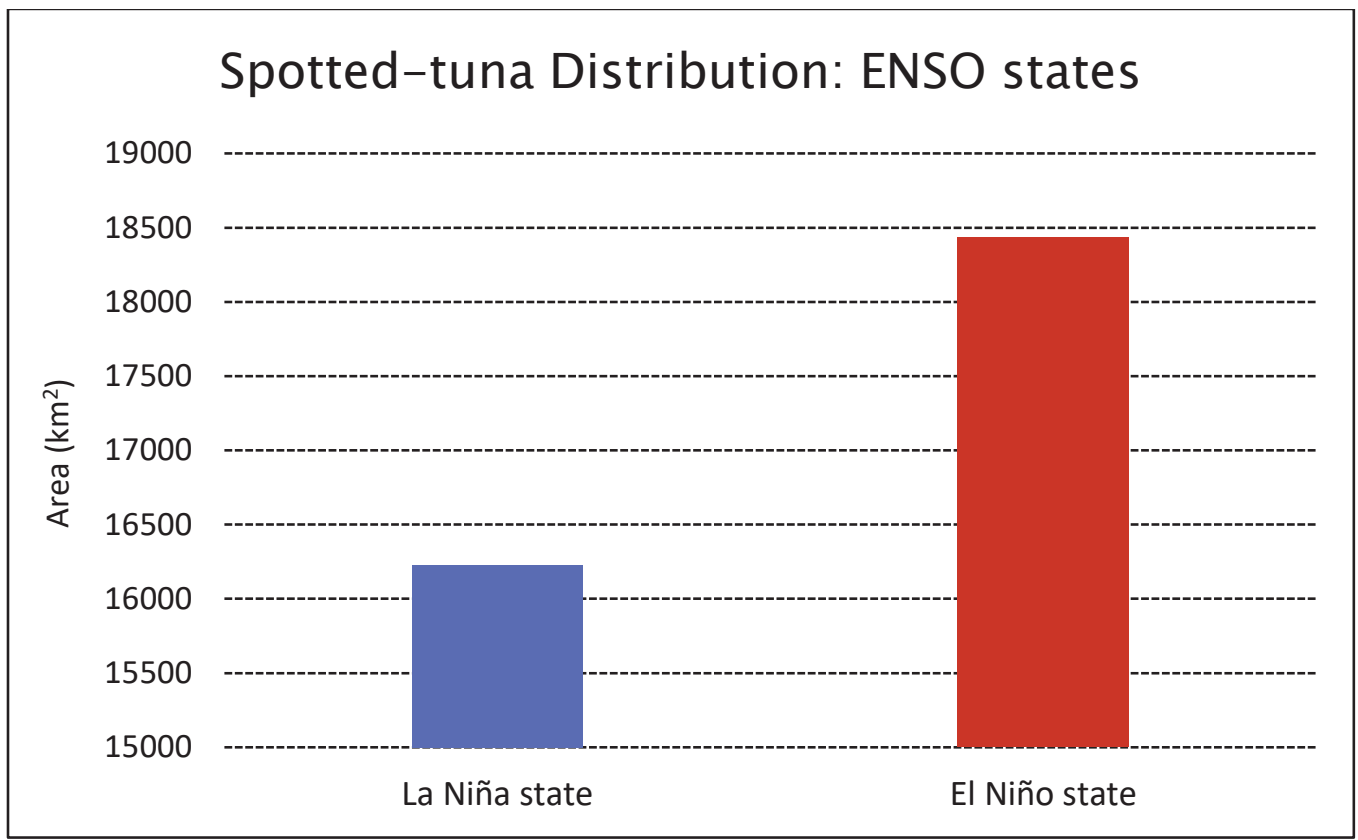

Figure 2.8 Area $\left(\mathrm{km}^{2}\right)$ covered by the spotted-tuna distribution during an average strong El Niño (ONI >=1) and strong La Niña (ONI <= -1) month, 19922015. 

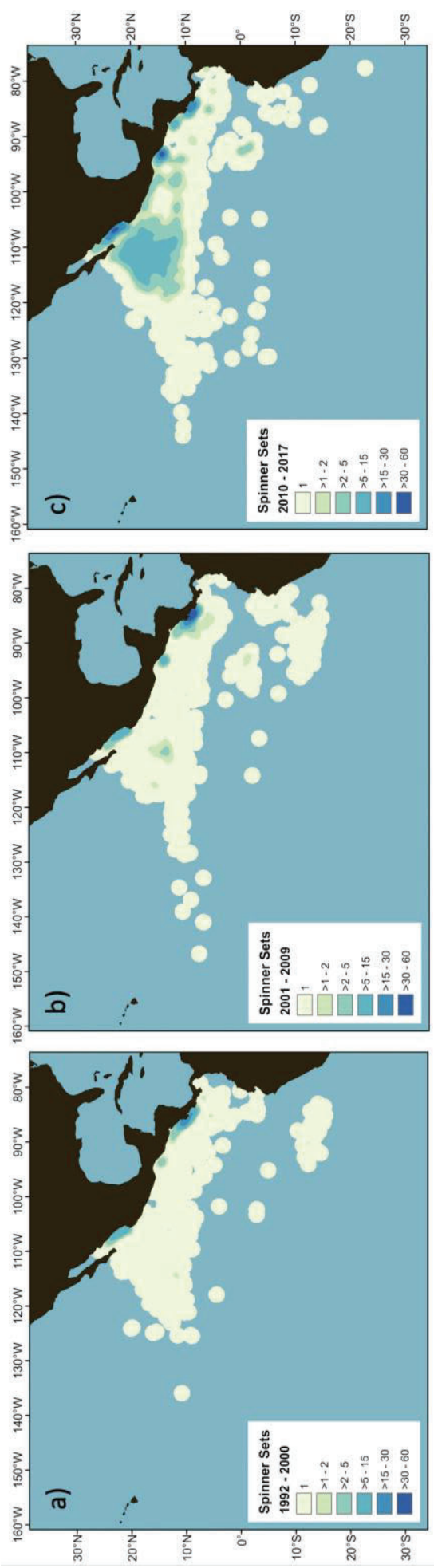

Figure 2.9 Multi-year averages of the spinner-tuna distribution: a) 1992-2000, b) 2001-2009, c) 2010-2017. 


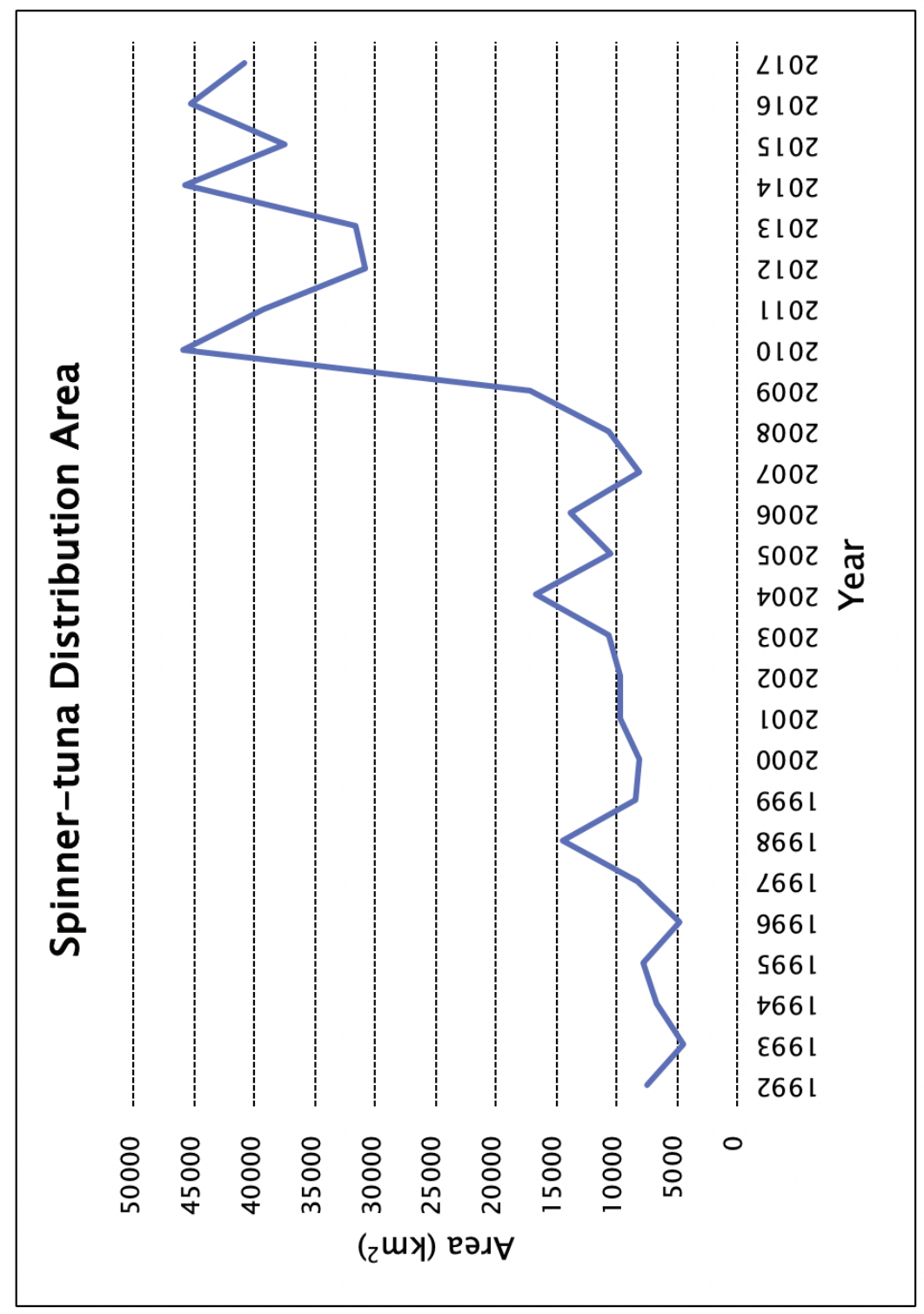

Figure 2.10 Area of distribution $\left(\mathrm{km}^{2}\right)$ covered by the spinner-tuna association averaged by year 1992-2017. 

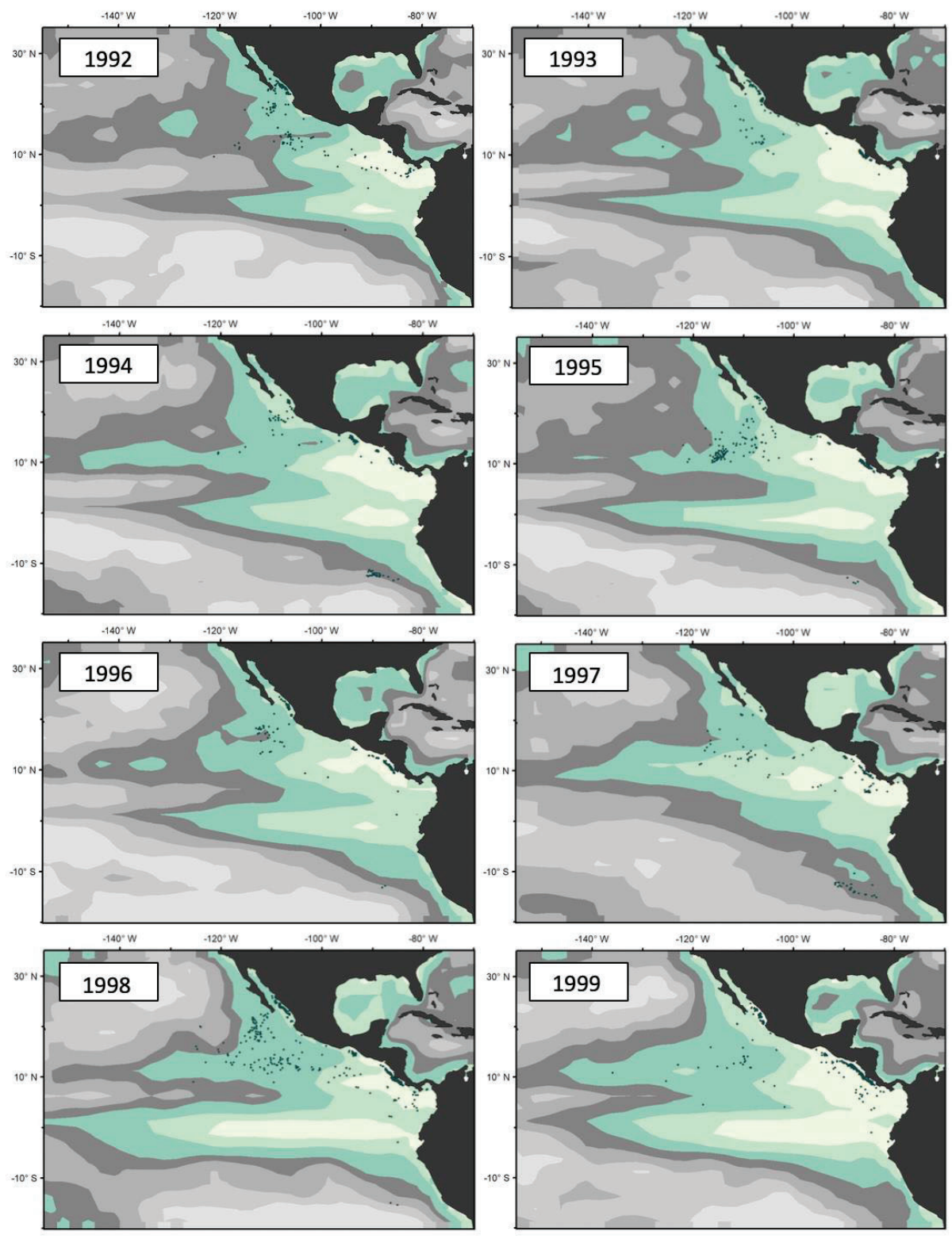

S Spinner Sets
Mixed Layer Depth

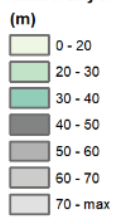

Figure 2.11 

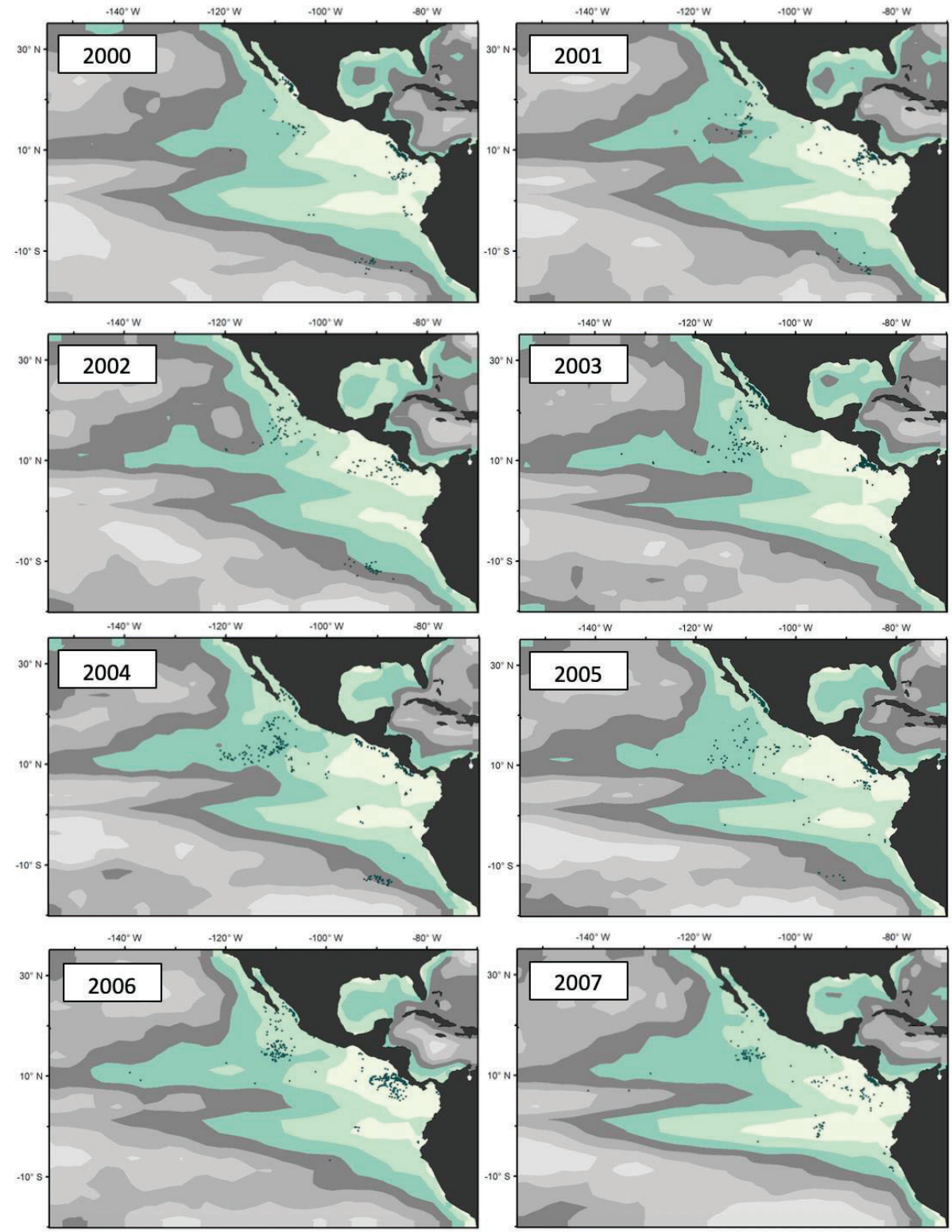

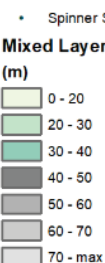

Figure 2.11 

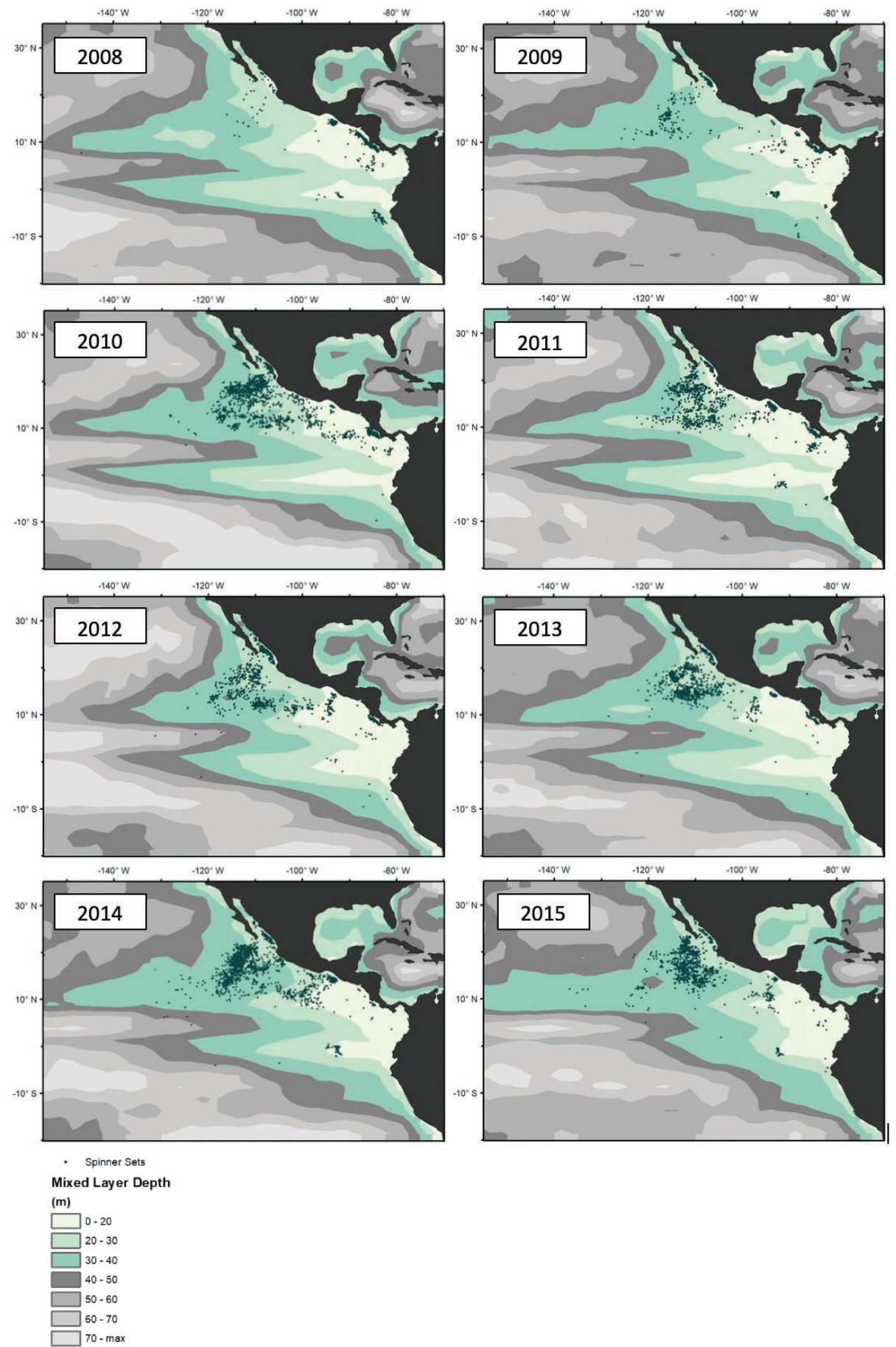

Figure 2.11 Spinner-tuna occurrences 1992 - 2015 overlaid on average annual mixed layer depth. 

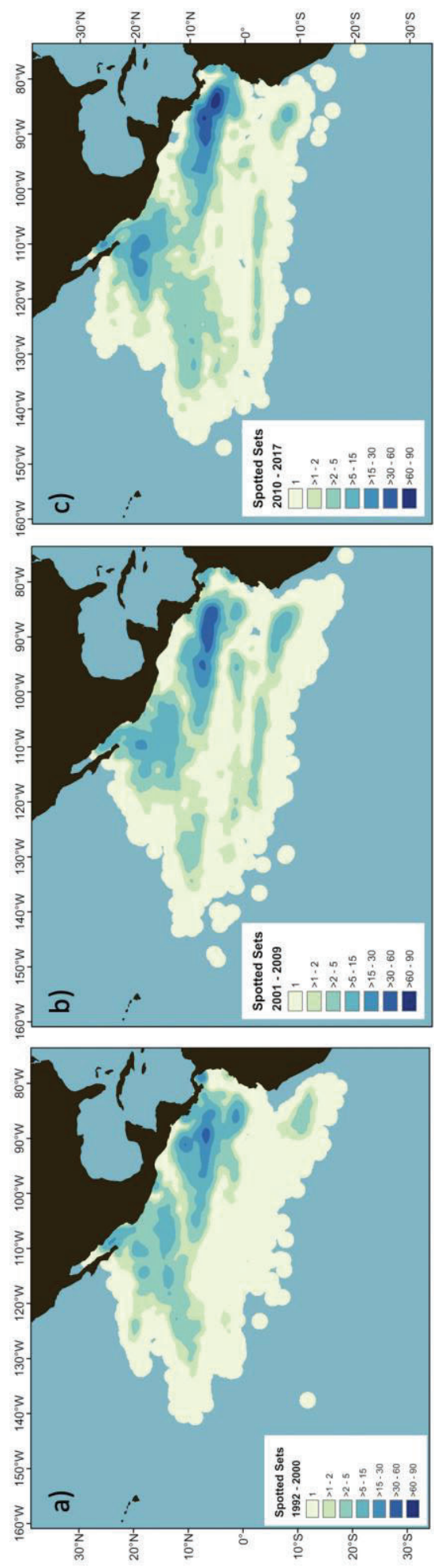

Figure 2.12 Multi-year averages of the spotted-tuna distribution 1992 - 2017; a) $1992-2000$, b) $2001-2009$, c) $2010-2017$. 


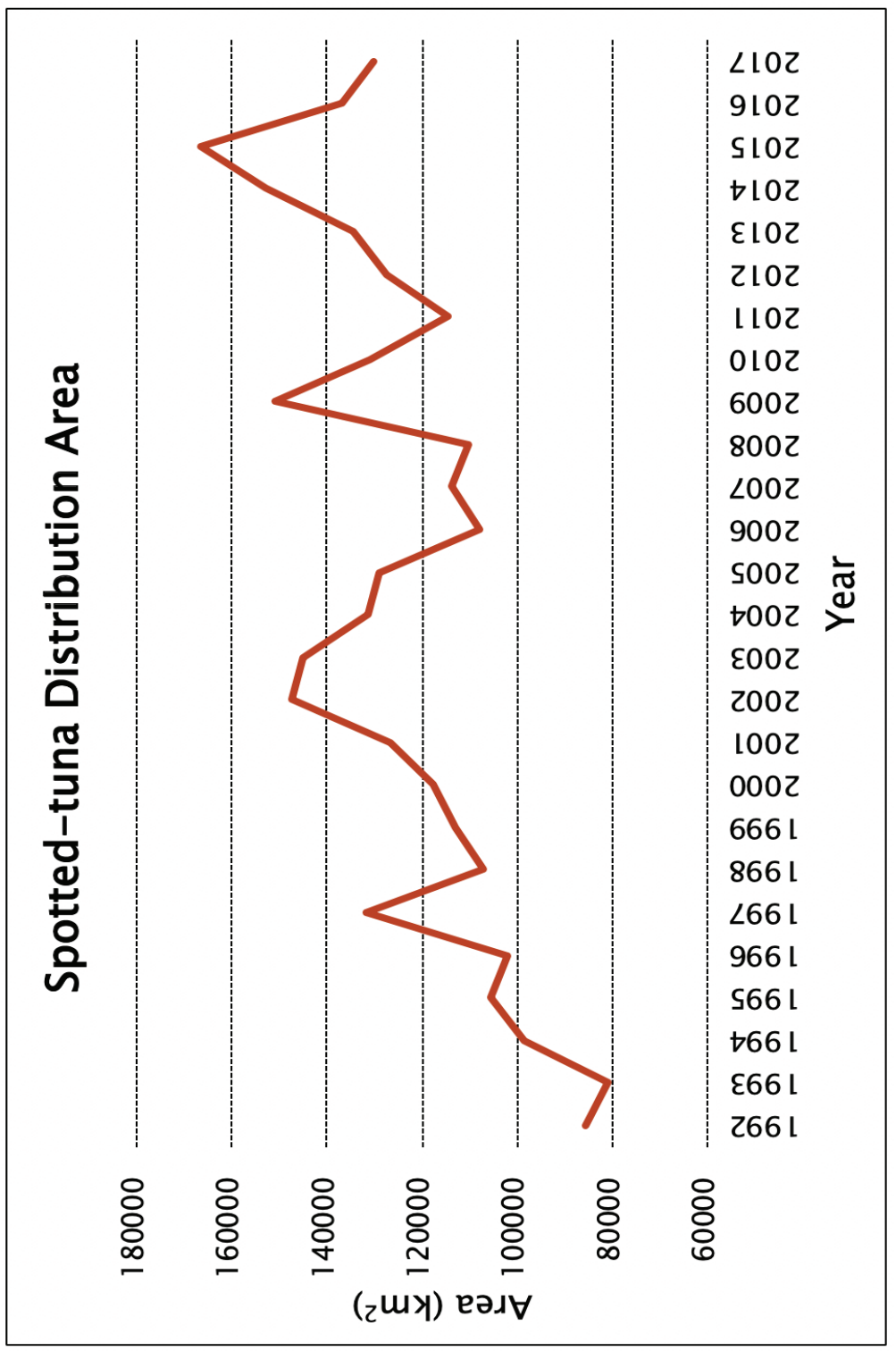

Figure 2.13 Area of distribution $\left(\mathrm{km}^{2}\right)$ covered by the spotted-tuna averaged by year, 1992-2017. 

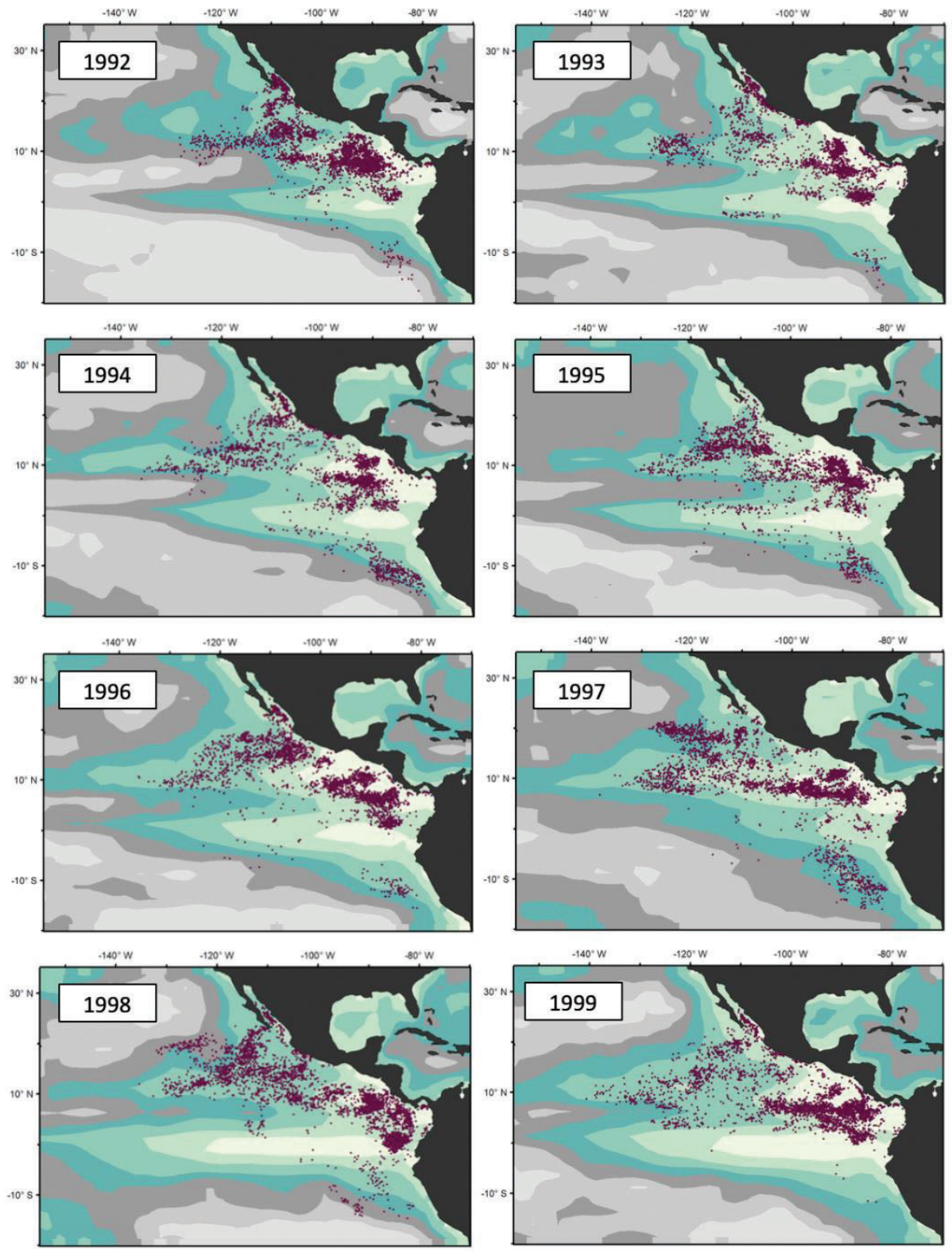

- Spotted Sets
Mixed Layer Depth

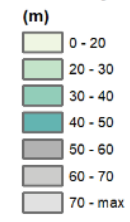

Figure 2.14 

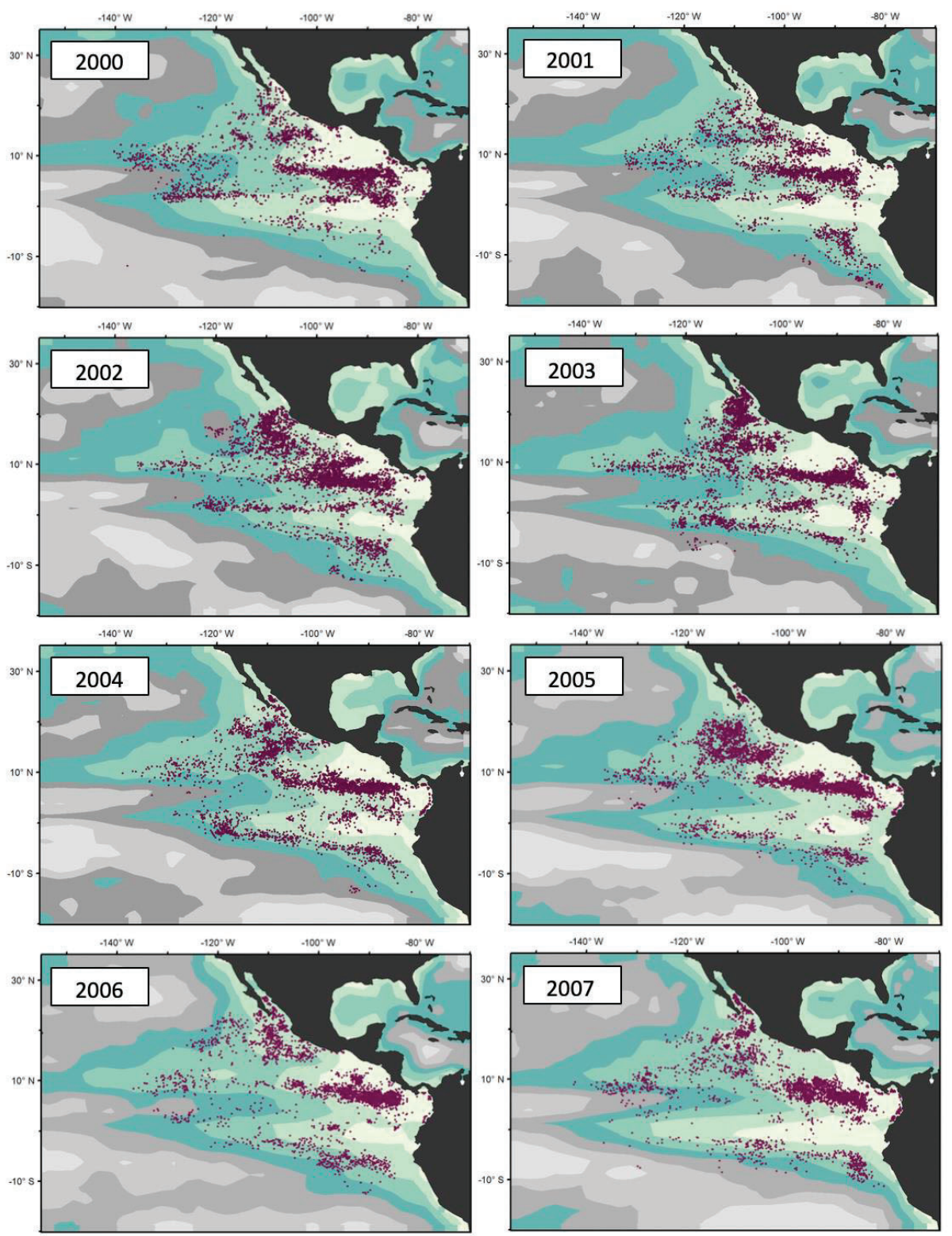

- Spotted Sets

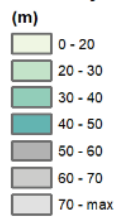

Figure 2.14 

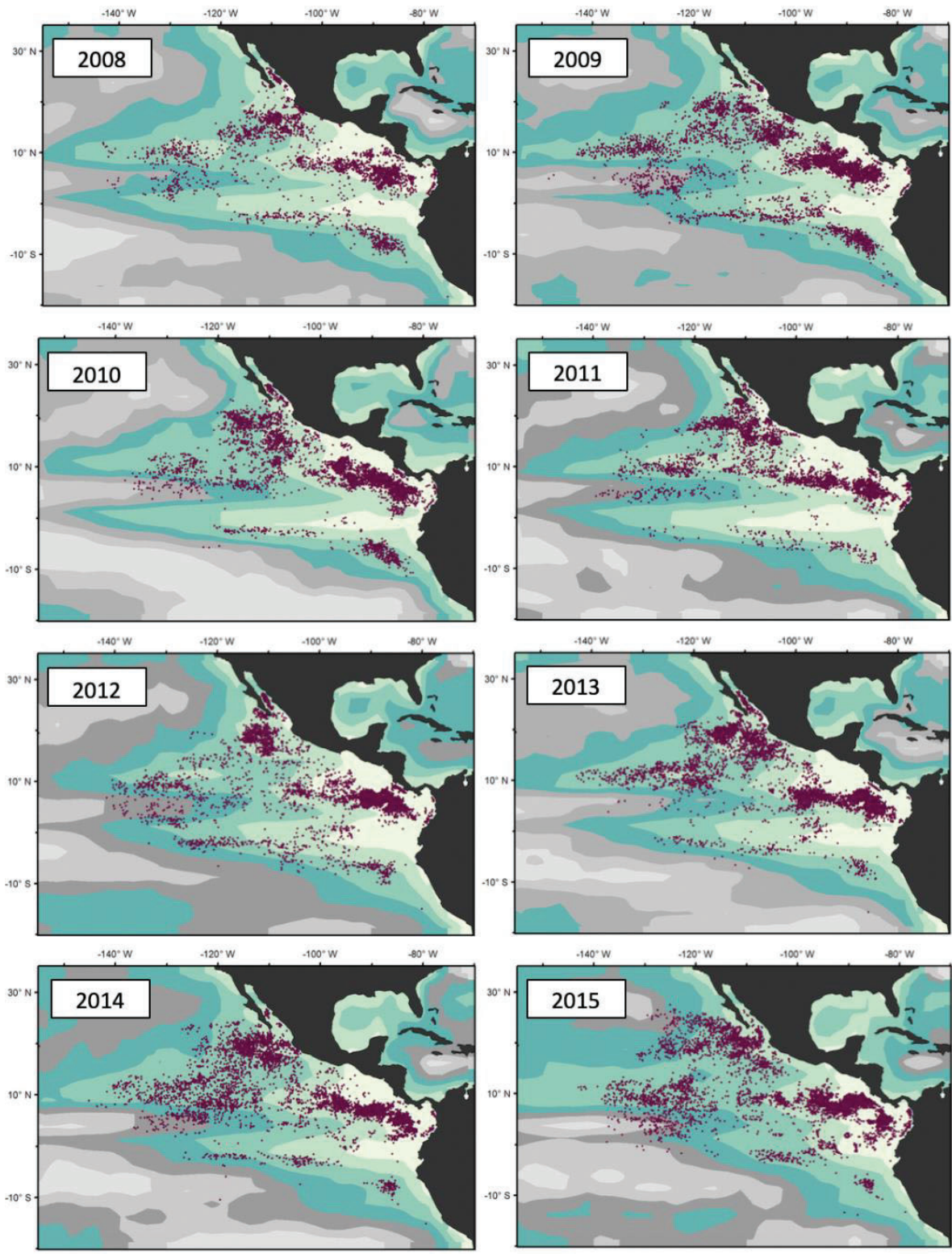

- Spotted Sets

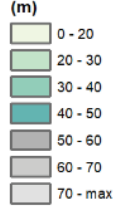

Figure 2.14 Spotted-tuna occurrences 1992 - 2015 overlaid on average annual mixed layer depth. 


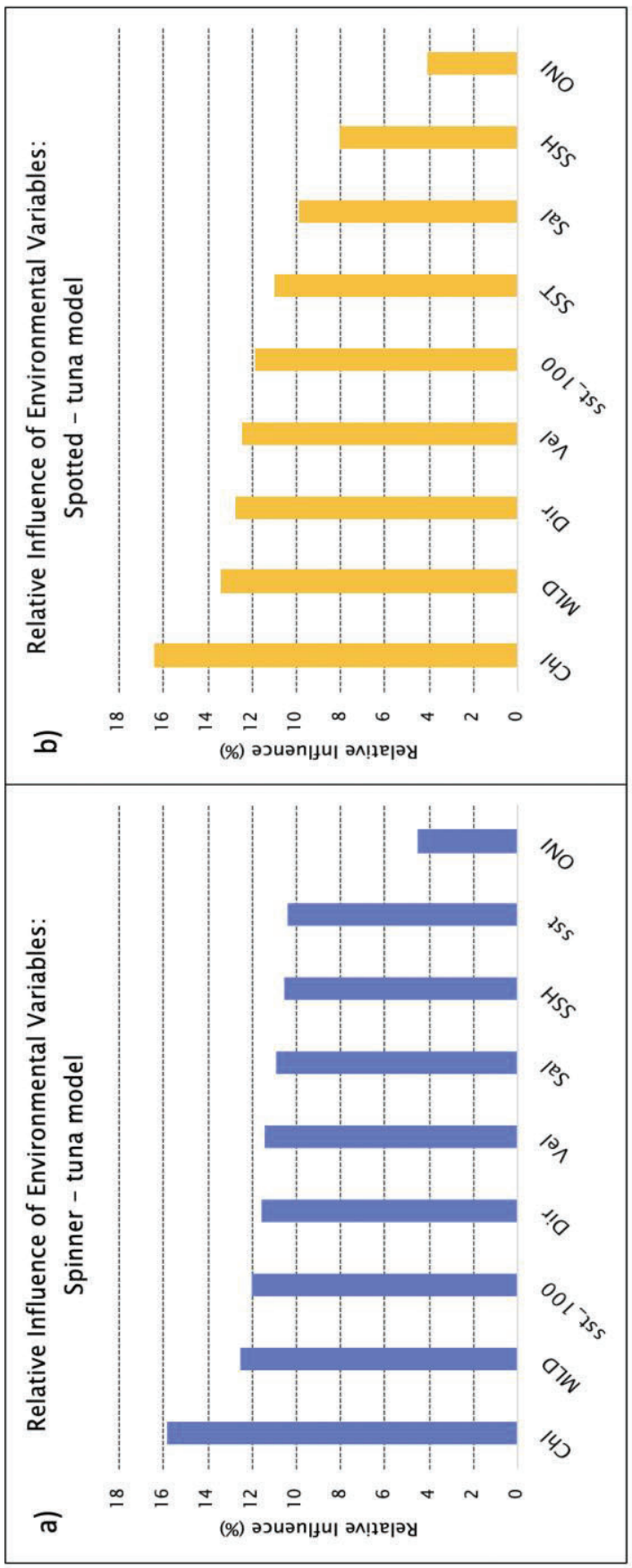

Figure 2.15 Relative influence of environmental variables included in the species distribution Boosted Regression Tree models: a) relative influence of variables on the spinner-tuna association; b) relative influence of variables on the spotted-tuna association. 

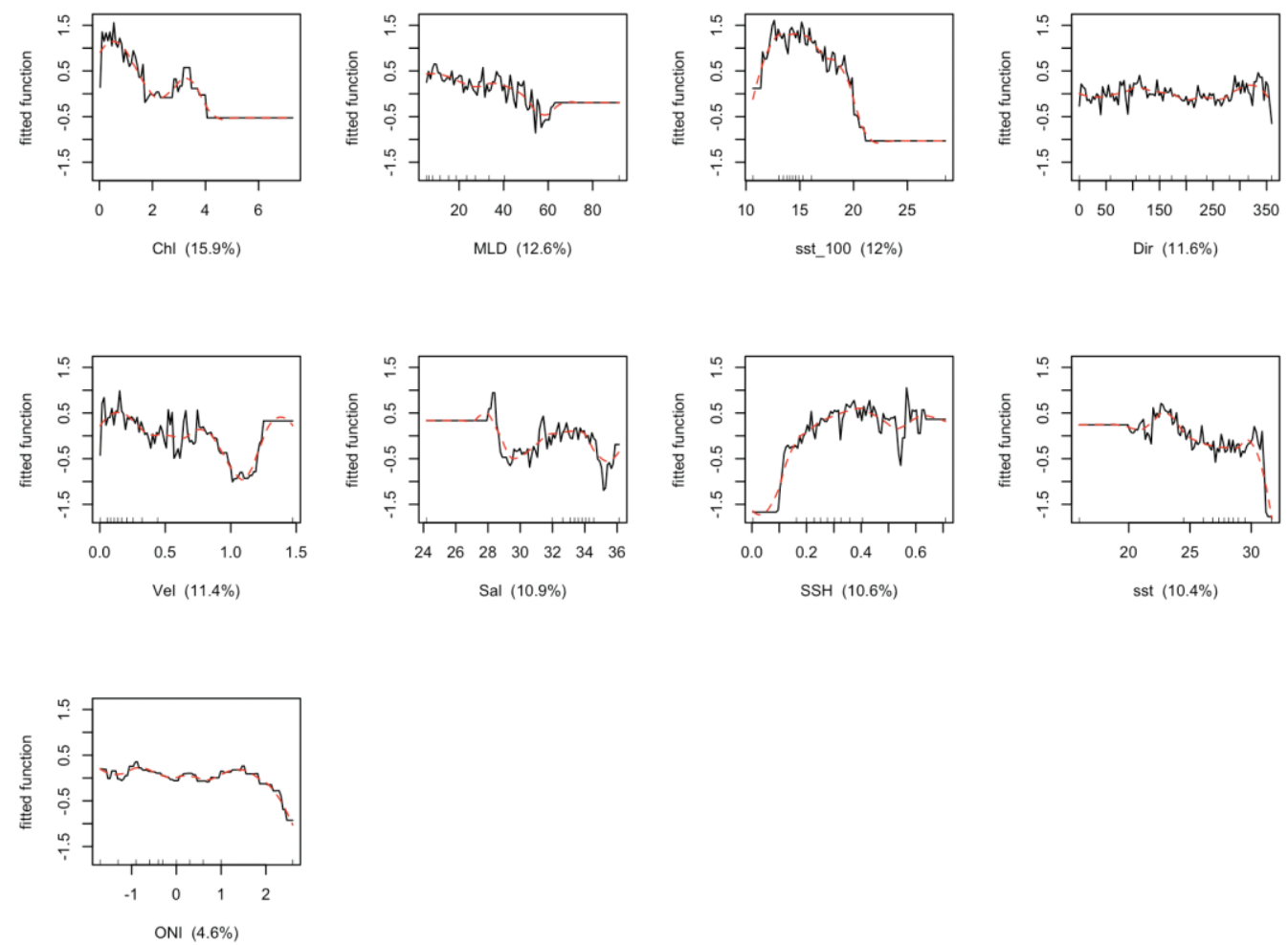

Figure 2.16 Partial dependence plots of presence-absence Boosted Regression Tree (BRT), showing relative probability of the presence of the spinnertuna association as a response to each environmental variable in M2.env. Variable relative importance scores are listed for each variable in parentheses. $Y$ axes are on the logit scale. 

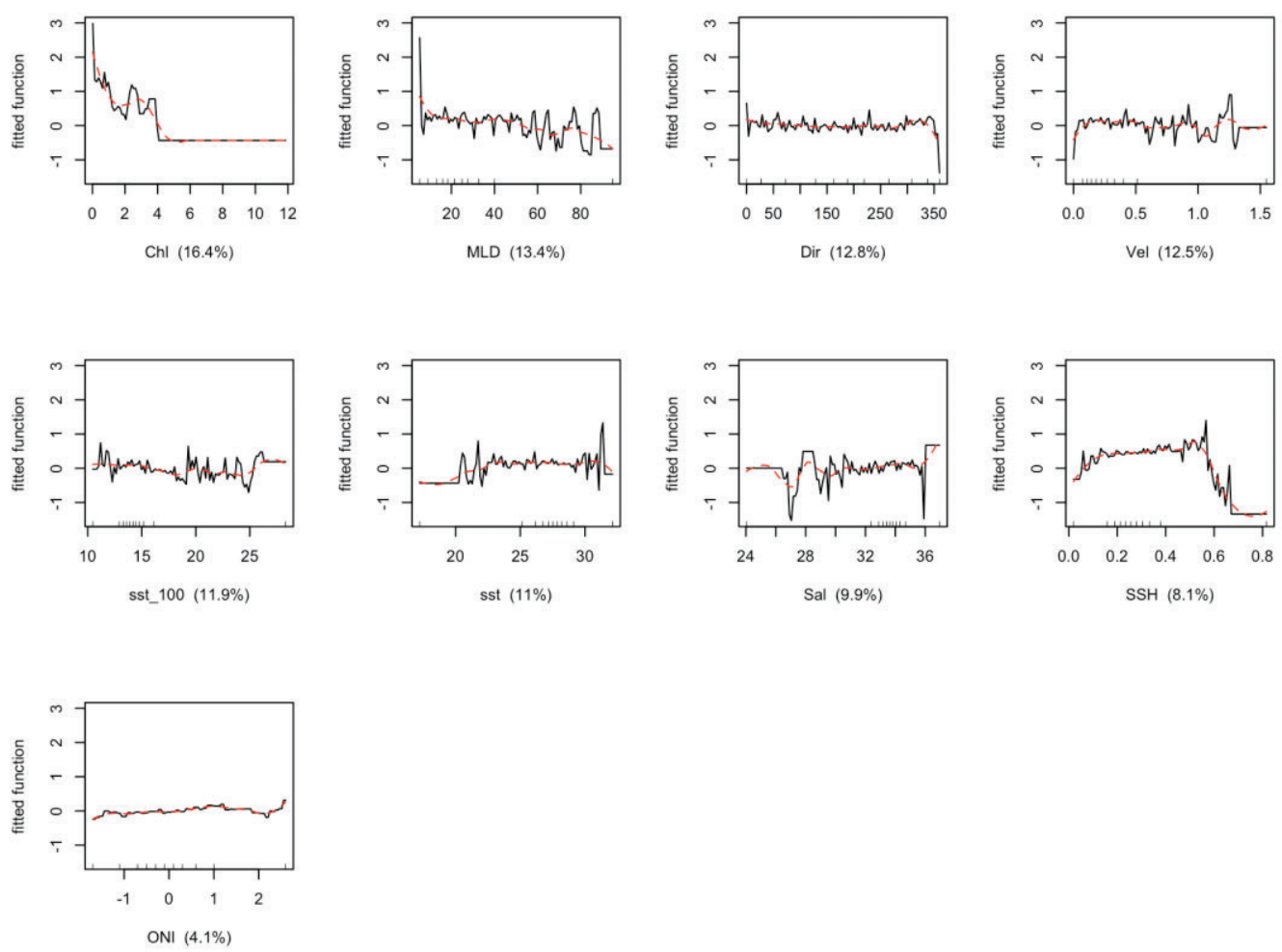

Figure 2.17 Partial dependence plots of presence-absence Boosted Regression Tree (BRT), showing relative probability of the presence of the spottedtuna association as a response to each environmental variable in model M1.env. Variable relative importance scores are listed below for each variable in parentheses. $Y$ axes are on the logit scale. 


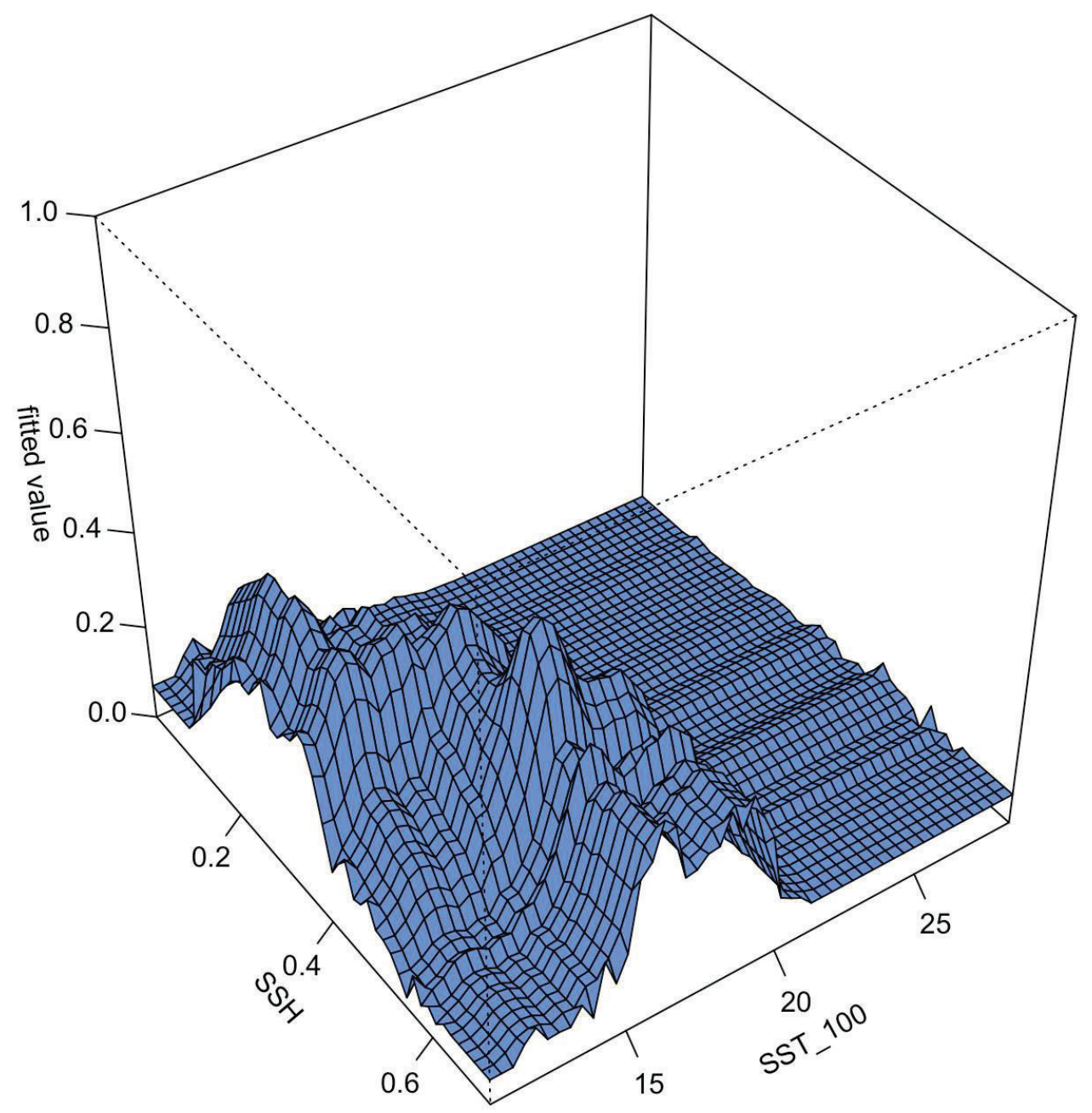

Figure 2.18 Three-dimensional partial dependence plot for the strongest environmental interaction (SSH - SST_100) in the Boosted Regression Tree model for the spinner-tuna association (M2.env). 


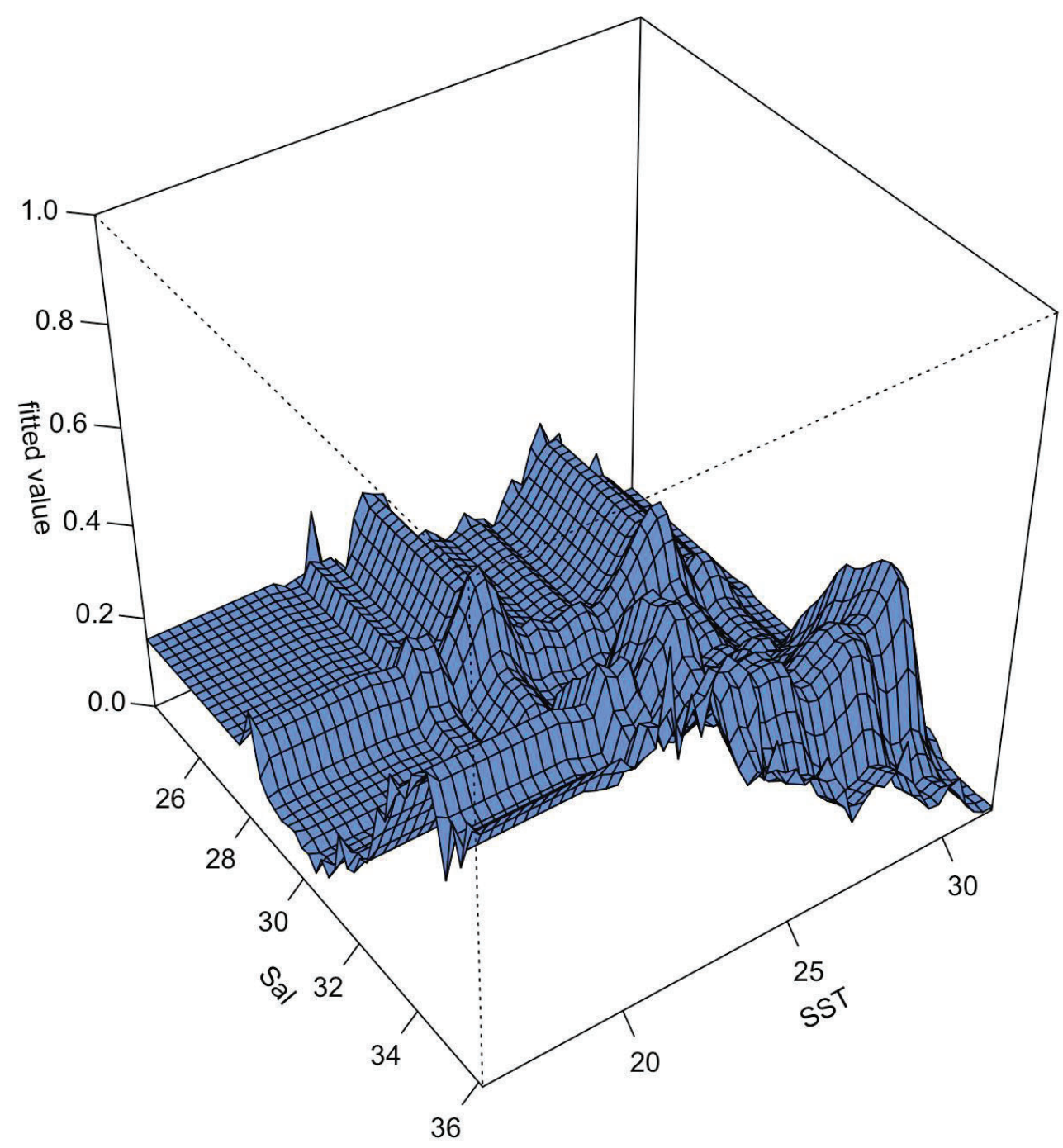

Figure 2.19 Three-dimensional partial dependence plot for the second strongest environmental interaction (Sal - SST) in the Boosted Regression Tree model for the spinner-tuna association (M2.env). 


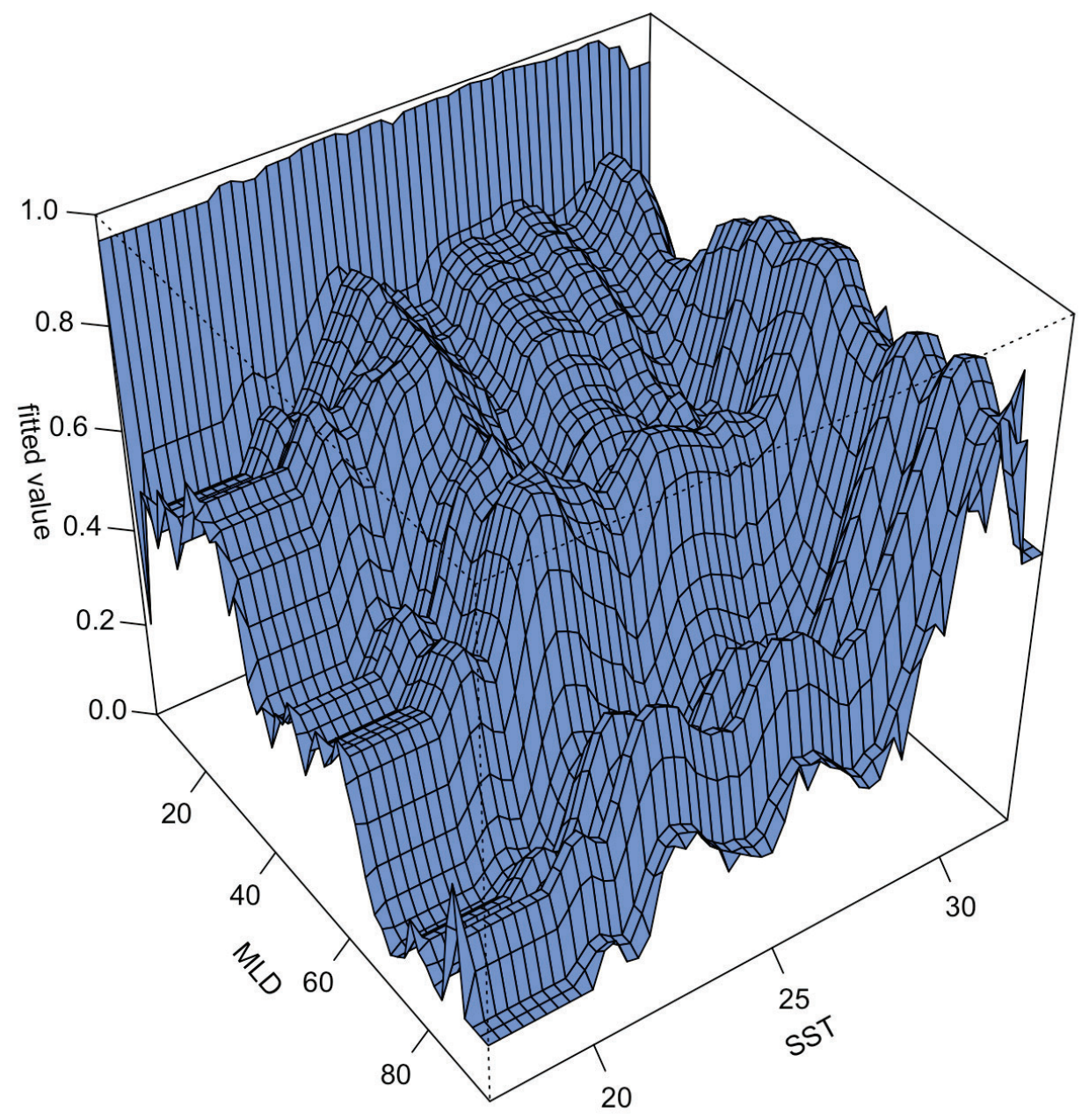

Figure 2.20 Three-dimensional partial dependence plot for the strongest environmental interaction (MLD-SST) in the Boosted Regression Tree model for the spotted-tuna association (M1.env). 


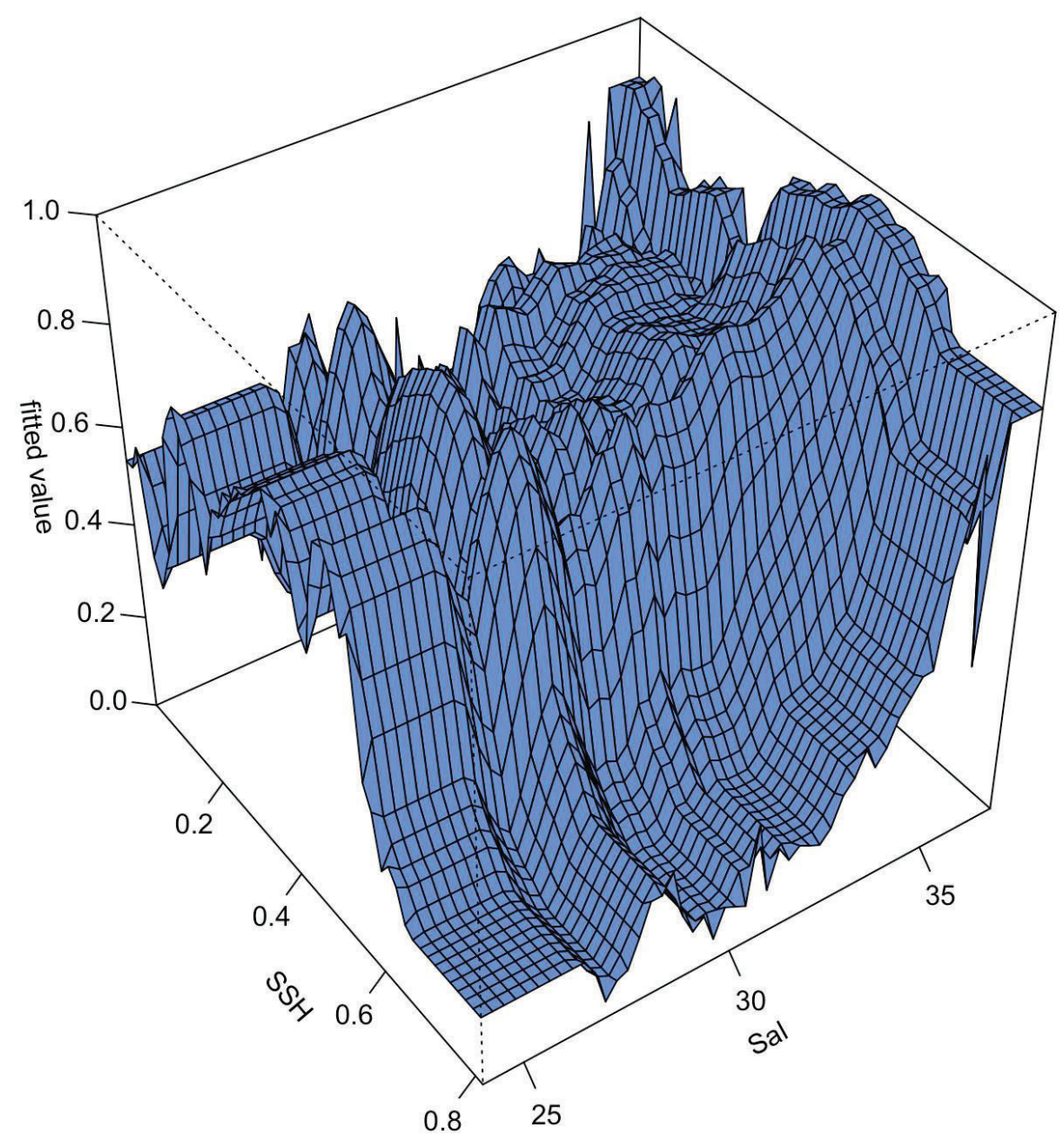

Figure 2.21 Three-dimensional partial dependence plot for the second strongest environmental interaction ( $\mathrm{SSH}-\mathrm{Sal}$ ) in the Boosted Regression Tree model for the spotted-tuna association (M1.env). 

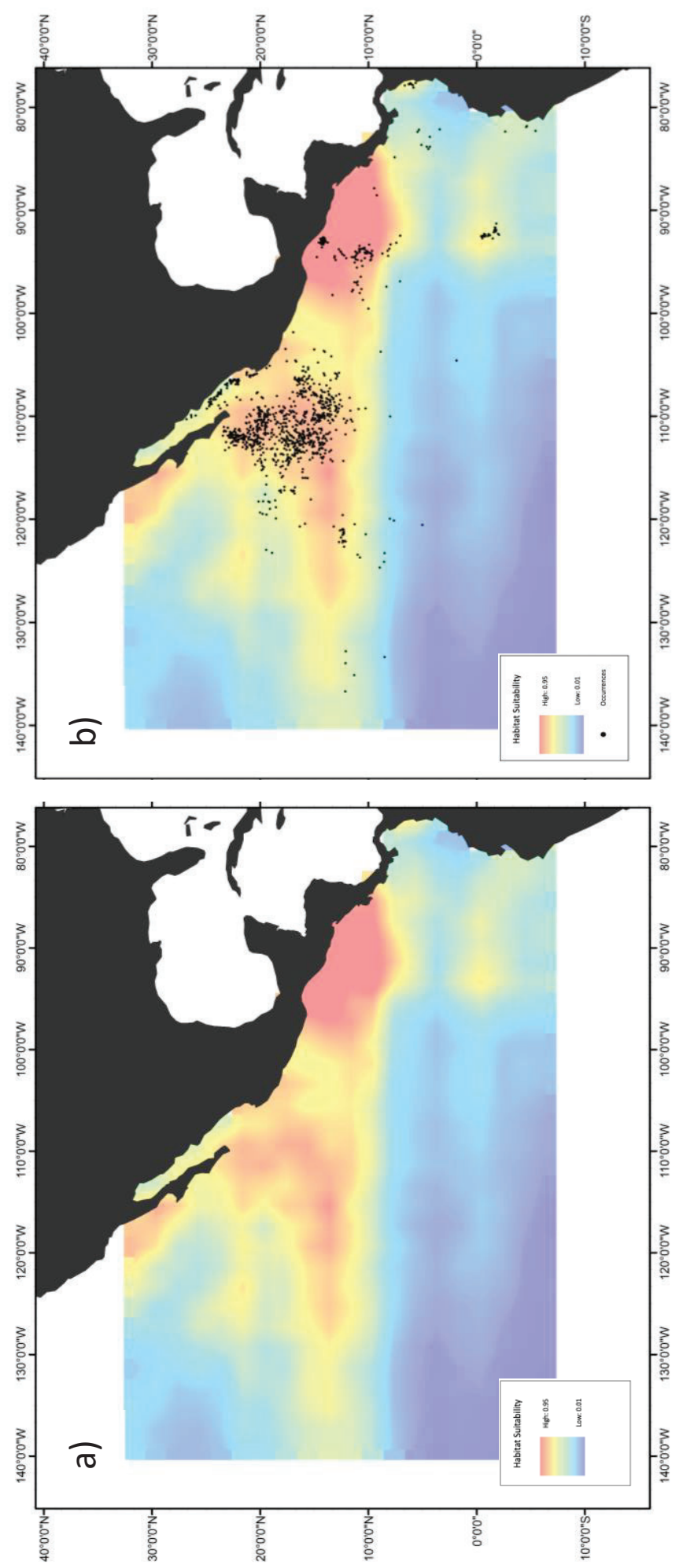

Figure 2.22 Habitat suitability projected for the full year 2015 by the spinner-tuna Boosted Regression Tree spatio-temporal model (M2): a) 2015 predicted habitat suitability, b) overlaid with 2015 spinner-tuna occurrence data. 

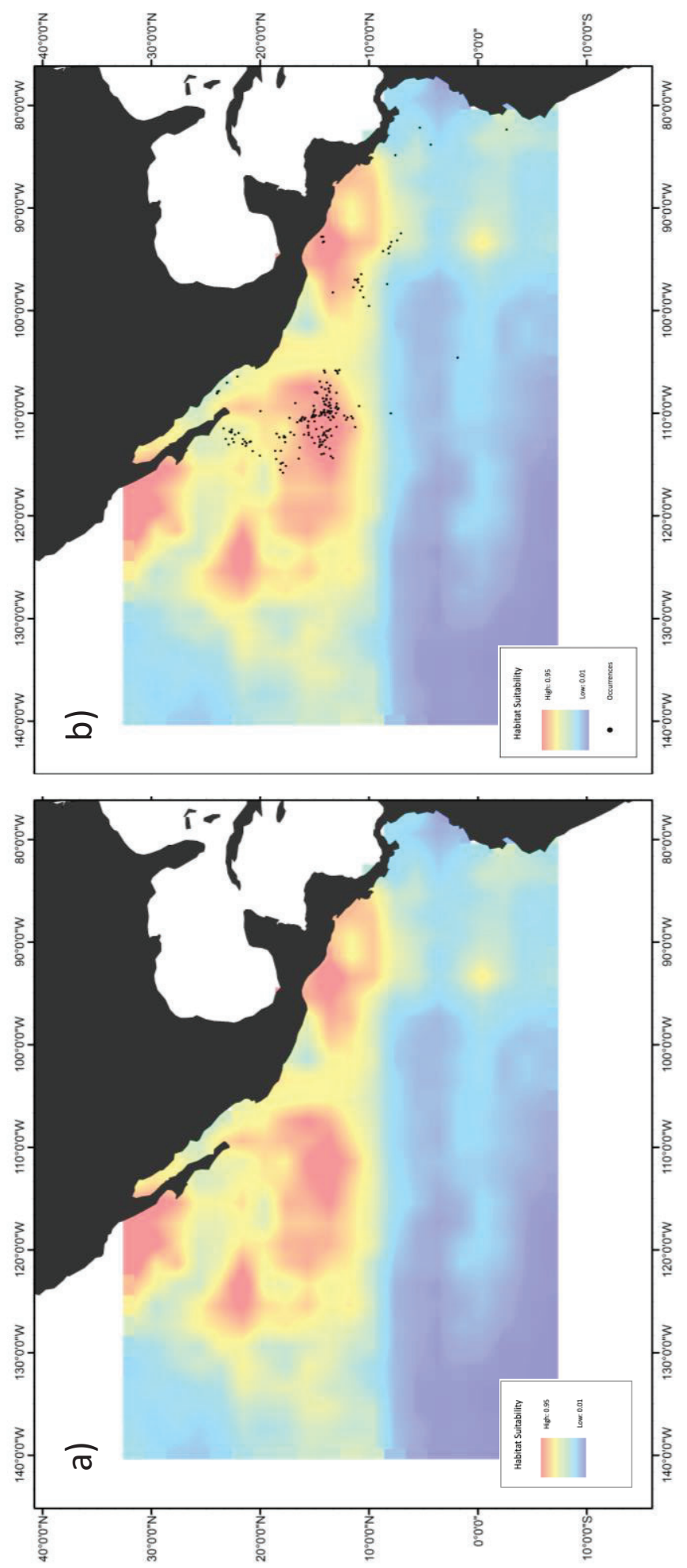

Figure 2.23 Habitat suitability projected for the months Dec - Feb of 2015 by the spinner-tuna Boosted Regression Tree spatio-temporal model (M2); a) Dec - Feb predicted habitat suitability, b) overlaid with spinner-tuna occurrence data. 

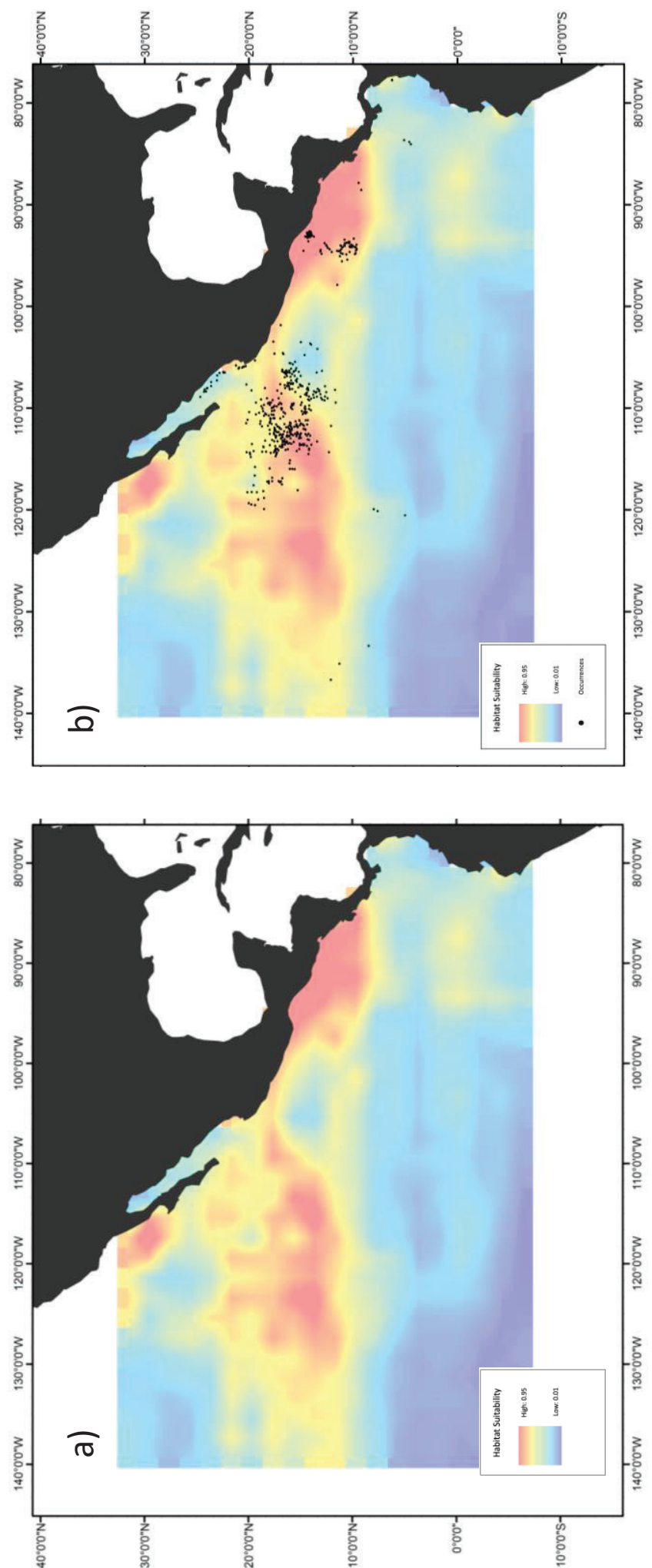

Figure 2.24 Habitat suitability projected for the months Mar - May of 2015 by the spinner-tuna Boosted Regression Tree spatio-temporal model (M2): a) Mar - May predicted habitat suitability, b) overlaid with spinner-tuna occurrence data. 

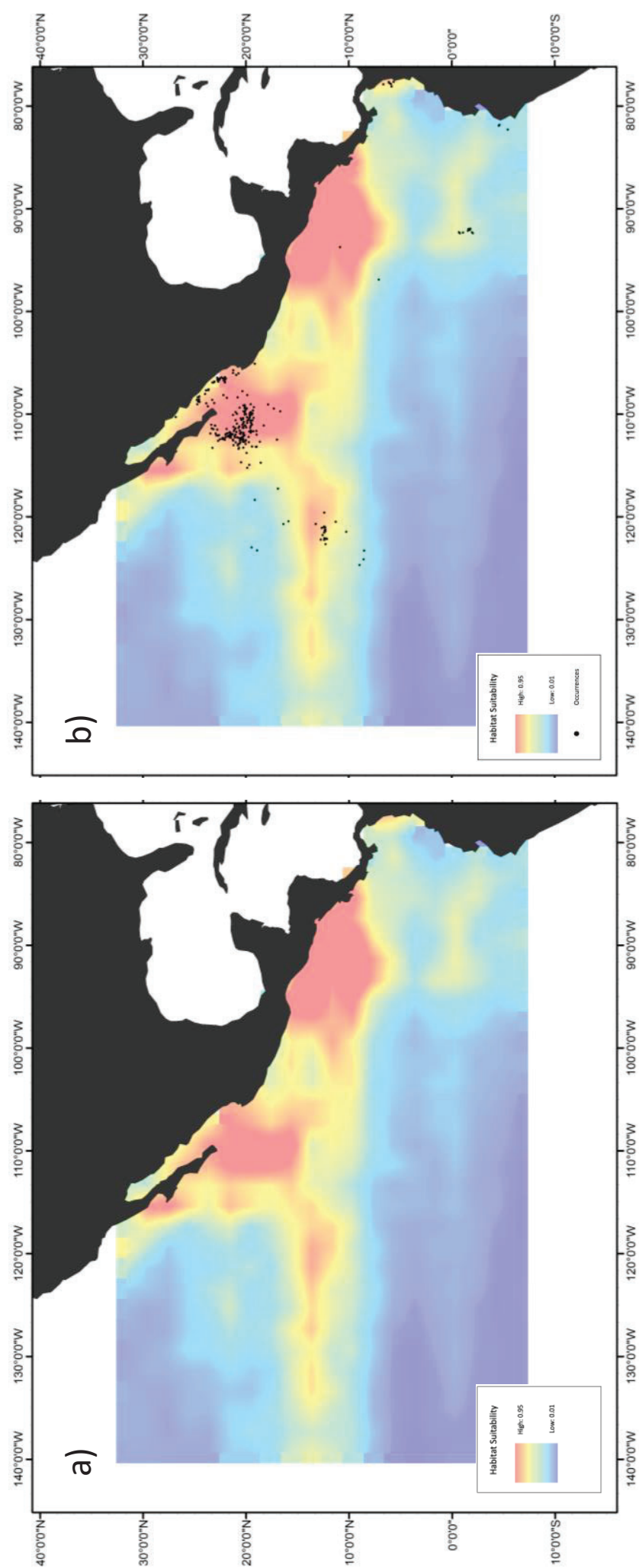

Figure 2.25 Habitat suitability projected for the months Jun - Aug of 2015 by the spinner-tuna Boosted Regression Tree spatio-temporal model (M2): a) Jun - Aug predicted habitat suitability, b) overlaid with spinner-tuna occurrence data. 

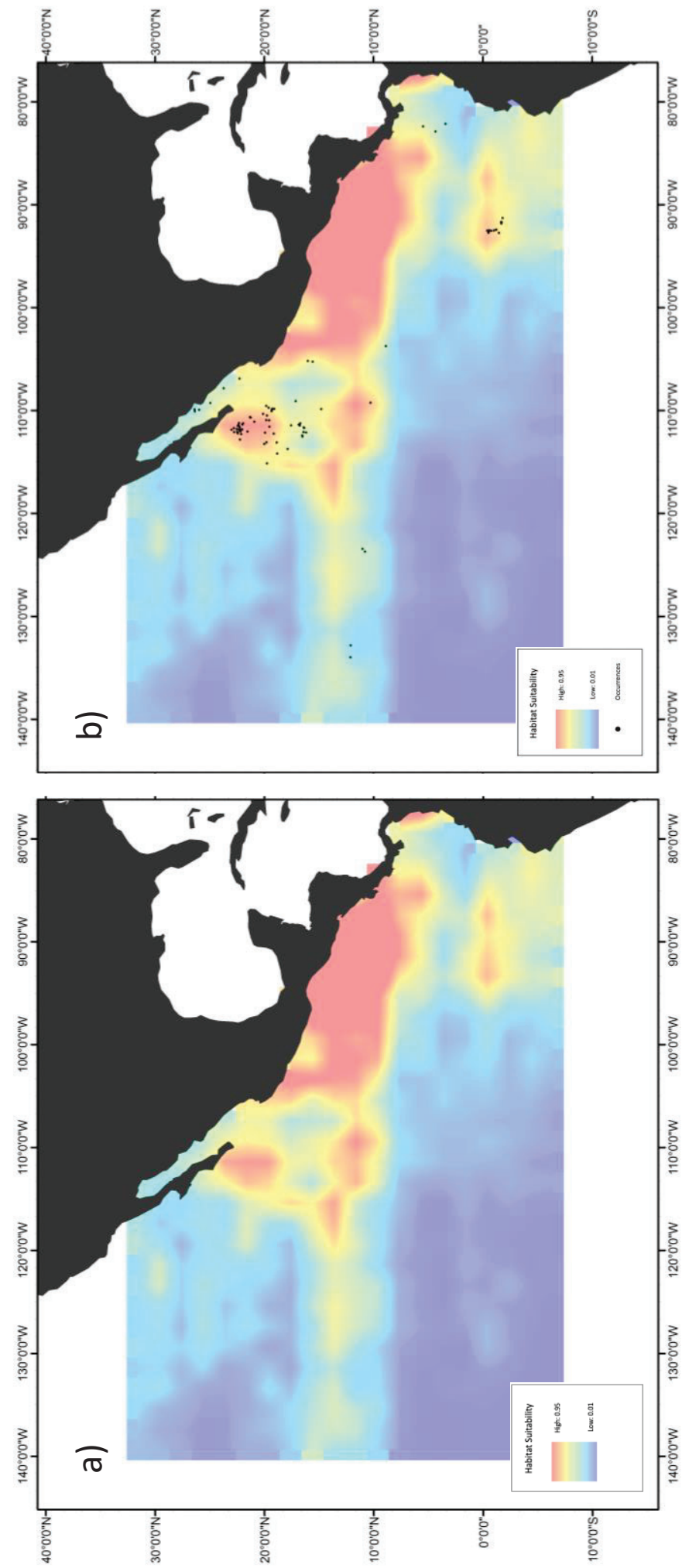

Figure 2.26 Habitat suitability projected for the months Sept - Nov of 2015 by the spinner-tuna Boosted Regression Tree spatio-temporal model (M2): a) Sept - Nov predicted habitat suitability, b) overlaid with spinner-tuna occurrence data. 

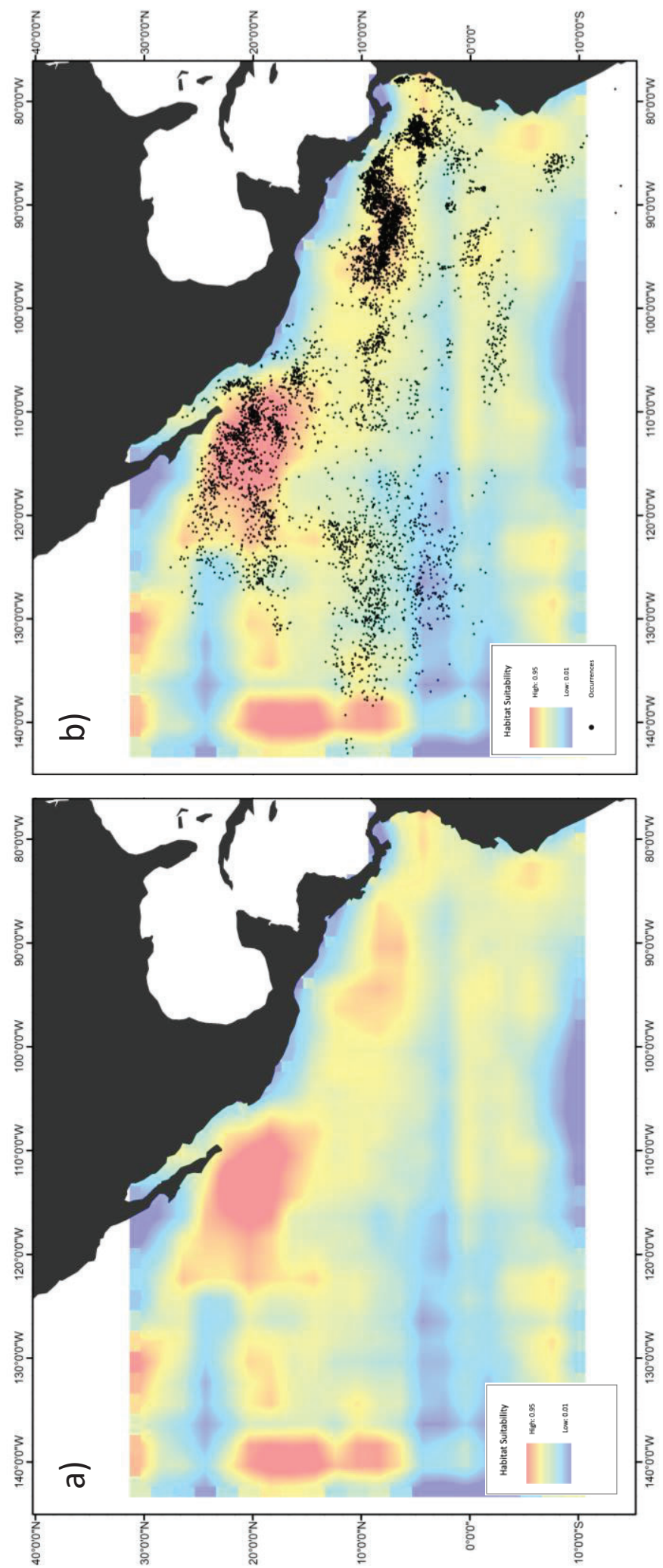

Figure 2.27 Habitat suitability projected for the full year 2015 by the spotted-tuna Boosted Regression Tree spatio-temporal model (M2): a) 2015 predicted habitat suitability, b) overlaid with 2015 spinner-tuna occurrence data. 

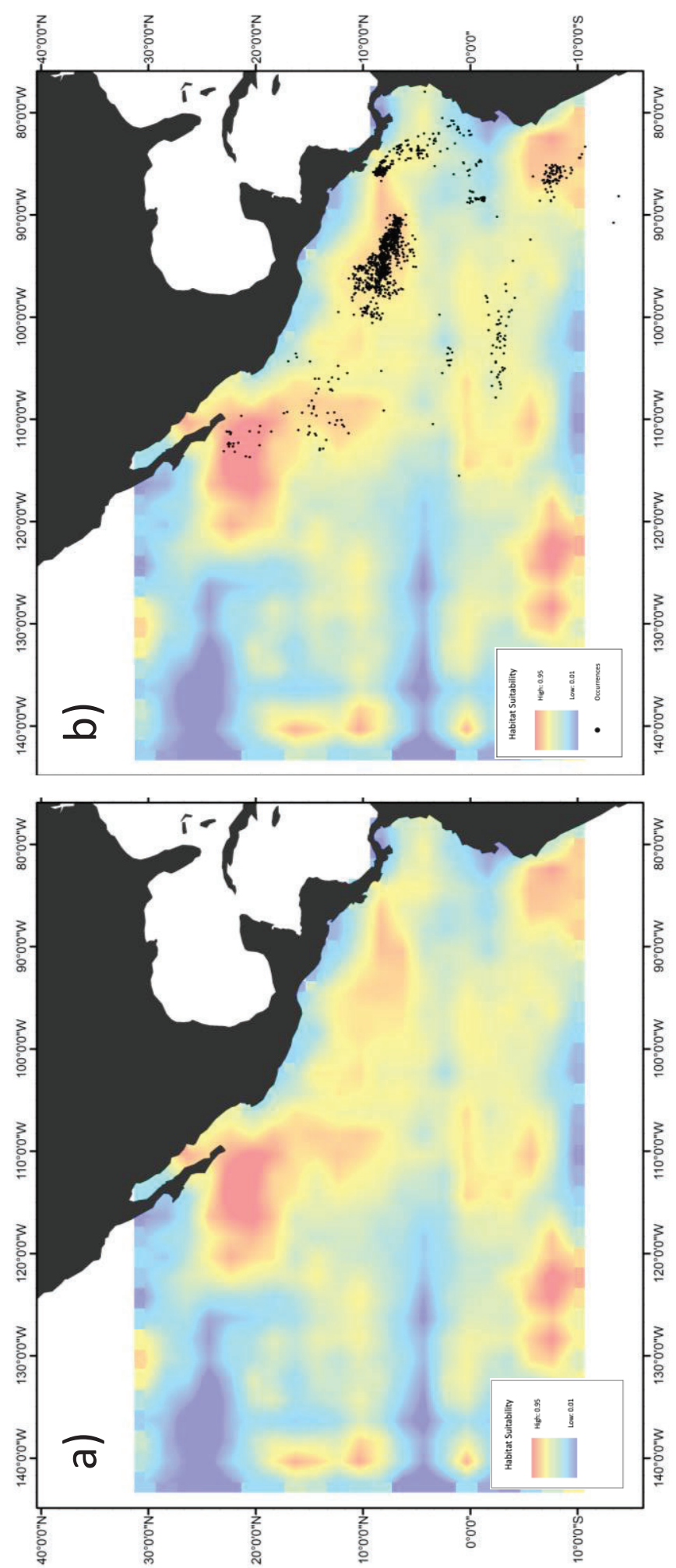

Figure 2.28 Habitat suitability projected for the months Dec - Feb of 2015 by the spotted-tuna Boosted Regression Tree spatio-temporal model (M1): a) Dec - Feb predicted habitat suitability, b) overlaid with spotted-tuna occurrence data. 

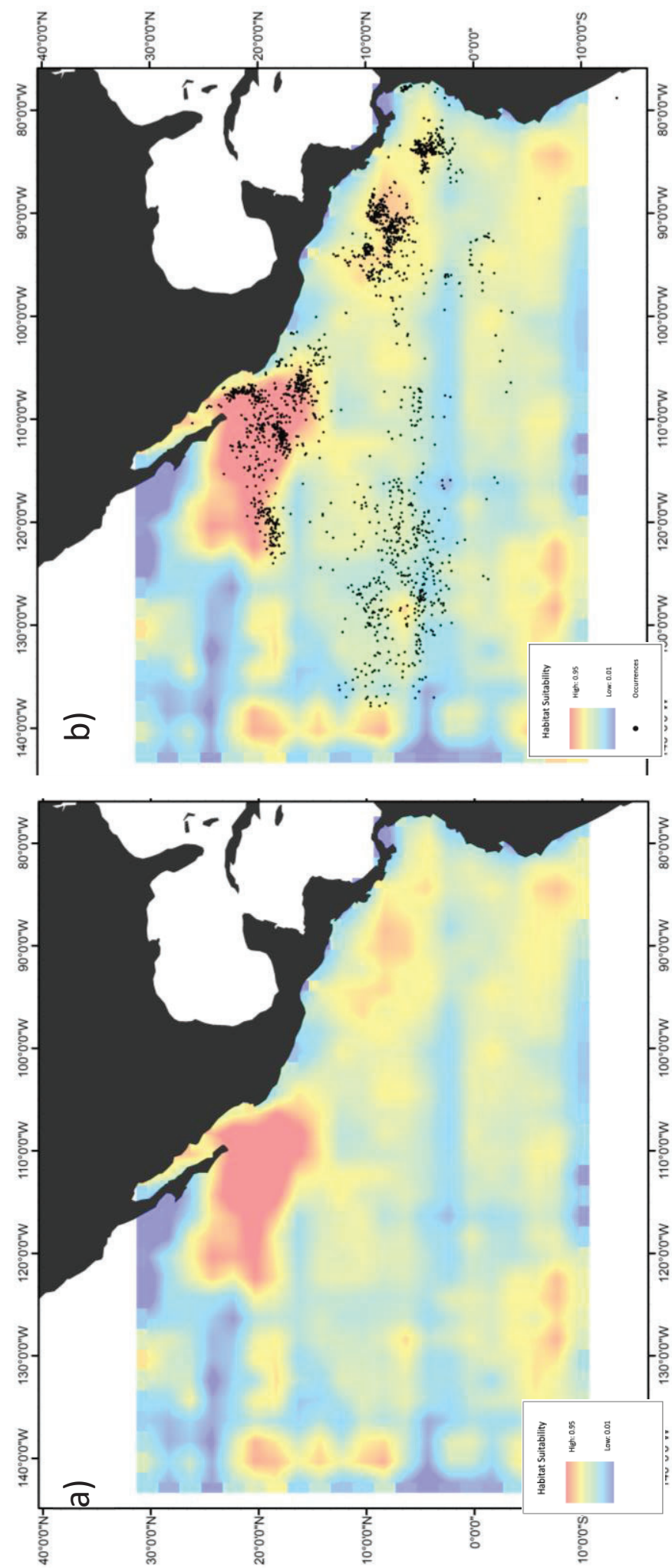

Figure 2.29 Habitat suitability projected for the months Mar - May of 2015 by the spotted-tuna Boosted Regression Tree spatio-temporal model (M1): a) Mar May predicted habitat suitability, b) overlaid with spotted-tuna occurrence data. 

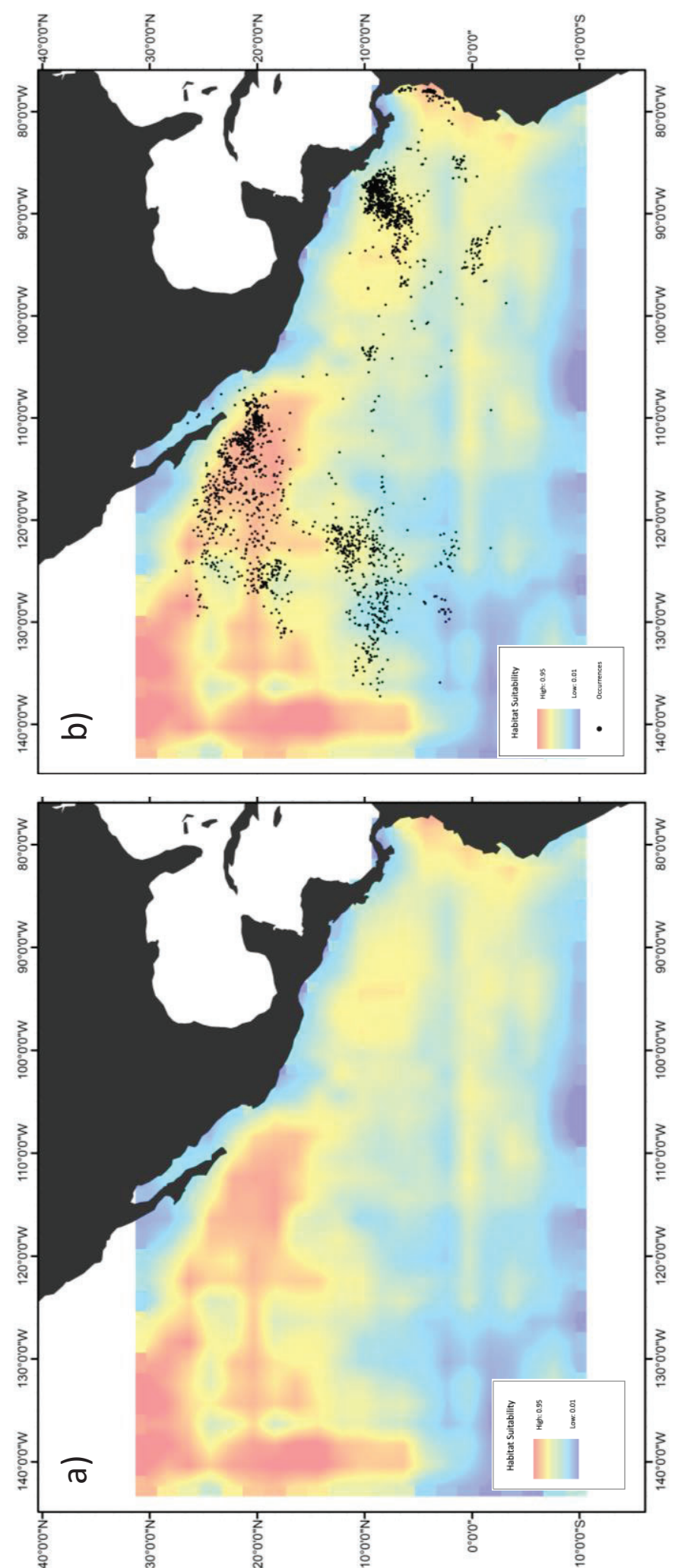

Figure 2.30 Habitat suitability projected for the months Jun - Aug of 2015 by the spotted-tuna Boosted Regression Tree spatio-temporal model (M1): a) Jun - Aug predicted habitat suitability, b) overlaid with spotted-tuna occurrence data. 

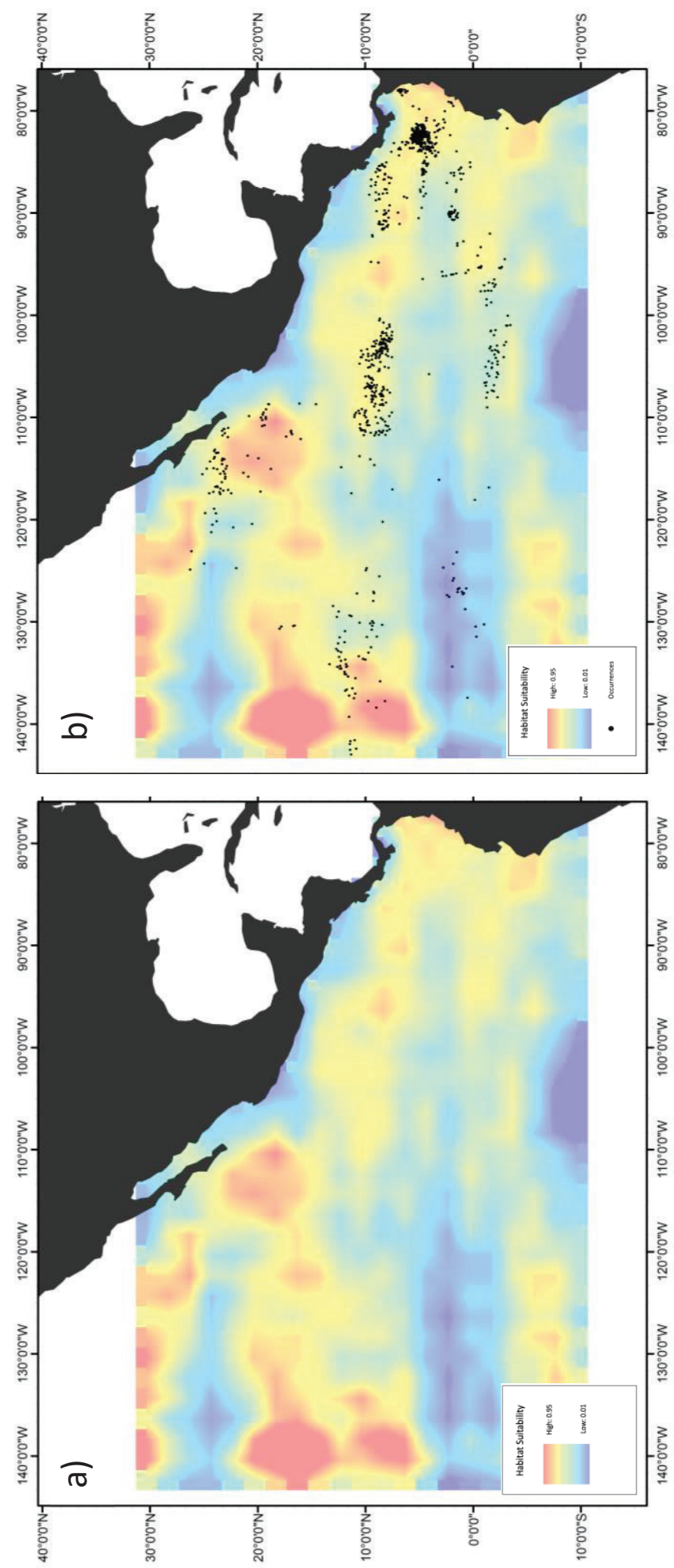

Figure 2.31 Habitat suitability projected for the months Sept - Nov of 2015 by the spotted-tuna Boosted Regression Tree spatio-temporal model (M1): a) Sept - Nov predicted habitat suitability b) overlaid with spotted-tuna occurrence data. 


\section{REFERENCES}

Allouche, O., A. Tsoar, and R. Kadmon. 2006. Assessing the accuracy of species distribution models: Prevalence, kappa and the true skill statistic (TSS). Journal of Applied Ecology 43:1223-1232.

Au, D. K., and W. Perryman. 1982. Movement and speed of dolphin schools responding to an approaching ship. Fishery Bulletin 80:371-379.

Au, D., and W. Perryman. 1985. Dolphin habitats in the eastern tropical Pacific. Fishery Bulletin 83:623-643.

Au, D. W. K., and R. L. Pitman. 1986. Seabird interactions with dolphins and tuna in the eastern tropical Pacific. Condor 88:304-317.

Becker, E. A., K. A. Forney, B. J. Thayre, A. J. Debich, G. S. Campbell, K. Whitaker, A. B. Douglas, A. Gilles, R. Hoopes, and J. A. Hildebrand. 2017. Habitat-based density models for three cetacean species off southern California illustrate pronounced seasonal differences. Frontiers in Marine Science 4:1-12.

Brock, V. E., and R. H. Riffenburgh. 1960. Fish schooling: A possible factor in reducing predation. Journal du Conseil / Conseil Permanent International pour l'Exploration de la Mer 25:307-318.

Buckley, T. W., and B. S. Miller. 1994. Feeding habits of yellowfin tuna associated with fish aggregation devices in American Samoa. Bulletin of Marine Science 55:445459 .

Cayré, P. 1991. Behaviour of yellowfin tuna (Thunnus albacares) and skipjack tuna (Katsuwonus pelamis) around Fish Aggregating Devices (FADs) in the Comoros Islands as determined by ultrasonic tagging. Aquatic Living Resources 4:1-12.

Cheung, W. W. L., V. W. Y. Lam, J. L. Sarmiento, K. Kearney, R. Watson, and D. Pauly. 2009. Projecting global marine biodiversity impacts under climate change scenarios. Fish and Fisheries 10:235-251.

Cohen, J. A. 1960. A coefficient of agreement for nominal scales. Educational and Psychological Measurement 20:37-46.

Collins, M., S.-I. An, W. Cai, A. Ganachaud, E. Guilyardi, F.-F. Jin, M. Jochum, M. Lengaigne, S. Power, A. Timmermann, G. Vecchi, and A. Wittenberg. 2010. The impact of global warming on the tropical Pacific Ocean and El Niño. Nature Geoscience 3:391-397.

De'ath, G. 2007. Boosted trees for ecological modeling and prediction. Ecology 88:243251. 
Deser, C., M. A. Alexander, S.-P. Xie, and A. S. Phillips. 2009. Sea surface temperature variability: Patterns and mechanisms. Annual Review of Marine Science 2:115143.

DiNezio, P., A. Clement, G. A. Vecchi, B. J. Soden, B. Kirtman, and S.-K. Lee. 2009. Climate response of the equatorial Pacific to global warming. Journal of Climate 22:4873-4892.

Edwards, E. F. 1992. Energetics of associated tunas and dolphins in the eastern tropical Pacific: A basis for the bond. Fishery Bulletin 90:678-690.

Elith, J., J. R. Leathwick, and T. Hastie. 2008. A working guide to boosted regression trees. Journal of Animal Ecology 77:802-813.

Elith, J., and J. R. Leathwick. 2009. Species Distribution Models: Ecological explanation and prediction across space and time. Annual Review of Ecology, Evolution and Systematics 40:677-697.

ESRI. 2011. ArcGIS Desktop: Release 10.1. Environmental Systems Research Institute, Redlands, CA.

Ferrier, S., and A. Guisan. 2006. Spatial modelling of biodiversity at the community level. Journal of Applied Ecology 43:393-404.

Fiedler, P. C., and L. D. Talley. 2006. Hydrography of the eastern tropical Pacific: A review. Progress in Oceanography 69:143-180.

Fiedler, P. C., and M. F. Lavín. 2006. Introduction: A review of eastern tropical Pacific oceanography. Progress in Oceanography 69:94-100.

Fiedler, P. C., and M. F. Lavín. 2017. Oceanographic conditions of the eastern tropical Pacific. Pages 59-83 in P. W. Glynn, D. Manzello, and I. C. Enochs, editors. Coral reefs of the eastern tropical Pacific: Persistence and loss in a dynamic environment. Springer Netherlands, Dordrecht, 657pp.

Fiedler, P., R. Mendelssohn, D. Palacios, and S. Bograd. 2013. Pycnocline variations in the eastern tropical and North Pacific, 1958-2008. Journal of Climate 26:583-599.

Fielding, A. H., and J. F. Bell. 1997. A review of methods for the assessment of prediction errors in conservation presence/absence models. Environmental Conservation 24:38-49.

Fréon, P., and O. Misund. 1999. Dynamics of pelagic fish distribution and behaviour: Effects on fisheries and stock assessment. Journal info 
Fréon, P., and L. Dagorn. 2000. Review of fish associative behaviour: Toward a generalization of the meeting point hypothesis. Review of Fish Biology and Fisheries 10:183-207.

Gosliner, M. L. 1999. The tuna-dolphin controversy. Pages 120-155 in J. R. Twiss and R. R. Reeves, editors. Conservation and management of marine mammals. Smithsonian Institutional Press, Washington, D.C. 471pp.

Green, R. E. 1967. Relationship of the thermocline to success of purse seining for tuna. Transactions of the American Fisheries Society 96:126-130.

Guisan, A., and N. E. Zimmermann. 2000. Predictive habitat distribution models in ecology. Ecological Modeling 135:147-186.

Guisan, A., and W. Thuiller. 2005. Predicting species distribution: Offering more habitat models. Ecology Letters 8:993-1009.

Hanley, J. A., and B. McNeil. 1982. The meaning and use of the area under a receiver operating characteristic (ROC) curve. Radiology 143:29-36.

Hastie, T. J., and R. J. Tibshirani. 1990. Generalized additive models. Chapman and Hall/CRC Press, Boca Raton, Florida. 476pp.

Hazen, E. L. 2018. A dynamic ocean management tool to reduce bychatch and support sustainable fisheries. Science Advances 4:1-7.

Hijmans, R. J., J. van Etten, J. Cheng, M. Mattiuzzi, M. Sumner, J. A. Greenberg, O. P. Lamigueiro, A. Bevan, E. B. Racine, and A. J. Shortridge. 2015. Package 'raster.' Available at http://CRANR- projectorg/package=raster.

Hijmans, R. J., S. Philips, J. R. Leathwick, and J. Elith. 2017. dismo: Species distribution modeling. R package version 1.1-4. Available at https://CRANRprojectorg $/$ package $=$ dismo.

Leathwick, J. R., J. Elith, F. M.P., T. Hastie, and T. P. 2006. Variation in demersal fish species richness in the oceans surrounding New Zealand: an analysis using boosted regression trees. Marine Ecology Progress Series 321:267-281.

McHugh, M. L. 2012. Interrater reliability: The kappa statistic. Biochemical Medicine 22:276-282.

Norris, K. S., W. E. Stuntz, and W. Rodgers. 1978. The behavior of porpoises and tuna in the eastern tropical Pacific yellowfin tuna fishery - preliminary studies. National Technical Information Service No. PB-283 970. 86pp. 
Olson, R. J., and F. Galván-Magaña. 2002. Food habits and consumption rates of dolphinfish (Coryphaena hipurus) in the eastern Pacific Ocean. Fishery Bulletin 100:279-298.

Pearce, J., and S. Ferrier. 2000. Evaluation the predictive performance of habitat models developed using logistic regression. Ecological Modeling 133:225-245.

Perrin, W. F., R. R. Warner, C. H. Fiscus, and D. B. Holts. 1973. Stomach contents of porpoise, Stenella spp., and yellowfin tuna, Thunnis albacares, in mixed-species aggregations. Fishery Bulletin 71:1077-1092.

Perrin, W. F. 2009. Early days of the tuna/dolphin problem. Aquatic Mammals 35:293305 .

Prince, E. D., and C. P. Goodyear. 2006. Hypoxia-based habitat compression of tropical pelagic fishes. Fisheries Oceanography 15:451-464.

R-Core-Team. 2014. A language and environment for statistical computing R. Foundation for Statistical Computing. Available online at: www.R-project.org/.

Redfern, J. V., T. J. Moore, P. C. Fiedler, A. de Vos, R. L. Brownell Jr, K. A. Forney, E. A. Becker, and L. T. Ballance. 2017. Predicting cetacean distributions in datapoor marine ecosystems. Diversity and Distributions 23:394-408.

Roberts, J. J., B. D. Best, L. Mannocci, E. Fujioka, P. N. Halpin, D. L. Palka, L. P. Garrison, K. D. Mullin, T. V. N. Cole, C. B. Khan, W. A. McLellan, D. A. Pabst, and G. G. Lockhart. 2016. Habitat-based cetacean density models for the U.S. Atlantic and Gulf of Mexico. Scientific Reports 6:22615.

Rogers, L. A., R. Griffin, T. Young, E. Fuller, K. St. Martin, and M. L. Pinsky. 2019. Shifting habitats expose fishing communities to risk under climate change. Nature Climate Change 9:512-516.

Scales, K., E. Hazen, S. Maxwell, H. Dewar, S. Kohin, M. Jacox, C. Edwards, D. Briscoe, L. Crowder, R. Lewison, and S. Bograd. 2017. Fit to predict? Ecoinformatics for predicting the catchability of a pelagic fish in near real-time. Ecological Applications 27:1-17.

Schaefer, K., D. Fuller, and B. Block. 2009. Vertical movements and habitat utilization of skipjack (Katsuwonus pelamis), Yellowfin (Thunnus albacares), and Bigeye (Thunnus obesus) tunas in the equatorial eastern Pacific Ocean, ascertained through archival tag data. Pages 12-44 in J. L. Nielsen, H. Arrizabalaga, N. Fragoso, A. Hobday, M. Lutcavage, and J. Sibert, editors. Tagging and Tracking of Marine Animals with Electronic Devices. Springer, New York, NY. 452pp. 
Scott, M. D., and K. L. Cattanach. 1998. Diel patterns in aggregations of pelagic dolphins and tunas in the eastern Pacific. Marine Mammal Science 14:401-422.

Scott, M. D., and S. J. Chivers. 2009. Movements and diving behavior of pelagic spotted dolphins. Marine Mammal Science 25:137-160.

Scott, M. D., S. J. Chivers, R. J. Olson, P. C. Fiedler, and K. Holland. 2012. Pelagic predator associations: Tuna and dolphins in the eastern tropical Pacific Ocean. Marine Ecology Progress Series 458:283-302.

Sydeman, W. J., E. Poloczanska, T. E. Reed, and S. A. Thompson. 2015. Climate change and marine vertebrates. Science 350:772-777.

Vecchi, G. A., B. J. Soden, A. T. Wittenberg, I. M. Held, A. Leetmaa, and M. J. Harrison. 2006. Weakening of tropical Pacific atmospheric circulation due to anthropogenic forcing. Nature 441:73-76.

Villarino, E., G. Chust, P. Licandro, M. Butenschön, L. Ibaibarriaga, A. Larrañaga, and X. Irigoien. 2015. Modelling the future biogeography of North Atlantic zooplankton communities in response to climate change. Marine Ecology Progress Series 531:121-142.

Wade, P. R. 1995. Revised estimated of incidental kill of dolphins (Delphinidae) by the purse-seine tuna fishery in the eastern tropical Pacific, 1959-1972. Fishery Bulletin 93:345-354.

Wood, S. N. 2017. Generalized Additive Models: An introduction to with R (2nd Edition). Chapman and Hall/CRC, Boca Raton, FL.

Wyrtki, K. 1966. Oceanography of the eastern equatorial Pacific Ocean. Oceanography and Marine Biology Annual Review 4:33-68.

Yoshida, H. O., R. N. Uchida, and T. Otsu. 1977. The Pacific tuna pole-and-line and live bait fisheries. Pages 36-51 in R. S. Shomura, editor. Collection of tuna baitfish papers. U.S. Department of Commerce, NOAA Technical Report NMFS Circular. 


\section{CHAPTER 3: Conclusions}

Despite the long history of fishing tuna associated with dolphins, there are still many questions that remain about the tuna-dolphin association. While previous studies have addressed the question of why the bond occurs, this study sheds light on the questions of when and where. These insights allow us to predict the effects of climate change on dolphin and tuna ecology, and also the fishery and future management and conservation needs. This study has expanded on decades of previous work on the environmental factors most critical to the formation of the tuna-dolphin association that are unique in the ETP region and provides tools to determine regions of habitat suitability for this association between highly mobile pelagic species.

Oceanic conditions that favor the association are expanding, particularly for the spinner-dolphin-tuna bond. The spatial extent of the tuna-dolphin association is also expanding, particularly for the spinner dolphin. Determining spatiotemporal distribution patterns in response to seasonal fluxes, ENSO, and climate change are critical in understanding the association's relationship with the ETP regional oceanography. The trends described are not just predictions, they are happening. The conclusions drawn in this study of an expansion of the oceanographic region that fosters the tuna-dolphin association suggest that continual monitoring is necessary to properly manage world fisheries on a shifting seascape. As climate conditions continue to warm, we will likely see the association's distribution continue to shift offshore as thermoclines shoal and coastal productivity decreases. Regional hotspots of the association will shift as prey distributions, productivity, and ocean conditions rapidly change.

Studies such as these that utilize historical datasets providing snapshots in time, monitor shifting trends, and use statistical modeling tools to determine and therefore predict suitable habitat, will provide researchers insight on how best to adapt management to changing climate conditions. Given the success of our 
models for this particular pelagic predator association, methods presented here can be applied to other mobile marine species and community-level associations that may be affected by a changing climate. 